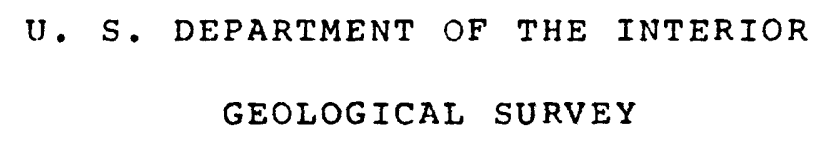

by
D. W. Moody, Thomas Maddock, III, M. R. Karlinger, and J. J. Lloyd

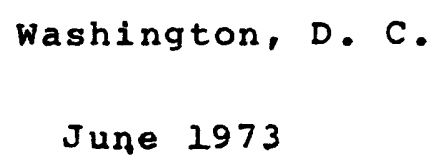




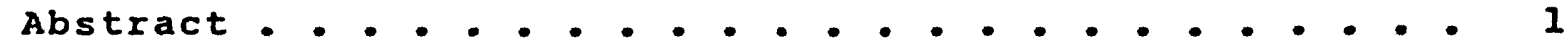
Introduction . . . . . . . . . . . . . . . . 2 Acknowledgments . . . . . . . . . . . . . . . 3 Puerto Rico Water Resources Planning Model . . . . . . . 4 Mathematical structure . . . . . . . . . . 8

Model assumptions and definitions of parameters ... . . . . . . . . . . . 13

cost coefficients . . . . . . . . . . . . . . 14 Water quantities . . . . . . . . . . . 16 Project capacities and yields . . . . . . . 16 Flow requirement constraint . . . . . . . 17 Model definition and control program (MODCOP) . . . . 21 Program organization . . . . . . . . . . . . 24 Subroutine DATA . . . . . . . . . . . 24 Subroutine PR . . . . . . . . . . . 33

Subroutine BLOCK DATA" . . . . . . . . 39

Operating requirements . . . ........... . 43

MPSX usage . . . . . . . . . . . . . . . . . . . 46 summary . . . . . . . . . . . . . . . . . . 48 References cited . . . . . . . . . . . . . . . . 49

\section{Appendices}

A. Puerto Rico Water Resources Planning Model notation................... A-1

B. Format of MODCOP input data cards . . . . . . B-

C. Format of MPSX input data cards..$\cdot$. . . . - -1 
Appendices (continued)

D. Example of MODCOP input data. MODCOP output tables, and MPSX output for a two-region planning model . D -1

E. Source listing of MOdCOP (version 3) ....... . . E-1

\section{ILIUSTRATIONS}

Page

Figure 1. - Schematic representation of the $i-t h$ region

in the Puerto Rico Water Resources.

planning Model (MODCOP version 3 )... .5

2. - Schematic representation of a four-region

planning model . . . . . . . . . . 7

3. -- Problem matrix nomenclature . . . . . . 22

Table 1. -- Summary. of MODCOP input data cards... . . 25

2. -- List of variables dimensioned in subroutine BLOCK DATA ............... . 40 .

3. - Equations for estimating the number of card

images in a MPSX data deck produced by

MODCOP (version 3)... . . . . . . . 44 


\title{
PUERTO RICO WATER RESOURCES
}

PIANNING MODEL

PROGRAM DESCRIPTION

by

D. W. Moody, Thomas Maddock, III, M. R. Karlinger, and J.J. Lloyd

\begin{abstract}
Because the use of the Mathematical Programming system -Extended (MPSX) to solve large linear and mixed integer programs requires the preparation of many input data cards, a matrix generator program to produce the MPSX input data from a much more limited set of data may expedite the use of the mixed integer programming optimization technique.

The Model Definition and Control Program (MODCOP) is intended to assist a planner in preparing MPSX input data for the Puerto Rico Water Resources Planning Model. The model utilizes a mixed-integer mathematical program to identify a minimum present cost set of water resources projects (diversions, reservoirs, ground-water flelds, desalinization plants, water treatment plants, and inter-basin transfers of water) which will meet a set of future water demands and to determine their sequence of construction. While MODCOP was specifically written to generate MPSX input data for the planning model described in this report, the program can be easily modified to reflect changes in the model's mathematical structure. :


INTRODUCTION

The purpose of the model definition and control program (MODCOP) is to assist the planner in preparing input data to the Mathematical Programming system -- Extended (MPSX). Because of the large number of constraints (rows) and variables (columns) associated with some optimization models, such as the Puerto Rico Water Resources Planning Model described below, the use of a matrix generator to produce MPSX input data from a much more limited set of data may expedite the solution of a given problem. While every. attempt has been made to keep MODCOP flexible, it is primarily designed to produce a specific problem matrix. By making minor changes to MODCOP and the input data, the planner can generate a variety of planning models to evaluate alternative water resources development schemes. However, the application of MODCOP to other models, which are substantially different from the one described in this report..probably will require extensive rewriting of the computer program. This report describes the MODCOP program as applied to the Puerto Rico Water Resources Planning Model and its use with MPSX. The first part of the report briefly describes the structure of the planning model. The second part discusses the operation of MODCOP together with the preparation and formatting of the input data. Finally, use of the program in conjunction with MPSX is illustrated by an example. 


\section{Acknowledgments}

The Puerto Rico Water Resources Planning Model is being developed as part of a cooperative program between the Commonwealth of Puerto Rico's Environmental quality Board and the U.S. Geological Survey. The authors gratefully acknowledge the assistance of the Puerto Rico Environmental Quality Board, the Aqueduct and Sewer Authority, the Planning Board, the Department of Natural Resources, the Department of Public Works, the Puerto Rico Water Resources Authority, the Puerto Rico Industrial Development Co.., and the Department of Agriculture in providing ready access to pertinent data, files, and reports. 
PUERTO RICO WATER RESOURCES PLANNING MODEL

The Puerto Rico Water Resources Planning Model is a mixed-integer program which aids the planner in screening. large numbers of water resources projects proposed for. possible implementation. Given a set of future water demands. the mathematical program selects and schedules the construction of proposed projects so that the demands are met at minimum present cost. similar planning models utilizing mixed integer programming are described by o'Neill.(1972) and Facet and Marks (1972).

A schematic representation of one region in the planning model is shown in figure 1. In any given planning region, water demands may be met from a number of different sources. Raw water may be obtained from reservoirs, run-of-the-stream diversions, or it may be imported from some other planning region. Treated water may be obtained from ground-water. fields (water is assumed to be chlorinated at the pumphouse). desalination plants, treated-water imports, or raw water may be processed at a water treatment plant. Thus the raw water demands may be met from either raw water or treated water supplies, while treated water demands may be only satisfied from treated water supplies. In addition to filling internal. water demands, the region may also export raw or treated water to meet demands in other regions. For each type of project, e.g., diversions, reservolrs, ground-water fields, desalination plants, water treatment 


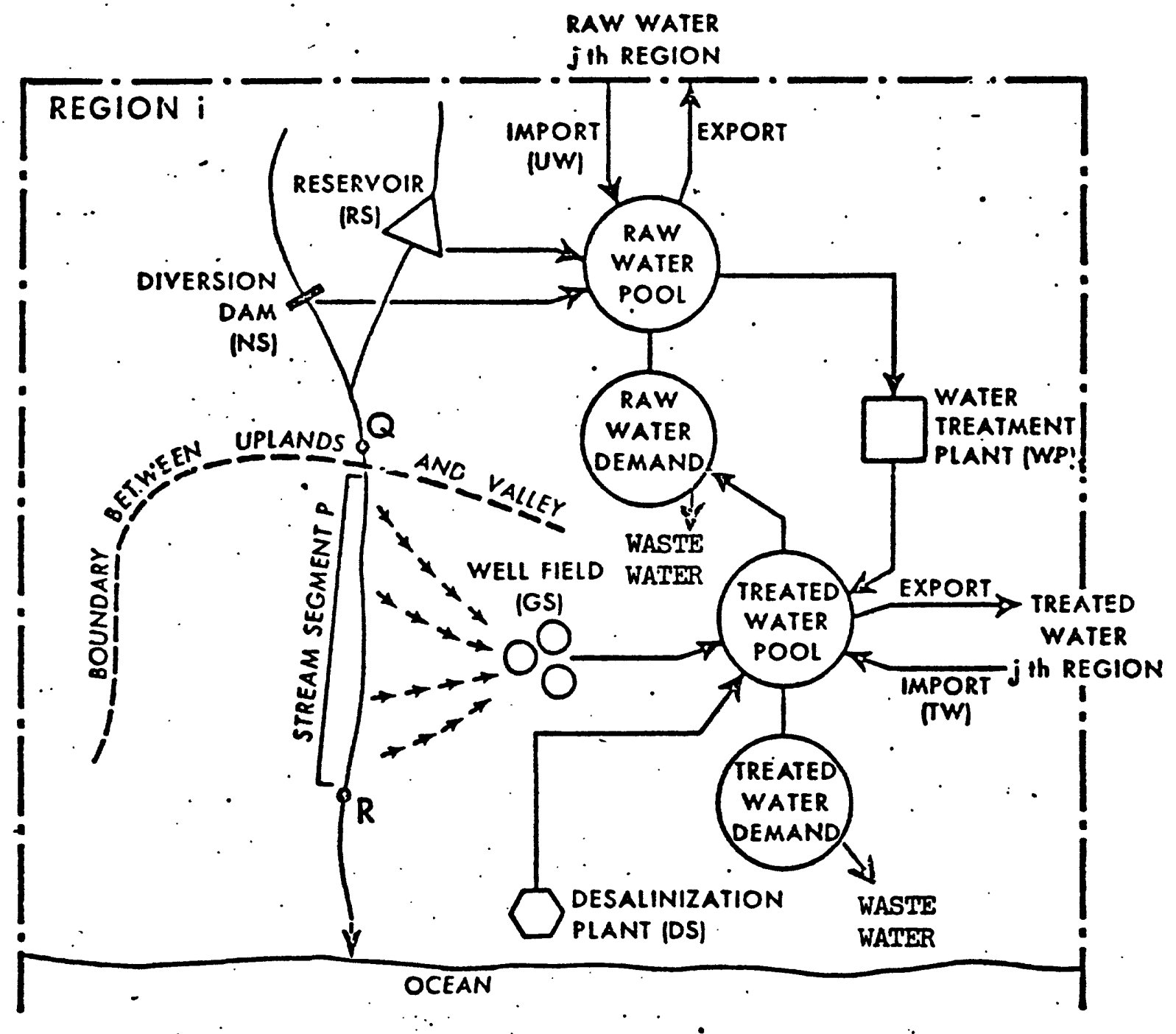

Figure 1. -- Schematic representation of the $i-$ th region in the Puerto Rico Water-Resources Planning Model (MODCOP version 3 ). 
plants, and raw or treated water import systems, the planner may wish to consider one or more different size projects located at different points within the region. For each proposed project the planner must estimate the project's yield or capacity, construction costs, operation-maintenance- : replacement (OMR) costs per unit of water produced, transported, or processed, and the projects economic life.

For legal or environmental reasons the planner may wish to require that downstream flows equal or exceed a-required flow value RFLOW. If ground-water development takes place in valley aquifers, ground-water surface-water interactions may cause water from the stream to recharge the ground-water supply. Evertually, the inflow to the valley from the uplands, QFLOW (fig. 1), may be reduced by drafts on diversions and reservoirs to the point where there is insufficient flow to both recharge the aquifer and meet downstream flow requirements. Therefore, the planning model has a constraint which represents the interactions between surface-water and groundwater development in the planning region and flow requirements at points specified by the planner.

In summary, the planning model consists of two or more planning regions interlinked by one or more water transfer projects (fig. 2). The model minimizes the present (or discounted) total cost of construction and operation of water. resources projects in all regions over the planning horizon. 


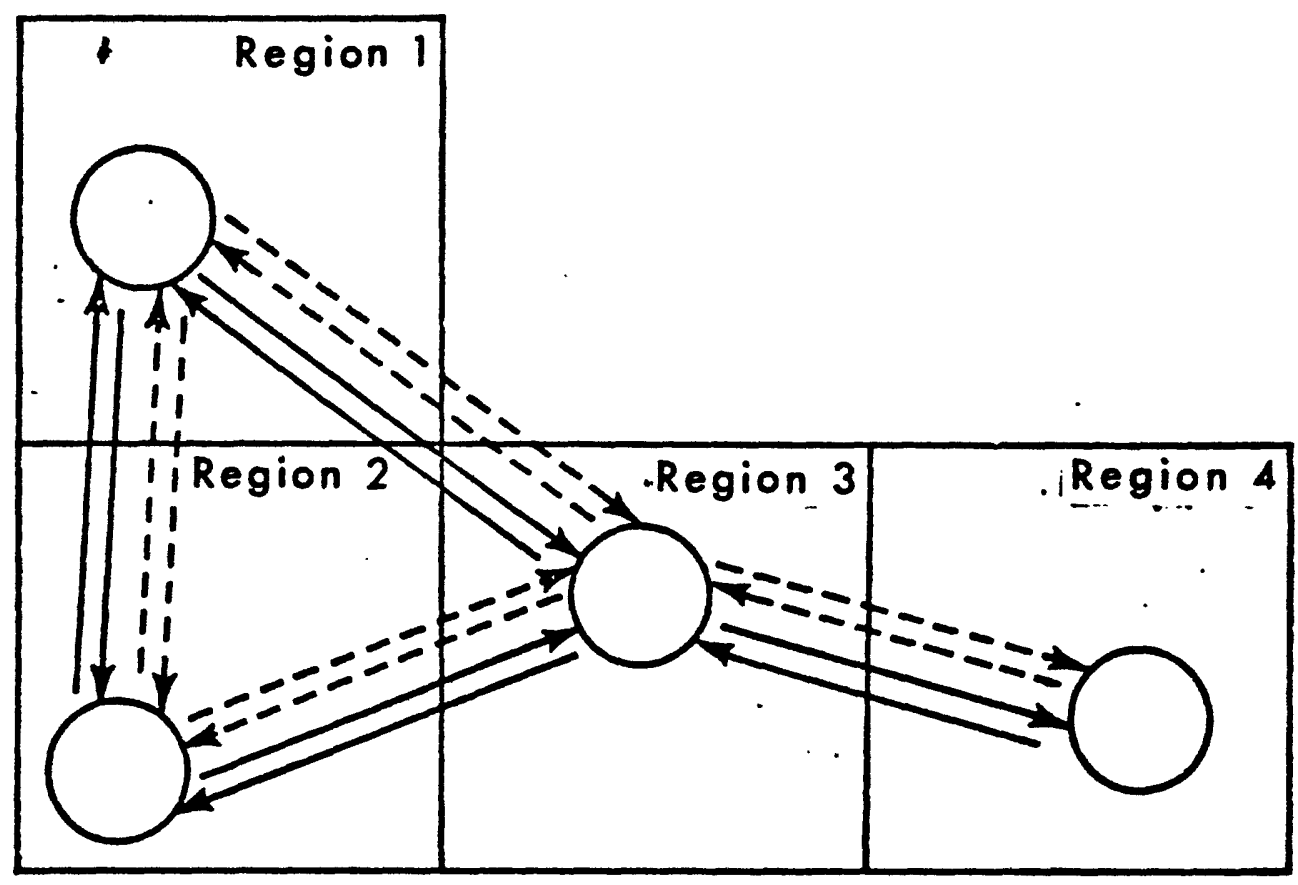

Symbols

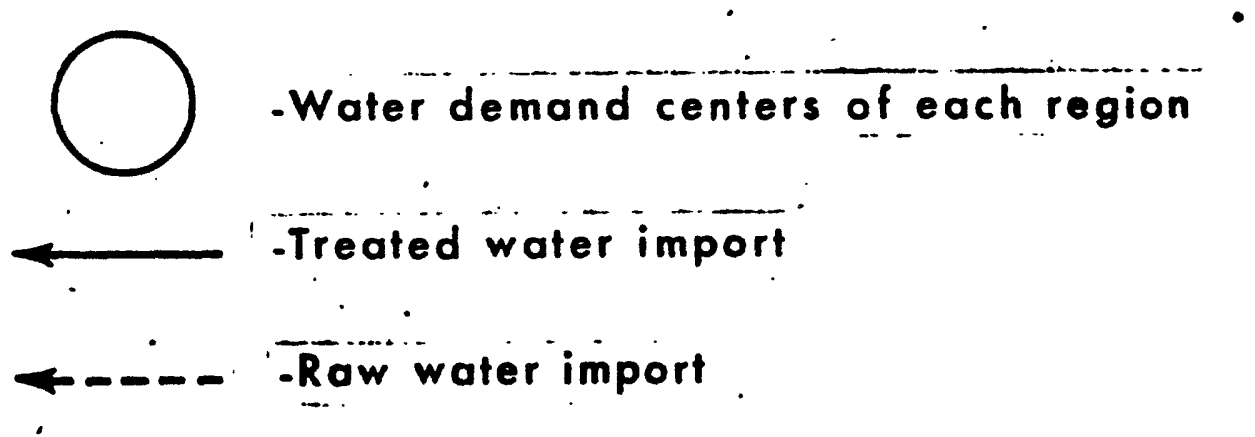

\footnotetext{
Figure 2. - A schematic representation of a fourplanning region model.
} 


\section{Mathematical structure}

A mixed-integer program determines a set of activity levels that optimizes an objective function subject to a set of constraints. Some of these activity levels are integer variables and others are continuous variables. The objective function of the Puerto Rico Water Resources Planning Model consists of minimizing the sum of the operating costs associated with producing, processing, and transporting a certain volume of water and the fixed construction costs associated with the individual projects (eq. 1). All costs are discounted to present value. The notation used in describing the objective function and the constraints is given in appendix $A$. The model's objective function 18

$$
\begin{aligned}
& \operatorname{Minimize} \sum_{k=1}^{5} \sum_{n=1}^{N} \sum_{i=1}^{I} \sum_{l=1}^{L_{i k}} \quad\left(c_{n i l}^{(k)} Q_{n i l}^{(k)}+F C_{n i l}^{(k)} I_{n i l}^{(k)}\right)
\end{aligned}
$$

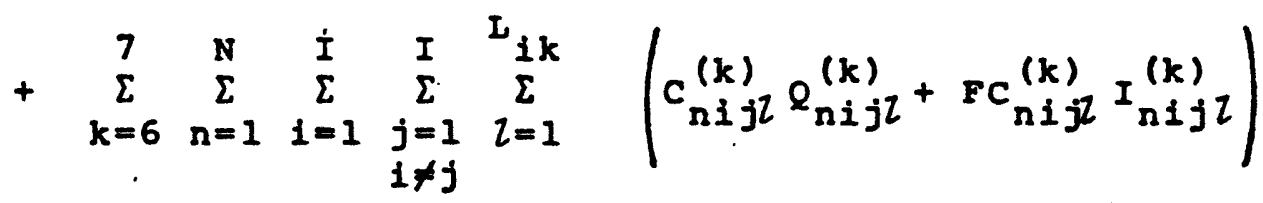

(eq. 1)

The first term of the objective function represents the operating costs and fixed costs of diversions, reservoirs, well-fields, desalinization plants, and water treatment plants. The second term represents the operating costs and fixed costs of raw and treated water imports. 
The objective function is subject to the following

constraints:

1. Project initiation constraint -- No water may be provided from project $l$ of type $k$ in planning region $i$ until the project has been constructed. Furthermore, once constructed. the project cannot provide more water than its yield or capacity. For water production projects,

$\begin{aligned} & U_{i l}^{(k)} \sum_{n=1}^{n} I_{n i l}^{(k)} \geq Q_{n i l}^{(k)} \quad k=1, \ldots, 5 ; n \cdot=1, \ldots, N, i=1, \ldots, I ; \\ & l=1, \ldots, I_{i k} \\ & \quad(\text { eq. } 2 a)\end{aligned}$

and for water tmport projects,

$v_{ \pm j l}^{(k)} \sum_{n=1}^{n !} I_{n i j i}^{(k)} \geq Q_{n i j l}^{(k)} \quad k=6,7, n^{\prime}=1, \ldots, N$,

$$
\begin{aligned}
& 1=1, \ldots, I ; j=1, \ldots ., I ; \\
& 1 \neq j, \tau=1, \ldots, I_{1 k}
\end{aligned}
$$

(eg. 2b)

If project $l$ of type, $k$ in planning region 1 already exists in the flrst planning period, then equation $2 a$ or $2 b$ can be replaced by a bound on the column variables which takes the following form:$$
0 \leq Q_{n i l}^{(k)} \leq v_{i Z}^{(k)}
$$$$
n=1, \ldots, N
$$$$
(e q \cdot .3 a)
$$

or

$$
0 \leq Q_{n i j l}^{(k)} \leq v_{i j Z}^{(k)} \quad n=1, \ldots, N
$$$$
\text { (eq. 3b) }
$$ 
2. Project limitation constraint - Project $l$ of type $k$ in planning region $i$ may be constructed once and only once during the design horizon. For water production projects.

$$
\begin{aligned}
& \sum_{n=1}^{N} I_{n i l}^{(k)} \leq 1 \quad k=1, \ldots, 5, i=1, \ldots, I, \\
& q=1, \ldots L_{1 k}
\end{aligned}
$$

and for water import projects,

$$
\begin{aligned}
& \sum_{n=1}^{N} I_{n i j l \leq 1}^{(k)} \leq 1, k=6,7,1, \ldots, \ldots, I, j=1 \ldots \ldots I, \\
& 1 \ldots j l=1, \ldots, L_{1 k}
\end{aligned}
$$

(eq. 4b)

If project $Z$ of type $k$ in planing region 1 already exists, this constraint is unnecessary.

3. Treated water demand constraint -- treated water production or processing (the output of well fields, desalinization plants, and water treatment plants) and treated water imports minus exports in planning region 1 and time period $n$ must be equal to or greater than treated water demands of planning region $i$ and time period $n$.

$$
\begin{gathered}
\sum_{-i=1}^{I_{1 k}}\left[\sum_{k=3}^{5} Q_{n i l}^{(k)}+\sum_{\substack{j=1 \\
i \neq j}}^{I}\left(Q_{n i j l}^{(7)}-Q_{n j i l}^{(7)}\right] \geq D F W_{n 1}\right. \\
n=1, \ldots, N i 1=1, \ldots, I
\end{gathered}
$$


4. Total water demand constraint -- Total water production (the output of diversions, reservoirs, ground water fields, and desalinization plants) plus the tmports of raw and treated water minus exports in planning region $i$ and time perlod $n$ must be equal to or greater than the total water demand of planning region 1 in time period $n$.

$$
\begin{array}{r}
\sum_{l=1}^{\sum_{i k}}\left[\sum_{k=1}^{4} Q_{n i l}^{(k)}+\sum_{k=6}^{7} \sum_{\substack{j=1 \\
i \neq j}}^{I}\left(Q_{n I j Z}^{(k)}-Q^{(k)}\right)\right] \\
\geq{ }^{\geq F W_{n i}+D_{n i}} n=1, \ldots, N, i=1, \ldots, I
\end{array}
$$

(eg. 6)

5. Flow requirement constraint -- The sum of the natural (unregulated) upland streamflows in planning region 1 in any time period $n$ which discharge into stream segment $p$, minus withdrawals from the stream system by upland diversion, reservoir, and raw water export profects, and minus losses from the stream due to ground water recharge induced by aquifer pumping must be greater than or equal to the required flows downstream of the rell fields.

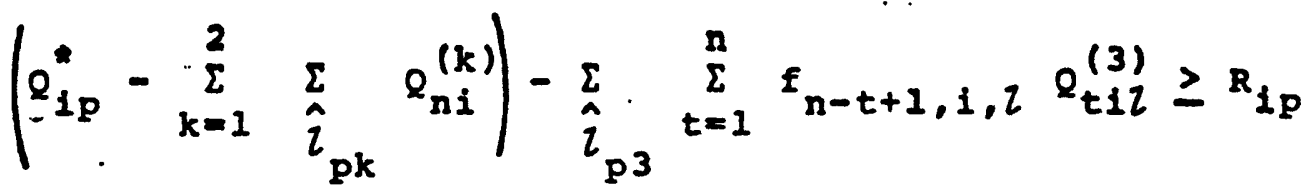

$$
\begin{aligned}
& n=1, \ldots, N_{i} 1=1, \ldots, I ; p=1, \ldots, P_{1} \quad(e q \cdot 7)
\end{aligned}
$$


The term in parentheses represents the streamflow available for recharging the aquifer in stream segment p. The vector $\hat{i}_{\text {pk }}$ is a list of project numbers $(Z)$ of type $k$ which affect. the flows in stream segment $p$. The vector $\hat{l}_{p 3}$ denotes a list of ground water fields which interact with stream segment $p$. The final term of the constraint computes the losses from the stream in segment $p$ during time period $n$ induced by the present and past pumpage of well field $Z$.

6. Bounds on integer variables -: All Integer variables are bounded between zero and one

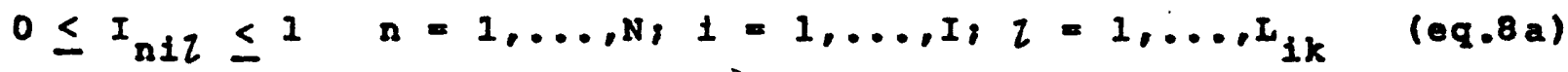

$0 \leq I_{n i j Z \leq} 1 \quad n=1, \ldots, N_{i} 1=1, \ldots, I_{i} j=1, \ldots, I_{i}$

$$
1 \neq j i l=1, \ldots . L_{i k}
$$

7. Non-negative constraint on continuous variables.

$$
\begin{aligned}
& Q_{n i l}^{(k)} \geq 0 \quad k:=1, \ldots, 5, n=1, \ldots, N, 1=1, \ldots, I, \\
& Z=1, \ldots . I_{i k} \\
& Q_{n i j Z}^{(k)} \geq 0 \quad k=6,7 ; n=1, \ldots, N, 1=1, \ldots, I_{1} \\
& j=1, \ldots, I_{1} 1 \neq j, \tau=1, \ldots, L_{1 k}
\end{aligned}
$$


3. A planning region contains one or more complete river basins. Where possible the boundaries of a region should coincide with political boundaries in order to simplify data compilation for water demands.

4. Waste water return flows are not considered as a potential source of water through either direct reuse, downstream storage or diversion, or recharge of the ground water supply. In other words once water has been extracted from a given supply. it is assumed to be removed from the hydrologic system. Additional assumptions are described in association with parameter definitions:

\section{Model Assumptions and Definitions of Parameters}

The Puerto Rico water Resources Planning Model described by equations 1 through 9 may be used to represent a variety of water supply planning problems by changing the size of the planning regions, the length of a planning period, the number of planning periods in the planning horizon, and level of aggregation of water demands and water supply projects. Obviously, the choice of levels of aggregation and the operational definitions given to model parameters will affect the interpretation of the results of model optimization. The-following assumptions and tentative definitions 
of parameters are given with a minimum amount of rationalization.

1. The minimization of water resource investments over the planning horizon and discounted to present value is a satisfactory criterion for evaluating alternative projects in a screening model.

2. Water resources projects proposed for development are associated with a specific site whereas water demands are assumed to be aggregated at a single point. It will often be convenient to assume that the raw and treated demand centers. raw and treated water pools, and water treatment plants are all located at the same point.

\section{Cost coefficients}

The determination of fixed and operating costs of projects depends upon the way in which projects are defined. The current model makes a distinction between projects which transport water within a planning region and projects which transport water between planning regions. Thus, the costs of reservolr and diversion projects include the costs of transporting water to the nearest water treatment plant. such transport costs. might include a diversion dam downstream of the reservoir, if the stream channelis used to transport reservoir releases earmarked for water supply, pipelines, and pumping stations.: 
Construction costs of ground water fields and desalinization plants Include the costs of transporting the water produced to the nearest connection within the existing water distribution system. Water treatment plant costs may or may not include transport costs depending on the location of the plant in relation to demand centers. The costs of expanding the existing water distribution system are not included in the model since such costs would be incurred regardiess of the source of water.

Conceptually, water import project costs include the construction costs of pipelines and pumping stations needed to connect raw and treated water pools (fig. 1) in the exporting and importing regions. However, the actual costs of construction may include only a pipeline from a reservoix in one region to a raw water pool in another region, since the phystcal distance between project and raw water pool may be shorter than the distance between the regional raw water pools. In such a case care must be taken to assure that if the import project is built, the reservoir is also built.

Another problem involves the handing of nonlinearities in the cost functions. Both operating costs and fixed costs are generally nonlinear with respect to capacity. since the. planner has already fixed the size of the alternative projects that he wishes to screen with the model, fixed costs are determined before the model is run. The quantity of water 
produced, processed, or transported, however, is a decision variable. The model assumes that the operating cost function can be determined by a linear approximation of the function in the range of water quantities demanded from the project. If this assumption does not hold, then adjustments in the operating cost coefficients will have to be made and the model will have to be reoptimized.

\section{Water quantities}

The continuous variables, $1 . e:$, the $Q$-values in the model are decision variables which represent the quantity of water produced, processed, or transported during the planning period. While the total quantity of water may vary from planning period to planning period, the ratelexpressed in milifons of gallons per day) is assumed to be constant during any given planning period.

$$
\text { Project capacities and yields }
$$

The design capacities of plpelines, desalination plants, and water treatment plants are determined by using standard englneering techniques and assumptions about system reliability. The yields of reservoirs, diversions, and well fields, however. present.problems of definition. The yield of a reservoir, for example..depends upon its capacity (usable storage). the pattern of inflows and drafts, its operating rules, and the way in which' project "reliability" is definea. The planning 
model assumes that the planner conducts separate hydrologic studies of proposed reservoirs, diversions, and ground water fields to obtain initial estimates of project yield. These studies take into account seasonal (possibly monthly) variations in both inflow and draft rates as well as other storage requirements for such purposes as flood control and low flow augmentation in the case of reservolrs. These initial estimates are used to obtain draft rates on each project from the planning model. At this point additional hydrologic studies may be undertaken to refine the yield estimates.

Flow Requirement Constraint

The flow requirement constraint parameters (eq. 7) require some explanation. First, the model assumes that waste water discharges enter a stream below ground water recharge areas (see assumption no. 4 listed above). It also assumes that the planner may wish to impose a constraint that requires a minimum quantity of water ( $R_{i p}$ ) to be available below stream reach $p$ for diluting these waste water discharges in order to maintain water quality standards in the stream. The aggregate unregulated inflow from the uplands to stream reach $p$ over the planning period will be $Q_{i p}^{*}$ With the development of upland reservoir and diversion sites some water will be removed from. the system. similarly, with the development of aquifers hydraulically connected to the stream along reach $P$, the stream irill become a source of water with which to recharge 
the aquifer. Thus, the term

$$
\sum_{t=12}^{n} t_{n-t+1, i, 2} Q_{t i l}^{(3)}
$$

represents the aggregate amount of water removed from the stream during time period $n$ due to pumping of the well field in time period $n$ and all previous time periods.

The coefficient $f_{n-t+1, i, l}$ may be interpreted as the fraction of water pumped by field $Z$ in time period $t$ that is removed from the stream in time period $n$.

The computation of the coefficlent $f$ is based.on the use of a digital ground water model (Maddock, 1969). Given that the vertical flow in an aquifer is insignificant, it is possible to construct a function relating the pumping of a set of wells to the drawdown at those welis even if the aquifer has irregularly shaped boundaries and nonhomogenous flow parameters such as transmissivity and storage coefficients (Maddock, 1972). Assuming that the head boundary is constant along the surface water stream, Maddock (1973) derived an expression relating the amount of water withdrawn from ground water storage by a well to the storage coefficient of the aquifer, the drawdown at the well, and the surface area of the aquifer. The difference between the amount of water pumped and the amount removed from storage is the amount of water removed from the surface water stream. 
Let

$$
F(n)=\sum_{t=1}^{n} \sum_{j=1}^{M}\left[1-\sum_{k=1}^{M} s(k) \Delta x^{2} B(k, j, n-t+1)\right] Q(j, t)
$$

(eq. 10)

where

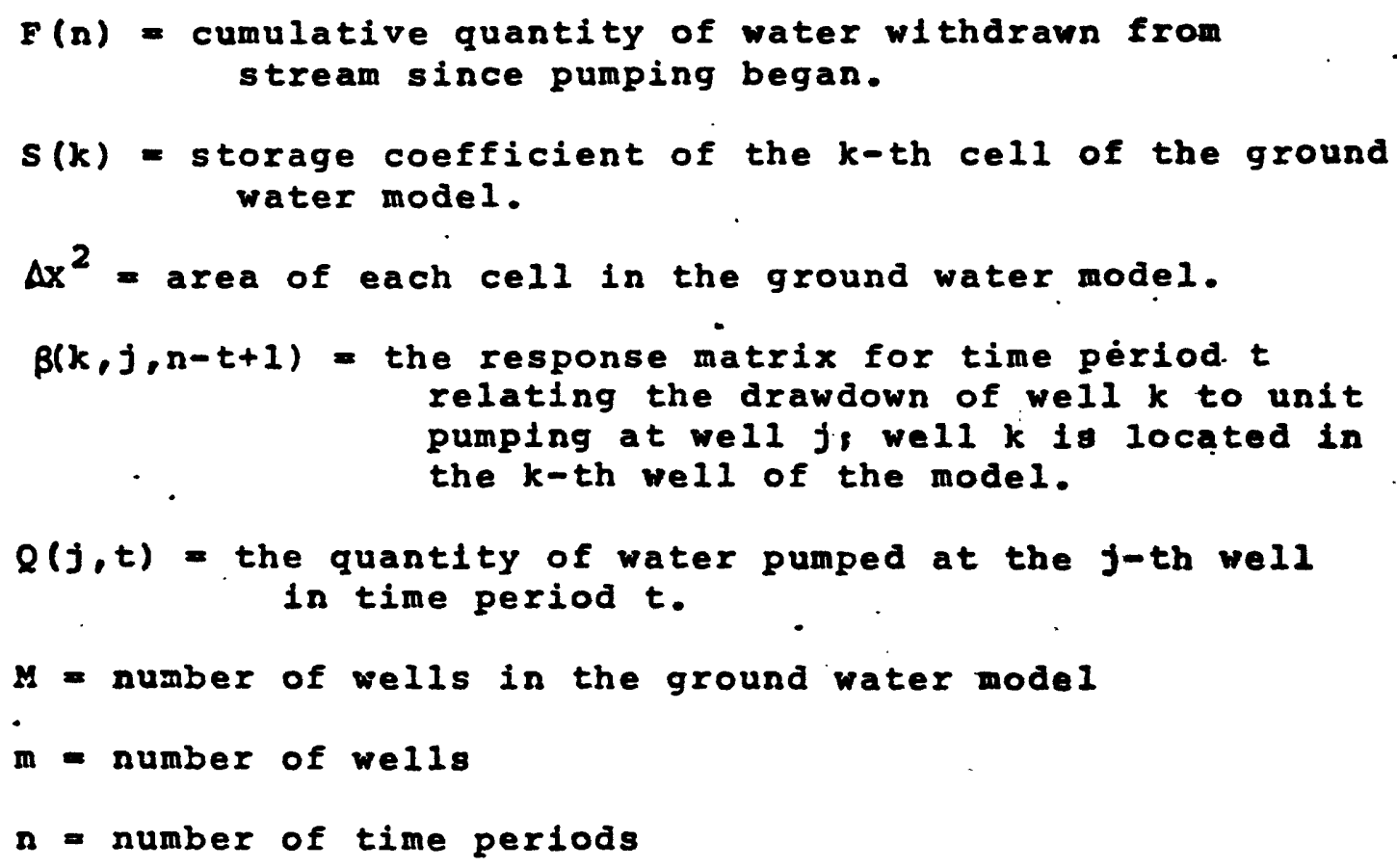

The $B$ coefficients are obtained by callbrating the ground water model with historical water level and pumping information.

By replacing the quantity in brackets by a coefficient, eq. 10 can be rewritten as

$$
F(n)=\sum_{t=1}^{n} \sum_{j=1}^{m} \psi(j, n-t+1) Q(j, t)
$$

Computational experience with the model has shown that once a pumping pattern is established among the $j$ wells of a well 
field, the pattern remains falrly constant from time period. to time period. The individual well pumpages can then be replaced by $\alpha(j) Q(t)$ where $Q(t)$ is total water pumped during time period $t$ and $\alpha(j ;$ is the fraction of the total quantity of water pumped by well j. Thus, the $\psi$ coefficient for the entire well field becomes

$$
\psi(n-t+1)=\sum_{j=1}^{m} \psi(j, n-t+1) \alpha(j)
$$

Thus, each well field $Z$ in each planning region 1 will have a coefficient $\psi_{n-t+1, i}$, computed for $1 t$. The f coefficient in eq. 7 can now be written

$$
f_{n-t+1,1,2}=\left\{\begin{array}{l}
\psi_{1,1,2,}, n=1 \\
\psi_{n-t+1,1,2-\psi_{n-t, 1,2}, n>1}>n
\end{array}\right\}
$$




\section{MODEL DEFINITION AND CONTROL PROGRAM (MODCOP)}

The model definition and control program (MODCOP) was written to assist the planner prepare input data to MPSX and to optimize the model described in the preceding section of this report. It is assumed that the user is familiar with IInear programming and the use of MPSX (IBM, 1971).

The problem matrix which describes the planning model to MPSX conststs of five major sections (figure 3 ):

1. Objective function -- a single row vector. of cost coefficients across the top of the matrix,

2. Bounds -- upper and/or lower bounds which constrain the values that the column. variables may assume,

-3. Right-hand side - a column vector of values which represent the right-hand side (RHS) of the constratnt equations;

4. Ranges -- a column vector of values which allow the RHS of the constraint equations to vary by fixed amounts

5. The main body of the problem matrix is divided into as many submatrices as there are planning regions..

Each position in the problem matrix is labeled by a column name and a row name. 


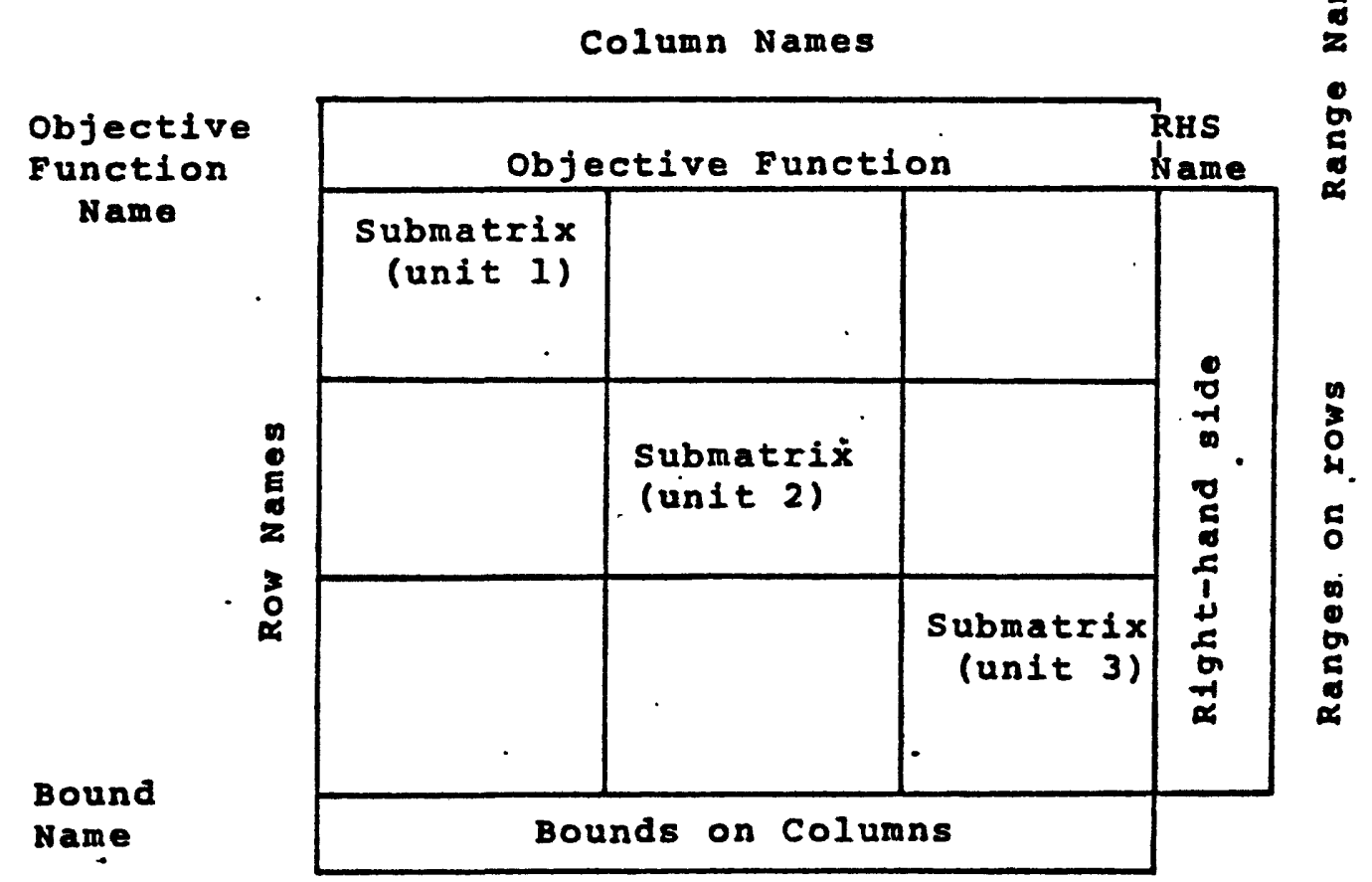

\footnotetext{
Figure 3. -- Problem matrix nomenclature. There are as many submatrices in the planning model as there are planning regions. The column variables of each submatrix consist of continuous variables and integer variables.
} 
MODCOP is programmed to prepare control cards and data cards required by MPSX to solve the Water Resources Planning Model. The required cards and their format are described in . the MPSX program description manual (IBM, 1971a). In general. once the appropriate equations of the mathematical program have been written (eqs. 1-9), a sample problem matrix should be filled in by hand with column names, row names, and the values of coefficients for each non-zero matrix element. Care should be taken to check and recheck the pattern of non-zero matrix elements to insure that they agree with the equations which describe the model. Later, this "picture" of the matrix can be compared with a picture produced on the computer's Iine printer by MPSX's PICTORE statement to verify the MPSX Input data produced by MODCOP. 
Program Organization and Operation

MODCOP calls on two main subroutines: DATA reads control cards and input data, and $P R$ sets up the MPSX control data and input data and transfers the card inages to disk storage.

\section{Subroutine DATA}

Subroutine DATA reads MODCOP control cards and Input data, prints tables of input parameters for verification by the user, and computer interest, rates, annual fixed costs, ground-water coefticients, and various other model parameters. Table I summarizes the cards read by this subroutine. Their formats are given in appendix B.

Each of the 12 types of data cards is preceded by a header card which is used by the subroutine to verify that the proper cards are being read. If the proper header card is not read, the program prints out an error message, although 1t does not terminate operation.

Model initialization parameter control cards. -- The first of these two control cards contalns four names which are used to identify the MPSX data deck, the objective function row, the right-hand side column, and bounds rows. Each name may be up to eight characters long. The first character of each name must be a letter and the name must not contain embedded blanks. The last parameter of the first card XWRITE 
Table 1. -- Summary of MODCOP Input data cards

1. Hodel Initlalization parameter control cards.

2. Row and column name symbol cards.

3. Number of water production (or processing) project cards.

4. Number of raw water import project cards.

5. Number of treated water Import project cards.

5. Water production project parameter cards.

7. Raw water Import project parameter cards.

8. Treated water import project parameter cards.

9. Water demand cards.

10. Surface water - ground water interaction parameter cards.

11. Surface water flow requirements cards.

12. Planning unit and project index cards. 
may be set to 'YESt', where o represents a blank character, if the card images produced by the $P R$ subroutine are to be displayed on the line printer.

The second card specifies the number of planning regions NPLAN, the number of time periods NTIME, the length of a. time period in years TIME, the annual present value interest rate RPV and the annual amortization interest rate RAM. The subroutine converts the annual present value interest rate to the effective interest rate for a planning period using the following equation:

$$
R=(1++R P V)^{\text {TIME }}-1 \text {. }
$$

All parameters are displayed in a table.

Row and columr name symbol cards. - The first card in this section gives the number of row symbols (NRSYMB) and the number of column symbols (NCSYMB) to be read from the cards to follow. A third parameter NP gives the number of types of water production (or water processing) projects as distinct from water import projects. The planning model descrlbed In this report has seven types of water resources projects, five of which are water production projects, e.g.. diversions, reservoirs, ground water fields, desalinization plants, and water treatment plants. Thus, NP should be set to 5 .

Each three-character symbol is displayed on a separate card with row symbols preceding the column symbols. In the 
planning model different symbols are used in place of the project type or $k$ Index. Each group of row constraints should be clearly identifled by different row symbols and continuous column variable symbols should be distingulshable from integer column variables. All symbols are displayed in a table. If the cards are out of order, e.g.. row symbol 10 is read when the program expected row symºl 9, an error message is printed but processing continues.

Number of water production (or water processing cards). -These cards provide the number of existing and proposed projects in each planning region by type, e.g., diversions, reservolrs, etc. There must be one card for each planning region. If there are no projects of a particular type of planning unit, a zero is entered in the appropriate column position. A maximum of 10 projects of each type is currently allowed in the program. The number of projects in each planning region are displayed in a table. If a card for a. planning region is missing or the cards are out. of planning region order; an error message will be printed.

Number of raw water import project cards. -- These cards give the number of raw water import projects in each planning region. Each card has three variables: I, the planning region importing water; $J$, the planning region exporting water, and NPIMP $(I, J)$, the number of transport projects (maximum of 10 projects). There must be at least one card 
for each planning region. If planning region I does not Import water, $J$ and NPIMP $(I, J)$ should be set equal to zero. In any case, the last card of a group of one or more cards for each planning region must have $J=0$ and NPIMP $(I, J)=0$ in order to terminate the read cycle for each planning reglon. After reading the cards, the program displays the number of projects in a table. If the cards are not in planningFegion order, an error message will be printed.

Number of located water import project cards. -- These cards give the number of treated water lmport projects in each planning region. The description of the "Number of raw water import project cards" is applicable to these cards except that the number of projects is given by the variable NPIMQ(I,J).

Water production project parameter cards. -- These parameter cards describe the economic life NL, the yleld (or capacity) YLD, the fixed costs $C F$, and the operating costs per million gallons co for each water production project in each planning region. The total number of cards must be equal to the total number of production projects. In addition to the information above, existing projects must be ldentified by setting FIX = 1 . After reading the project parameters, the DATA subroutine calis another subroutine, ACOST, to compute the discounted fixed costs of each project for earh planning period during which it might be constructed. The capital recovery factor CFR is calculated as follows: 


$$
C E R=\frac{\operatorname{RAM}(1++\operatorname{RAM})^{N L}}{\left(1+\operatorname{RAM}^{N L}-1\right.}
$$

where RAM is the interest rate to be used in amortizing the capital costs of the project over its economic life NL expressed in years. The annual fixed costs AFC are then obtained by multiplying the fixed costs CF by the capital recovery factor.

$$
A F C_{i l}^{(k)}=\operatorname{CFR}(C F \underset{i l}{(k)})
$$

The data subroutine also converts project yields and capacities from millions of gallons per day (MGD) to millions of gallons per planning period. Finally, all data and the results of the computations are displayed in a table.

Raw water and treated water import project parameter cards. - These two types of cards contain the same kinds of information as is on the water production project parameter cards. one card must be prepared for each project.

Water demand cards. -- This set of cards gives the future demands for fresh (treated water) DFW and for raw water DIW by land unit. Water loss factors are also given for each type of demand and indicate the fraction of the water supplied that is lost in transmission and treatment. The program then adjusts the.given water demands upwards to compensate for these expected losses. For example,

$$
\text { DFW (ạjusted) }=D F W /(1 .-\dot{P L F W})
$$


The total water demand for a given planning period in a given planning region is the sum of the adjusted raw and treated water demands. The program displays both the unadjusted water demands in MGD, and then the adjusted demands in MG per planning period. There must be NPLAN*: NTIME water demand cards in the data deck.

Surface water - ground water interaction parameter cards. If a well field is developed in an aquifer which is hydrauliealy connected to a river whose flow is also developed as a water supply, then the interaction between the two sources of supply must be taken into account in evaluating the quantity of water that may be pumped. In general, if ground water is developed first, then as demands increase beyond the capacity of the well fields, upland surface water sources are developed. Withdrawals from these sources reduce the amount of water available for recharging the aquifer which in turn reduce the water available from the ground water system. If the planner believes that these interactions are Important, then he must supply for each well field a set of coefficients $P H I$ which reflect the amount of water lost from a. stream in this and future planning periods due to unit pumping of the well field in the current time period. If there 18 no interaction, then the $P H I$ values are set to zero. 
Each surface water - ground water interaction card contains the PHI values for NTIME time periods for ground water field $l$ in planning region $i$. After reading the PHI values, equation 13 is used by subroutine GWCøMP to compute coefficients for for the ground water decision variables $0^{(3)}$. Alf values are peinted in tables. If no ground water projects are in the model, this section of data input must be skipped.

Surface water flow requirements cards. -- For one or more stream segments in a region, the planner may wish to set up flow requirements. This flow requirement states that the natural runoff of the region must exceed the ground water and surface water withdrawals by a certain amount. . The first card in this section lists the number of points at which flow requirements are necessary. One card must be provided for each planning region. The next two cards are read by the program in pairs: the first card gives the natural upland flow QFLOW, the flow requirement RFLOW, and the index number of the stream segments of interest. The second card identifies those reservolr and diversion projects whose withdrawals.must be subtracted from QFLOW in adition to those ground water pumpages which Induce recharge from the stream and therefore decrease the flow of the stream. In this way several flow requirements on a single stream or on several different streams within a 
single planning region can be accommodated. There must be one palr of cards for each flow requirement point in the model.

planning unit and project index cards. -- The final set of cards in the input data to MODCOP is optional. They are for the convenience of the user and allow him to label any or

- all of the various planning regions and projects. Whenever an end-of-file card is encountered, subroutine DATA is terminated. 
Subroutine PR

Subroutine PR in MODCOP transcribes the data read by subroutine DATA into the format required by MPSX.

The MPSX input data may be divided into seven sections:

1. NAME of data deck.

2. Rows section specifies the row names of the problem matrix and the type of each row constraint.

3. CoLUMNS section specifies the column variable names of the problem matrix and the value of each nonzero matrix element. The position of the element is given by a column name and a row name. Marker cards are inserted in this section to identify where integer column variables begin and end.

4. RHS section specifies the name of the right-hand side column vector and the nonzero values of the row constraints. The matrix elements are identified by the RHS name and row name.

5. RANGES section used when a row is to represent both a > and sinequality constraint. The section is optional and is not used in the current version of the Puerto Rico planning Model.

6. BOUNDS section specifies the limits to be imposed on the values of the column variables and the type of bounds. Normally, the MPSX automatically assigns a lower bound of zero and an upper bound of $+\infty$ to all columin variables. Each nonzero bound value is identified by the Bound name and a column name. Note that all integer variables in the planning model must have an upper bound of one.

7. ENDATA card signifies the end of the data deck.

w1th the exception of the RANGES section, which is not used in the planning model, subroutine PR is programmed to write card images on disk for each of the sections listed above. If XXWITE = 'YESb' on the first model parameter card 
read by subroutine DATA, the card images will also be printed.

NAME section. - writes the NAME card and assigns PNAME to the data deck name.

Rows section. -- The program writes the name of the objective function OBNAME, as the first row name and identifies it as an unconstrained row (type $N$ ). The program then loops through each planning unit writing the row names of constraints in the order that they are given in equations 2 through 10. The row (and column) names are created as follows: The number of the planning region ( $I$ or $J$ index) is converted to a letter, e.g., A $=1, B=2$, etc. Then the appropriate threecharacter row symbol (RSYMB(K)) is concatenated with the planiing region letter, the planning period number (N), and the project number (M). In the case of import projects a second letter ( $J$ index) is inserted after the first letter to indicate the source of the imported water. The cost coefficients of the integer column variables are calculated from the projects annual fixed costs (eg. 16). Each annual fixed cost payment made during the economic life of the project or during the number of years remaining in the planglng horizon, whichever is smaller, is discounted to present value and summed as shown in eq. 18. 


$$
F C_{n i l}^{(k)}=\sum_{t=t_{1}}^{t_{2}} \frac{1}{(1+R P V)^{t}} \operatorname{AFC}(k)
$$

where $F C_{n i l}^{(k)}$ - present value of equivalent fixed cost payment assumed to be made during the first year of time period $n$.

$t_{1}$ - year in which payment is made, $t_{1}=N$ - TIME TIME + I where TIME is the number of years in a planning period and $N$ is the number of the planning period.

$t_{2}$ - year in which payments end; $t_{2}=N \cdot T I M E+N L$ or $t_{2}=$ NTIME - TIME, whichever is smaller, where NL is the economic life of the project in years and NTIME is the number of planning periods in the planning horizon.

- RPV - annual discount rate

$\operatorname{AFC}_{i l}^{(k)}$ - annual fixed cost payment for project $l$ of type $k$ in planning region $i$.

The only zero coefficients in the objective function row will be the fixed costs of existing projects.

The row constraints are written in the following orders

1. Project initiation constraints for water production and water import projects (eq. $2 a$ and $2 b$ ).

- 2. Project limitation constraints for water production and water import projects (eq. $4 a$ and $4 b$ ).

3. Treated water demand constraints (eq. 5).

4. Total water demand constraints (eq. 6).

5. Flow requirements constraints (eq.. 7 ). 
Colums section. - The columns section is written in two parts: the continuous variable section and the integer variable section. Marker cards are inserted before and after the Integer variable section. The column names are created as described for the Rows section. To determine which matrix elements are nonzero for any given column variable, the user should rewrite the constraints in such a way that the column variables appear in the constraint in the same order that they are to be written by subroutine PR. The order is determined by the column symbol list CstMB(K) and the DO-loops indexed on planning unit $I$ (and $J$ for import projects), the planning period $N$, and the project number $M$, if appropriate to the constraint.

The first row of each column vector will always contain a cost coefficient. For the continuous variables column, the cost coefficients in the objective function are the present values of operating costs per unit of water produced or. transported, COP. COP is. calculated from the pperating costs Co, COIMP, and coIMQ read by subroutine DATA. For example,

$$
\operatorname{COP}=\frac{\mathrm{CO}}{(1 .+R)^{N}}
$$

where $R$ is the effective interest rate for a planning period (eq.-14) and $N$ is the number of the planning period.

The program then writes any nonzero values in the column vector together with the row name. Coefficients with values of 1 or -1 are usually written as part of a format statement in the computer program. Other values, such as project 
capacity must be read by subroutine data. If new constraints are added to the model, the user must determine which rows have nonzero coefficients and develop the logic of whether or not . to write a coefficient in a particular column. The logic and appropriate write statements and formats must be added to. this section of the PR subroutine.

RHS section. -- The nonzero right-hand-side values of each row constraint are next written in the same order as the row names were defined. The RHS column is given the name assigned to RHNAME on the first model parameter card read by subroutine DATA. The program also creates four additional columns as part of the RHS section. The first column vector, XCHCOLRI, duplicates the treated water and total water demands in the RHS column. The second, XCHCOLR2 duplicates the RHS of the required flows constraint bearing in mind that this value is the difference between the natural inflows and the required flows (QFLOW-RFLOW): Column XCHCOLR3 and 4 contain negative values of columns XCHOLRI and 2 respectively. These four "change" columns and the RHS are used for parametric program using the MPSX procedure PARARHS.

Bounds section. -- The program next writes out the bound row rector, which is given the name assigned to BNAME on the first model parameter and read by subroutine DATA. All withdravals from water producing or transporting projects are bounded by their yields and capacities. All integer variables are given upper bounds of one. 
ENDATA section. -- The last step in subroutine PR is to write an 'ENDATA' card to complete the MPSX data deck. 


\section{Subroutine BLOCK DATA}

The final subroutine in MODCOP that should be mentioned is BLOCK DATA. This subroutine initializes the values of data arrays that are shared in common with the DATA and PR subroutines. The current dimensions of data arrays in MODCOP version 3 are listed in table 2. If the user wishes to enlarge or reduce the dimensions of the current model for some reason, the dimension and Initialization statements in BLOCK DATA will have to be changed as well as the approprlate COMMON statements in the DATA, PR, ACOST, and GWCOMP suisroutines. 
Table 2. -- List of variables dimensioned in subroutine BLOCK DATA

Variable Name

RSYMB (25)

CSYMB (25)

$\operatorname{NPROJ}(K, I)$

$\operatorname{NPIMP}(I, J)$

$N P I M Q(I, J)$

$N L(K, I, P)$

$\operatorname{NLIMP}(I, J, P)$

$\operatorname{NLIMQ}(I, J, P)$

$Y L D(K, I, P)$

$\operatorname{YLDIMP}(I, J, P)$

YLDIMQ $(I, J, P)$

$\operatorname{CAP}(K, I, P)$

$\operatorname{CAPIMP}(I, J, P)$

$\operatorname{CAPIMQ}(I, J, P)$

$C F(K, I, P)$

$\operatorname{CFIMP}(I, J, P)$

$\operatorname{CFIMQ}(I, J, P)$

\section{Description}

Row symbol list

Column symbol list

Number of water producing (or processing projects)

Number of raw water import projects

Number of treated water import projects

Economic life of water producing projects

Economic life of raw water import projects

Economic life of treated water import projects)

Yield/capacity of water producing projects (MGD)

Capacity of raw water import projects (MGD)

Capacity of treated water import projects (MGD)

Y1eld/capacity of water producing projects (MG per planning period)

Capacity of raw water import projects (MG per planning period)

Capacity of treated water import projects (MG per planning period)

Fixed costs of water producing projects

Fixed costs of raw water import projects.

Fixed costs of treated water import projects 
Table 2. - (continued)

Variable Name

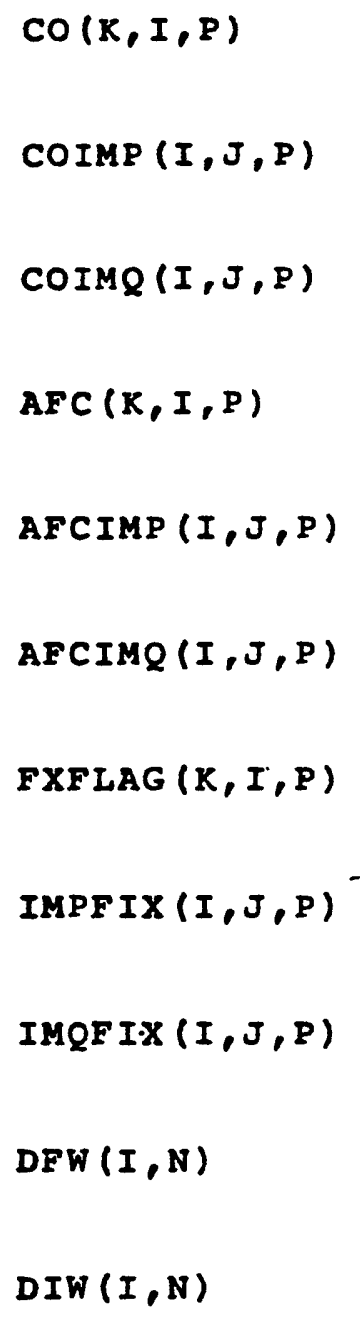

$\operatorname{NPX}(I)$
Description

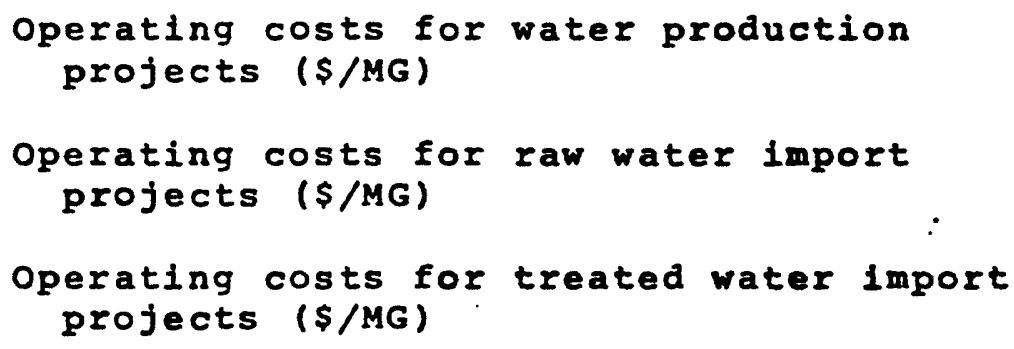

Annual fixed costs for water production projects

Annual fixed costs for raw water import projects

Annual fixed cósts for treated water import projects

Logical flags for existing water production projects

Logical flags for existing raw water import projects

Logical flags for existing treated water import projects

Demand for treated water (MG per planning period)

Demand for raw water (MG per planning period)

Total water demand (MG per planning period)

Treated water losses (percent/100)

Raw water losses (percent/100)

Ground water - surface water interaction coefficient

Ground water - surface water interaction coefficient

Number of stream segments 
Table 2.-- (continued

Variable Name

QF LOW (I, KP)

RFLOW $(I, K P)$

KPDFL $(I, K P, 6)$

\section{Index}

\section{$I, J$ \\ $\mathbf{K}$}

$\mathbf{K P}$

\section{Description}

Opland runoff above stream segments (MG per planning period)

Required flow below stream segments (MG per planning period)

Project IInkage array 


\section{Operating Requirements}

The current version of MODCOP (version 3 ) is written for the IBM $360 / 65$ computer in the FORTRAN IV programing language. The program requires $154 \mathrm{~K}$ bytes of storage to compile and approximately $250 \mathrm{k}$ to execute. If the data arrays are increased, additional core may have to be allocated to the program for execution of the load module.

An error-free compilation of the source program takes about one minute. Execution time will depend upon the number of planning regions, planning periods, and projects in the model, but few models will require more than one minute.

MODCOP will usualiy be set up to write the MPSx data deck as card images on disk. To determine the disk space requirements of the MPSX data deck the user should first estimate the number of card images produced by MODCOP using the equations in table 3. If 90 card images are written in 7200-byte blocks per track, then the user should allocate [total number of cards / 90] + 1 tracks to MODCOP's output data set.

A complete listing of the source program is shown in appendix E. 


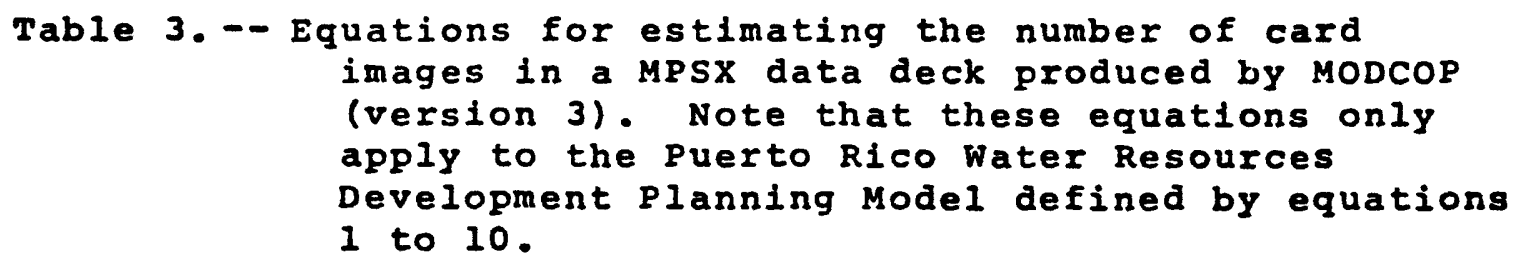

Let $n=$ total number of projects in all planning regions. $n_{e}=\begin{gathered}\text { total number of existing projects in all planning } \\ \text { regions. }\end{gathered}$

$n_{k}=$ total number of projects of type $k$ in all planning regions.

$t$ - number of planning periods.

$q$ - total number of flow requirement points in all planning regions.

$p$ number of planning regions.

where $\underline{k}="$ Type of project

1 Diversion dams

2 Reservoirs

3

Ground water fields

4 Desalinization plants

5 water treatment plants

6 . Raw water import projects

7 Treated.water import projects

Section of MPSX Data Deck

Number of Cards

NAME

1.

ROWS $. \cdots, \therefore$

1. Objective function

1

2. Initiation constraints (eq. 2)

$=(n-n) t$

3. Iimitation constraints (eq. 4)

$=i_{n}-n_{e}$ 
Table 3.-- (continued)

4. Treated water demand constraints (eq. 5) = pt

5. Total water demands constraints (eq. 6) = pt

6. Flow requirement constraints (eq. 7) =qt

\section{COLUMNS}

1. Continuous variable section

$$
=\left[4 n_{1}+4 n_{2}+4\left(n_{3}+t\right)+4 n_{4}+3 n_{5}+4 n_{6}+6 n_{7}\right] t
$$

2. MARKER cards for integer variables

3. Integer variable section

$=2\left(n-n_{e}\right) t$

RHS

1. Iimitation constraints

$=\mathbf{n}-\mathbf{n}_{\mathbf{e}}$

2. Treated water demands constraints

$=p t$

3. Total water demands constraints

$=p t$

4. Flow requirement constraints

$=q t$

BOUNDS

1. Continuous variables

$=n t$

2. Integer váriables

$=\left(n-n_{e}\right) t$ 
MPSX USAGE

Before using MPSX the user should be familiar with the concepts of linear and integer programming. Wagner (1969). for example, provides a good introduction to these subjects. Geoffrion and Marsten (1972) review the state-of-the art of

- Integer programming algorithms and include a discussion of MPSX. Finally, the user should carefully read the MPSX program description (IBM, 1971 a and 1971b) for detailed instructions in the use of MPSX.

As an example of the use of MODCOP and MPSX, a two-region planning model was developed for the Yabucoa Municipio: Puerto Rico. The urban area of Yabucoa was treated as a single demand center with a second planning region representing the rest of the world. Demands in the rest of the world were assumed to be zero and an ample supply of raw and treated water was assumed to be available for importing to Yabucoa. The first part of appendix D lists the input data to MODCOP. This listing is followed by the tables produced by MODCOP and a sample of the MPSX data deck created by MODCOP. Note that listing of MPSX data was obtained by setting XWRITE = 'YESS' on the first model initialization parameter control card (p. 24). The second part of appendix D 11lustrates the MPSX control program used to obtain an optimal integer solution to the problem and part of the MPSX program 
output. The problem consisted of 165 continuous column variables, 140 integer column variables, and 199 rows. The matrix density was 1.62. MPSX was able to prove optimality for this problem in 10 minutes on the IBM $360 / 65$ and 3.8 minutes on the IBM $360 / 91$ computer using the MPSX default search strategy. 


\section{SUMMARY}

within the limitations of the least-cost model described. by equations 1 through 9 , MODCOP offers the user considerable latitude in combining different types of water resources projects to approzimate existing and proposed regional water

resources development schemes. The use of the surface waterground water interaction parameters introduces the impact of ground water pumping on surface water flows in areas where upland surface water development is. likely to limit surface water available for ground water recharge. The mixed integer model described in this report does not provide optimai schemes of water resources development. All of the model's parameters, the cost coefficients, project capacities, future water. demands, etc., are subject to uncertainty while the model provides a deterministic least cost solution to just one set of parameter estimates. On the other hand, given the assumptions upon which the model is based, the planner can explore a variety of water resources development proposals and eliminate or screen out those which are clearly more costly than others, and therefore probably less desirable. The successful application of this model will depend in large part on the planner's ability to identify potential development schemes, choose appropriate scales of parameter aggregation, and interpret the results of model optimization. 
Facets, T. B. and Marks, D. H., 1972, Scheduling and sequencIng in water resource investment models: Internat. Symposium on Water Resources Planning, Mexico City, 1972, Proc., v. 1 .

Geoffrion, A. M. and Marsten, R. E., 1972, Integer programming algorithms, a framework and state-of-the-art survey: Management Science, v. 18, no. 9, p. 465-491.

IBM, 1971a, Mathematical programming system extended (MPSX) Linear and separable programing program description (program no. 5734-XM4): IBM Corporation, white plains, N. Y.. Manual no. SH 20-0968-0, 298 p.

- 1971b. Mathematical programming system extended (MPSX) mixed integer programing (MIP) program description (program no. 5734-XM4): IBM Corporation, White plains, N. Y.. Manual no. SH 20-0960-0, 153 P.

Maddock, Thomas, III, 1969, A program to simulate an aquifer using alternating direction implicit-iterative procedure: U.S. Geol. Survey, Open-file Report, 71 p.

Maddock, Thomas, III, 2972, Algebraic technological function from a simulation model: Water Resources Research, $v$. B, no. 1. p. 129-134.

Maddock, Thomas, III, 1973, The operation of a stream-aquifer system under stochastic demands: Water Resources Research, (to be published).

O'Ne111, P. G.. 1972, A mathematical-programming model for planning a regional water resources system: Jour. Inst. Water Engineers, v. 26, no. 1, p. 47-61.

Wagner, H. M... 1969, Principles of operations researchs Englewood Cliffs, N. Y.. Prentice-Hal1, 937 p. 
Appendix A. - Puerto Rico Water Resources

Development Planning Model notation

A-1 
Appendix A. -- Puerto Rico Water Resources Development Planning Model notation

Indexes

$\mathbf{k}$

n

$1 . j$

Z

$\hat{\imath}_{\mathbf{p}} \mathbf{k}$

.

$\mathbf{p}$

\section{Description}

Index to type of water resources project, $k=1, \ldots, 7$.

\begin{tabular}{ll} 
k & \multicolumn{1}{c}{ Project } \\
1 & Diversion dam \\
2 & Reservoir \\
3 & Ground-water well field \\
4 & Desalinization plant \\
5 & Water treatment plant \\
6 & Raw water import project \\
7 & Treated water import project
\end{tabular}

Index to time within a planning horizon of $N$ periods; $n=1, \ldots ., N$.

Planning region or land unit index; $i=1, \ldots$. I $J=1, \ldots . .1$.

Project number index which specifically designates the location and size of a water resources project. The number of projects of type $k$ will vary from region to region; $=1, \ldots . \mathrm{L}_{i k}$.

List of project numbers of type $k$ which affect the flow requirements downstream of stream segment $p$.

Number of stream segments for which there is a downstream flow requirement. The number of segments will vary from region to region; $p=1, \ldots P_{1}$.

\section{Continuous Viariables}

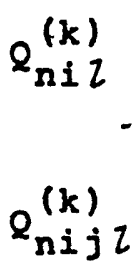

Amount of water produced or processed by project $Z$ of type $k$ in planning region $i$ during time. period $n ; k=1, \ldots, 5$.

Amount of water ( $r a w$ or treated) imported by project $l$ of type $k$ in time period $n$ from land unit $j$ to land unit $i$. Exports from 


\section{Appendix A (continued)}

Ground Water Coefficients Description

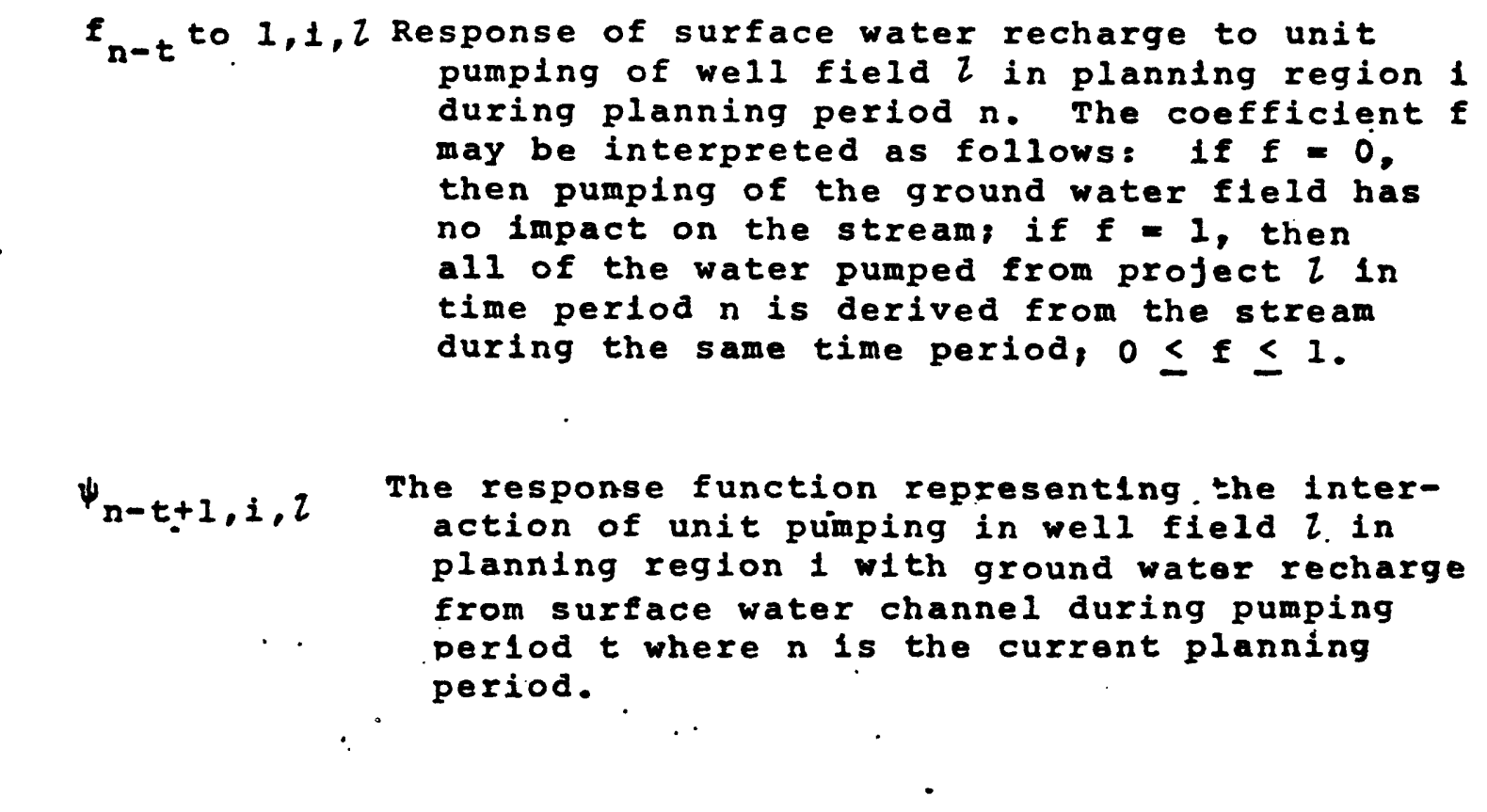

Water Demands

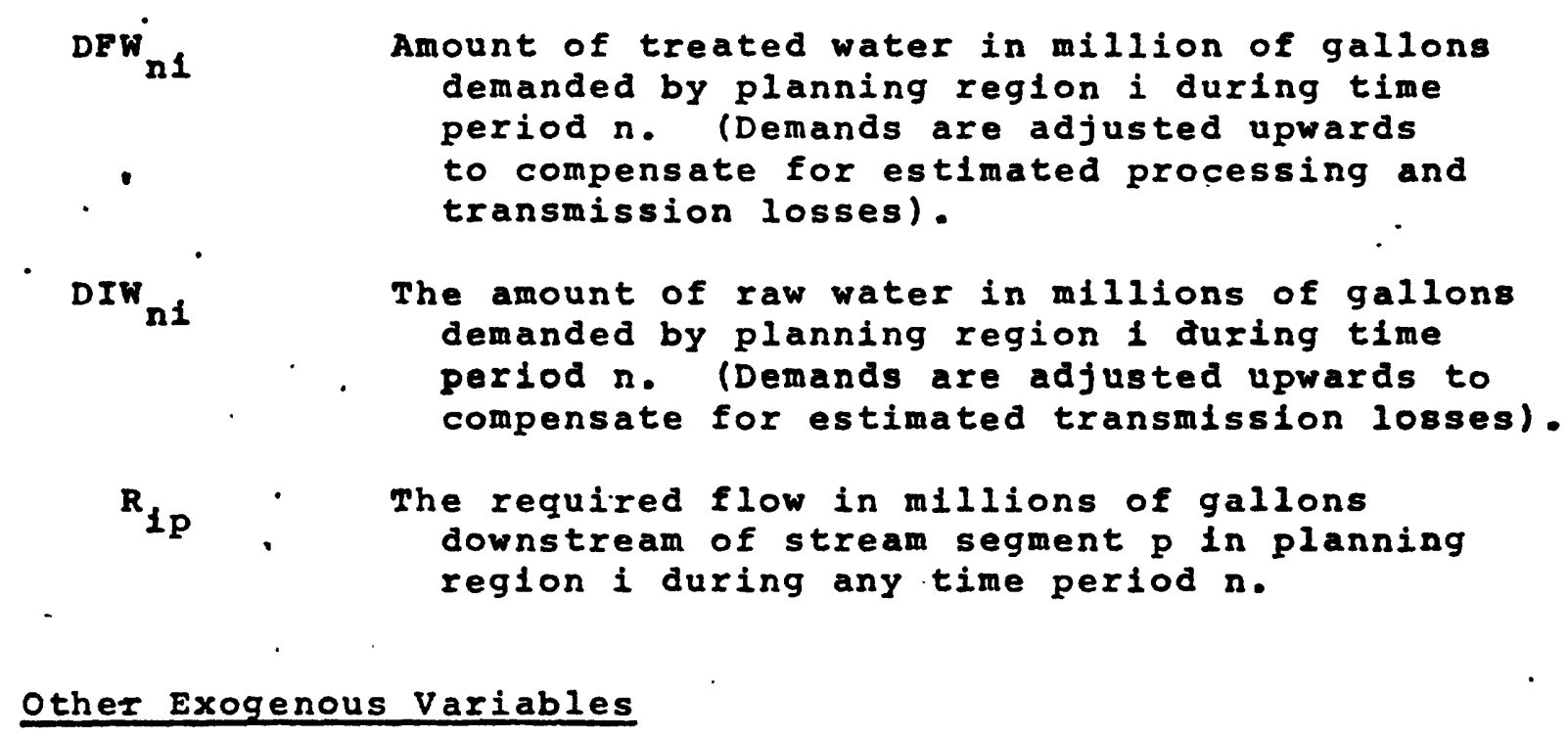

Other Exogenous Variables 
Appendix A (continued)

Continuous variables (cont'd) Description

land unit 1 to land unit $j$ are represented by switching the $i$ and $j$ indexes. Thus, an export from land unit $i$ appears in the model as an import to land unit $j ; k=6,7$.

\section{Integer Variables}

$I_{n i l}^{(k)}$

Integer variables indicate when specific projects are to be constructed in each planning region. If I equals one, then project $l$ of type $k$ will be constructed in planning region $i$ during time period $n$. otherwise, I equals zero; $k=1, \ldots, 5$.

$I_{n i j l}^{(k)}$

Integer variables indicating the construction of water import project $l$ of type $k$ in time period $n$ which transfers water from planning region $j$ to planning region $1, k=6,7$.

Cost. Coefficients

$$
\mathrm{FC}_{\mathrm{ni}}^{(k)}
$$

and

Fc (k) nijl

$c^{(k)}$

nil

and

$c^{(k)}$

n1j
Discounted annual fixed costs associated with project $Z$ of type $k$ in region $i$ and constructed in time $n$; $k=1, \ldots, 5$ and $k=6,7$.

Discounted operation, mainter nce; and replacement costs per million gallons associated with project $l$ of type $k$ in planning region $i$ $k=1, \ldots, 5$ and $k=6,7$.

\section{Capacity Coefficients}

$v_{i l}^{(k)}$

and

$u_{1 j q}^{(k)}$
Design capacity or yield in millions of gallons of water resources project $l$ of type $k$ in any time period $n ; k=1, \ldots, 5$ and $k=6,7$. 
Appendix A (continued)

Other Exogenous Variables (cont'd) Description

$\mathbf{N}$

Number of time periods of $t$ years in the design horizon of the planner. If the design horizon is for $T$ years, $N=T / t$.

I

Number of planning regions or land units to be studied.

$I_{\text {ik }}$

Number of projects of type $k$ in each land unit.

$P_{1}$

Number of stream segments which have flow requirements in land unit $i$.

$\boldsymbol{r}$

Effective interest rate for a single time period (t years) used to reduce monies to present values. 
Appendix B. -- Format of MODCOP

Input data cards

B-1 


\section{Appendix B-1.-- Model initialization parameter control cards (REQUIRED)}

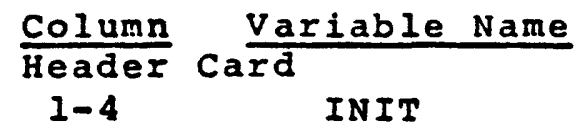

Card 1 $1-8$

PNAME

$9-16$

OBNAME

$17-24$

RHNAME

$25-32$

BNAME

$33-37$

XWRITE

Card 2 $1-4$ NPLAN

$5-8$ NT IME

\section{Description}

'INIT' -- The remainder of the card may be used to describe the cards to follow.

Problem name assigned to NAME card of MPSX data deck. The first character of all names must be alpha. The fteld is left justified as are all the names on card 1.

Objective function name assigned to the first row of the MPSX problem matrix.

Right-hand-side name assigned to the RHS column vector in the MPSX problem matrix.

Bounds name assigned to the BøuNDS row vector in the MPSX problem matrix.

Parameter for controliding printout of the matrix created by M $\varnothing D C \varnothing P$. If 'YESb' is punched, the MPSX data card images will be printed!'

Total number of planning regions (maximum of 8 ).

Total number of time periods in planning horizon (maximum of 10).

If The character $\not 6$ represents a blank.

2/ All numbers in this and following sections are right justified in their field positions.

$$
\mathrm{B}-2
$$




\section{Appendix $B-1$ (continued)}

\begin{tabular}{|c|c|c|}
\hline Column & Variable Name & Description \\
\hline$\underset{9-16}{\operatorname{Card} 2}$ & $\begin{array}{r}(\operatorname{con} t \cdot d) \\
T I M E\end{array}$ & $\begin{array}{l}\text { Length of time period in years (punch } \\
\text { decimal point). }\end{array}$ \\
\hline $17-24$ & RPV & $\begin{array}{l}\text { Present value interest rate (punch } \\
\text { decimal point). }\end{array}$ \\
\hline $25-32$ & RAM & $\begin{array}{l}\text { Amortization interest rate (punch } \\
\text { decimal point). }\end{array}$ \\
\hline
\end{tabular}




$$
\begin{aligned}
& \text { Appendix B-2.-- Symbol control cards for row and } \\
& \text { column names (REQUIRED) }
\end{aligned}
$$

\begin{tabular}{|c|c|c|}
\hline Column & Variable Name & Description \\
\hline $\begin{array}{l}\text { Header } \\
1-4\end{array}$ & $\begin{array}{l}\text { Card } \\
\text { SYMB }\end{array}$ & $\begin{array}{l}\text { 'SYMB' -- The remainder of the card } \\
\text { may be used to describe the cards } \\
\text { to follow. }\end{array}$ \\
\hline$\underset{1-4}{\operatorname{Card} 1}$ & NRSYMB & Number of row symbols (maximum of 25 ). \\
\hline $5-8$ & NCSYMB & $\begin{array}{l}\text { Number of column symbols (maximum } \\
\text { of 25). }\end{array}$ \\
\hline $9-12$ & NP & $\begin{array}{l}\text { Number of water producing or water } \\
\text { processing types of projects } \\
\text { including water treatment plants } \\
\text { but not including water transport } \\
\text { projects. Set } N \text { to } 5 \text { for this } \\
\text { version of the planning model. }\end{array}$ \\
\hline
\end{tabular}

Row or Column, Symbol Cards.

$\begin{array}{cl}1 & - \\ 2-3 & \mathrm{KK} \\ 5-7 & \operatorname{RSYMB}(\mathrm{K}) \\ \cdot & \operatorname{Or} \\ 8-80 & \operatorname{CSYMB}(\mathrm{K}) \\ & \operatorname{RESC}(\mathrm{K}, \mathrm{J}) \\ & \operatorname{CDESC}(k, J)\end{array}$
" $R$ " or "C" -- Identification of card type: row or column.

Number of Kth symbol.

Three-character prefix of kth row or column symbol. First character must be alpha.

up to 72 characters of text describing the kth row or column symbol.

Notes The row cards must precede the column cards in the data deck, and the cards must be in ascending order of the KK value. There will be a total of NRSYMB+NCSYMB. symbol cards. 


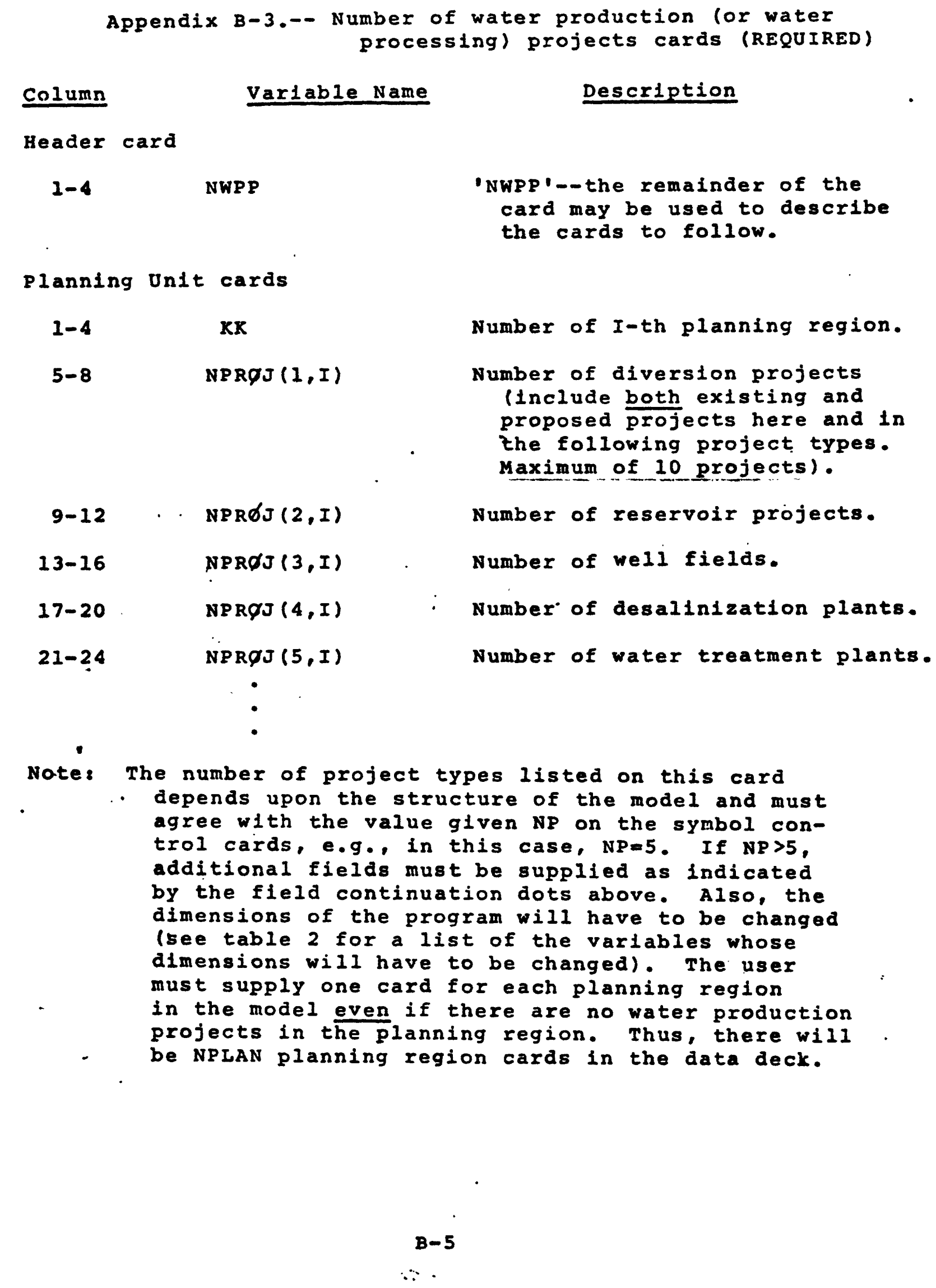

Note: The number of project types listed on this card

- depends upon the structure of the model and must agree with the value given NP on the symbol control cards, e.g., in this case, $N P=5$. If $N P>5$, additional fields must be supplied as indicated by the field continuation dots above. Also, the dimensions of the program will have to be changed (see table 2 for a list of the variables whose dimensions will have to be changed). The user must supply one card for each planning region in the model even if there are no water production projects in the planning region. Thus, there will - be NPIAN planning region cards in the data deck. 


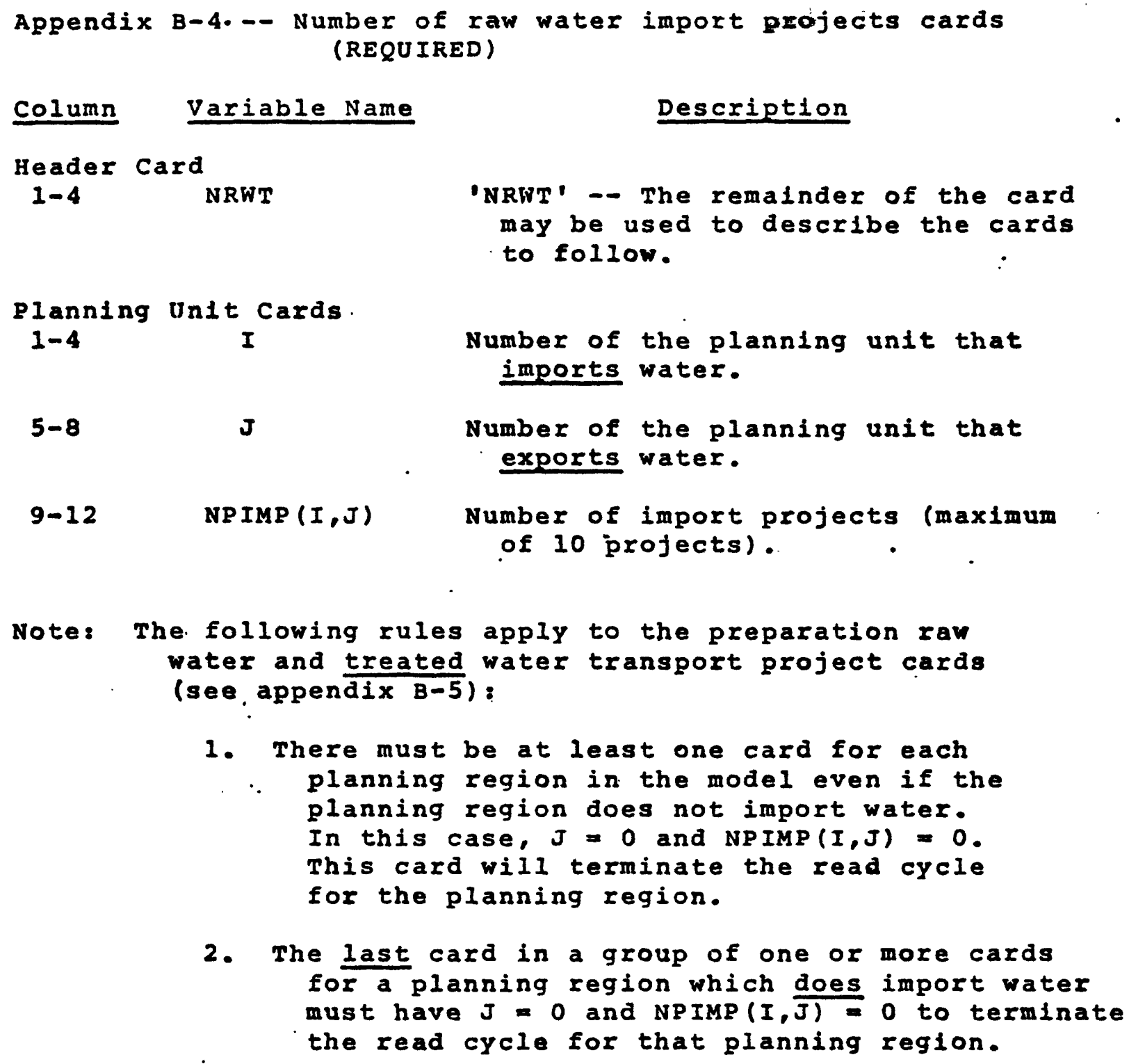

2. The last card in a group of one or more cards for a planning region which does import water must have $J=0$ and $\operatorname{NPIMP}(I, J)=0$ to terminate the read cycle for that planning region. 
Appendix B-5. -- Number of treated water import project cards (REQUIRED)

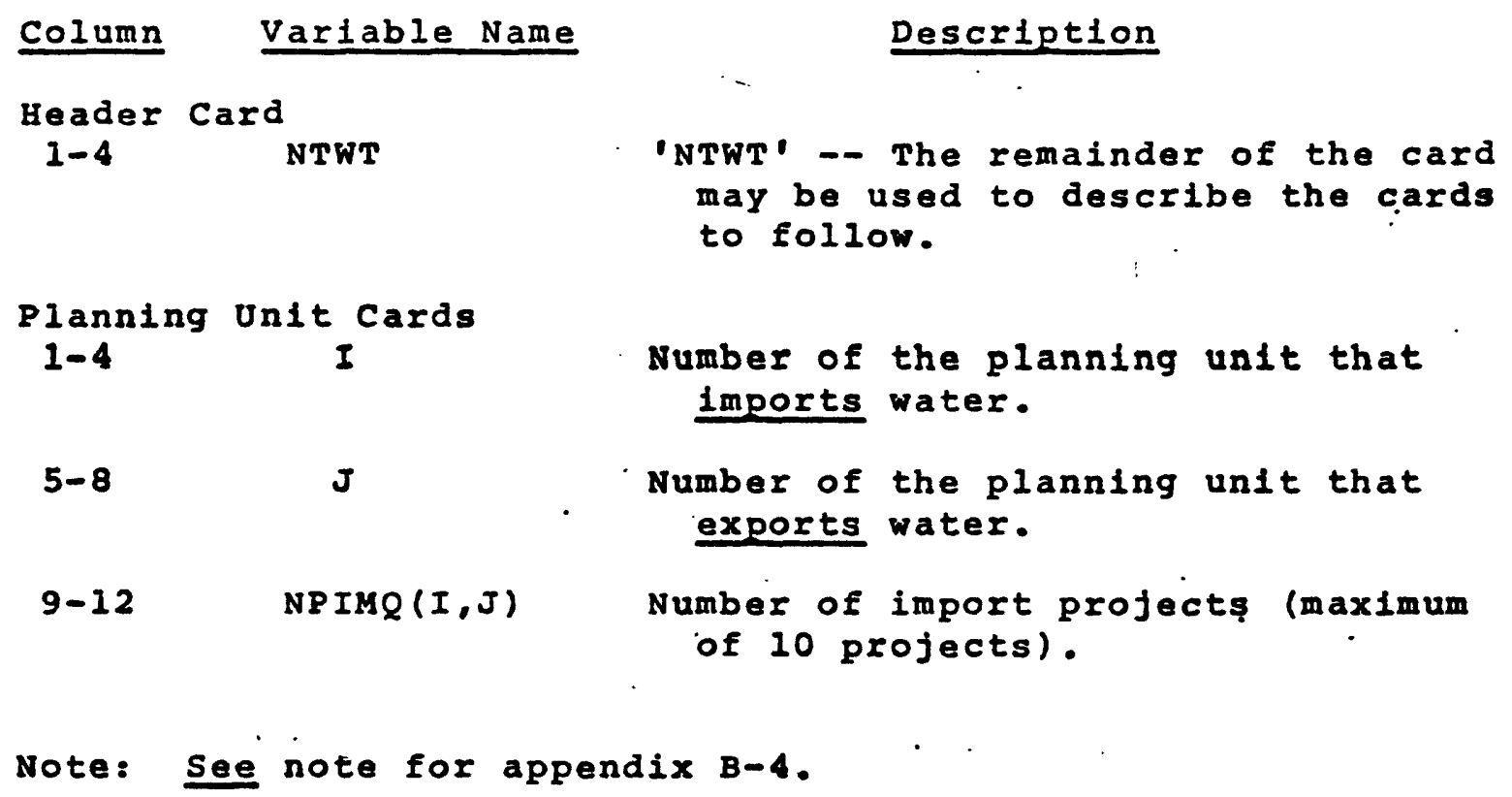

Note: See note for appendix B-4. 
Appendix B-6. - Water production project parameter cards (OPTIONAL)

\begin{tabular}{|c|c|c|}
\hline Column & Variable Name & Description \\
\hline $\begin{array}{c}\text { Header } \\
1-4\end{array}$ & $\begin{array}{l}\text { Card } \\
\text { FCWP }\end{array}$ & $\begin{array}{l}\text { 'FCWP' - - The remainder of the card } \\
\text { may be used to describe the cards } \\
\text { to follow. }\end{array}$ \\
\hline $\begin{array}{l}\text { Project } \\
1-4\end{array}$ & $\underset{I}{\text { Parameter Cards }}$ & Number of planning region. \\
\hline $5-8$ & $\mathbf{k}$ & Project type code (appendix A). \\
\hline $9-12$ & $\mathbf{I}$ & $\begin{array}{l}\text { Number of project. project numbers } \\
\text { must be assigned sequentially and } \\
\text { grouped so that those which affect } \\
\text { a given stream segment fall within } \\
\text { the Inclusive range of two project } \\
\text { numbers (see appendix B-ll). }\end{array}$ \\
\hline $10-16$ & $N L(K, I, I)$ & Economic life of project in years. \\
\hline $17-26$ & $Y I D(K, I, I)$ & $\begin{array}{l}\text { Yield or capacity of project in } \\
\text { MGD (punch decimal point). }\end{array}$ \\
\hline $\begin{array}{r}27-36 \\
\end{array}$ & $C F(K, I, I)$ & $\begin{array}{l}\text { Fixed costs of project construction } \\
\text { in dollars (punch decimal point). } \\
\text { If project already exists, set } \\
\text { value to zero. }\end{array}$ \\
\hline $37-46$ & $C \varnothing(K, I, I)$ & $\begin{array}{l}\text { Operating costs per MG of water } \\
\text { produced or processed in dollars } \\
\text { (punch decimal polnt). }\end{array}$ \\
\hline 49 & : $F I X$ & $\begin{array}{l}\text { If the project currently exists, } \\
\text { set FIX=l; otherwise, leave field } \\
\text { blank. }\end{array}$ \\
\hline
\end{tabular}

NOTE: The "FCWP' header card is not required if there are no" water production projects to be described. Normally, however, it will be present followed by one card for each existing or proposed water production card counted in the numbers reported on the Number of water Production Projects cards (appendix B-3). 


$$
\begin{array}{r}
\text { Appendix B-7. - Raw water import project } \\
\text { parameter cards (OPTIONAL) }
\end{array}
$$

\begin{tabular}{|c|c|c|}
\hline Column & Vartable Name & Description \\
\hline \multirow{2}{*}{$\begin{array}{l}\text { Header } \\
1-4\end{array}$} & Cara & \\
\hline & FCRW & $\begin{array}{l}\text { 'FCRW' - The remainder of the card } \\
\text { may be used to describe the cards } \\
\text { to follow. }\end{array}$ \\
\hline $\begin{array}{l}\text { Project } \\
1-4\end{array}$ & $\begin{array}{c}\text { Parameter Cards } \\
I\end{array}$ & $\begin{array}{l}\text { Number of the planning region that } \\
\text { imports water. }\end{array}$ \\
\hline $5-8$ & $\mathbf{J}$ & $\begin{array}{l}\text { Number of the planning region that } \\
\text { exports water. }\end{array}$ \\
\hline $9-12$ & I & Number of project. \\
\hline $13-16$ & $\operatorname{NLIMP}(I, J, I)$ & "Economic life of project in years. \\
\hline $17-26$ & $\dot{C A P I M P}(I, J, I)$ & $\begin{array}{l}\text { Capacity of project in MGD (punch } \\
\text { decimal point). }\end{array}$ \\
\hline $27-36$ & $\operatorname{CF} I M P(I, J, I)$ & $\begin{array}{l}\text { Fixed costs of project construction } \\
\text { in dollars (pinch decimal point). }\end{array}$ \\
\hline $37-46$ & $\operatorname{C\emptyset IMP}(I, J, I)$ & $\begin{array}{l}\text { Operating costs per MG of water } \\
\text { imported in dollars (punch decimal } \\
\text { point). }\end{array}$ \\
\hline $49^{\prime}$ & FIX & $\begin{array}{l}\text { If project currently exists, set } \\
\text { FIX=l; otherwise, leave field } \\
\text { blank. }\end{array}$ \\
\hline
\end{tabular}

Note: The 'FCRW' header card is not required if there are no raw water import projects to be described. If there are raw water import projects, there must be one card for each existing or proposed project. The number of cards will be equal to the total number of projects reported on the Number of Raw water Import Project cards (appendix B-4). 


$$
\begin{array}{r}
\text { Appendix B-8. -- Treated water import project } \\
\text { parameter cards (OPTIONAL) }
\end{array}
$$

\begin{tabular}{|c|c|c|}
\hline Column & Variable Name & Description \\
\hline $\begin{array}{l}\text { Header } \\
1-4\end{array}$ & $\begin{array}{l}\text { Card } \\
\text { FCTW }\end{array}$ & $\begin{array}{l}\text { 'FCTW' -- The Remainder of the card } \\
\text { may be used to describe the cards } \\
\text { to follow. }\end{array}$ \\
\hline $\begin{array}{l}\text { Project } \\
1-4\end{array}$ & $\begin{array}{c}\text { Parameter Cards } \\
I\end{array}$ & $\begin{array}{l}\text { Number of the planning region that } \\
\text { imports water. }\end{array}$ \\
\hline $5-8$ & $\mathbf{J}$ & $\begin{array}{l}\text { Number of the planning region that } \\
\text { exports water. }\end{array}$ \\
\hline $9-12$ & $\mathbf{L}$ & Number of project. \\
\hline $13-16$ & $\operatorname{NLIMQ}(I, J, I)$ & Economic life of project in years. \\
\hline $17-26$ & $\operatorname{CAPIMQ}(I, J, I)$ & $\begin{array}{l}\text { Capacity of project in MGD (punch } \\
\text { decimal point). }\end{array}$ \\
\hline $27-36$ & $\operatorname{CFIMQ}(I, J, I)$ & $\begin{array}{l}\text { Fixed costs of project construction } \\
\text { in dollars (punch decimal point). }\end{array}$ \\
\hline $37-46$ & $\operatorname{C\varnothing IMQ}(I, J, I)$ & $\begin{array}{l}\text { Operating costs per MG of water } \\
\text { imported in dollars (punch decimal } \\
\text { point). }\end{array}$ \\
\hline $49^{\prime}$ & FIX & $\begin{array}{l}\text { If project currently exists, set } \\
\text { FIX=l, otherwise, leave field } \\
\text { blank. }\end{array}$ \\
\hline
\end{tabular}

Note: The 'FCTW' header card is not required if there are no treated water import projects to be described. If there are treated water projects, there must be one card for each existing or proposed project. The number of cards will be equal to the total number of projects reported on the Number of Treated Water Import Project cards (appendix B-5). 


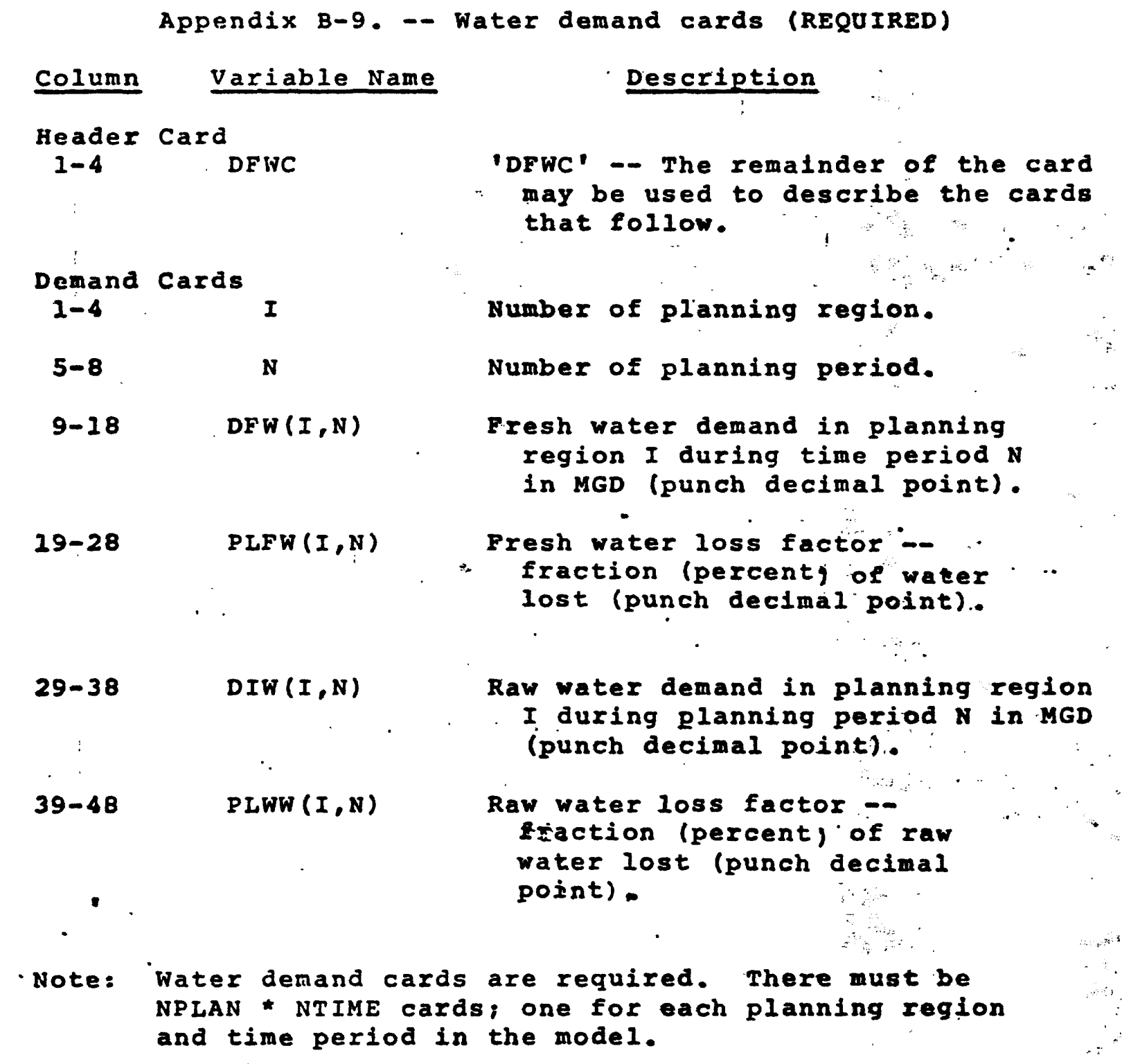




$$
\begin{array}{r}
\text { Appendix B-10. - Surface water - ground water } \\
\text { Interaction parameters (OPTIONAL) }
\end{array}
$$

Column Variable Number Description

Header Card

1-4 SWGW

'SWGW' -- The remainder of the card may be used to describe the cards to follow.

Interaction Parameter Cards

$1-4$

5-8

$9-16$

$17-24$

25-32

$:$

.

L

$$
\operatorname{PHI}(I, I, I)
$$

$\operatorname{PHI}(2, I, I)$

$\operatorname{PHI}(3, I, I)$
Number of planning unit. Number of well field.

$$
\text { PHI }(N T I M E, I, L)
$$
(punch decimal point).

NOTE: The 'sWGW' header card' is only required if the model Includes ground water projects. Each ground water project inust have an Interaction Parameter Card. If the model contains more than 9 time periods, the PHI values will overflow onto a second card beginning In the first column. For example, $P H I(10, I, L)=$ columns 1-8, PHI $(11, I, L)=$ columns 9-16, etc. for the 1st, 2 nd, $3 r d, \ldots$, and NTIME-th planning perlods which relate the recharges from the river to unit pumping of the aquifer at well field $L$ in planning region $I$ . 
Appendix B-ll. -- Surface water flow

requirements cards (REQUIRED)

Column Variable Number Description

Header Card

1-4 SWFL 'SWFL' -- The remainder of the :card may be used to describe the cards to follow.

$\underset{1}{N u m b e r}$ of
$1-4$
$5-8$
$N P X(I)$
Flow Requirements, Card 1 $1-4$ I 5-8 $\cdot \cdot \cdot$

9-16 QFLøW (I,J)

17-24 RFLøW (I,J)

Flow Requirements - Card 2

$\begin{array}{cc}\begin{array}{cc}1-4 \\ 5-8\end{array} & I \\ 9-12 & \operatorname{KPDFI}(I, J, I) \\ 13-16 & \operatorname{KPDF}(I, J, 2) \\ 17-20 & \operatorname{KPDFI}(I, J, 3) \\ 21-24 & \operatorname{KPDFI}(I, J, 4) \\ 25-28 & \operatorname{KPDF}(I, J, 5) \\ 29-32 & \operatorname{KPDFI}(I, J, 6)\end{array}$

Number of planning unit.

Number of flow requirement point (stream reach) under investigation.

Inclusive project numbers of diversions. whose withdrawals are to be subtracted from $\operatorname{QFI} \varnothing W(I, J)$.

Inclusive project numbers of reservolrs whose withdrawals are to be. subtracted from $\operatorname{QFI} \varnothing W(I, J)$.

Inclusive project numbers of ground water fielcs whose pumping effects on stream flows are to be computed and subtracted from $\operatorname{QFL}(I, J)$ in order to determine if flow requirement $\operatorname{RFI} \phi W(I, J)$ is met. 
Notes: The surface water flow requirements cards are required.

Number of points card -- There must be one of these cards for each planning unit preceding the flow requirement cards even if any or all planning units have zero flow requirement points.

Flow requirements -- These cards occur as palrs for each planning unit and flow requirement point qiven on the number of points cards. Card l given the upland Inflows (QFL $\varnothing W$ ) and the downstream flow requirement (RFL $\varnothing W$ ). Card 2 gives the inclusive range of diverston, reservolr, and ground water Field project numbers to be considered in evaluating the flow requirements for a given point. If only one project is to be considered, enter tts number twice, e.g., if reservoir 3 is the only reservolr which affects reach $J$, then $\operatorname{KPDFL}(I, J, 3)=3$ and $\operatorname{KPDF} L(I, J, 4)=3$. Care should be taken to number the projects above reach $P$ consecutively so that the single range of fleld project numbers includes only the projects that affect that reach. 


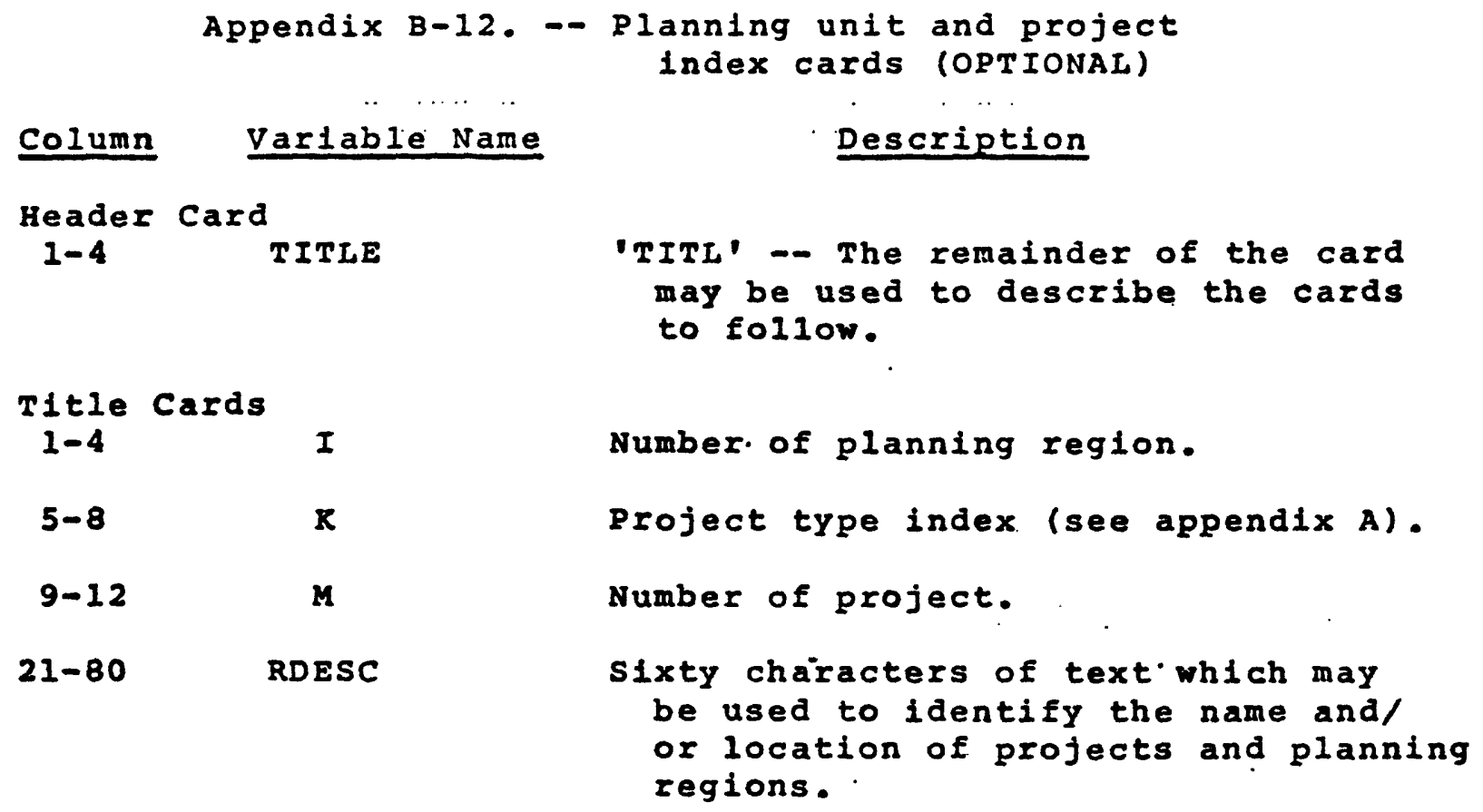

Note: These cards are optional and are provided as an aid to the user in identifying which projects. planning regions, etc., were analyzed in any given run of the model. If a planning region is identified, set $K=B$ and leave M blank. 
APPENDIX C. - Format of MPSX input data cards

C- 1 
APPENDIX C. -- Format of MPSX input data cards

If the MODCOP program ts not used to prepare the control card and data cards, these will have to be prepared manually. There are two major types of cards in a MPSX data deck:

1. Indicator cards -- specify the type of data to follow.

2. Data cards. -- contain row and/or column names and values of matrix elements.

Data cards have the following format:

\begin{tabular}{|c|c|c|c|}
\hline Pleld & Column & Name & Description \\
\hline 1 & $2-3$ & Code & $\begin{array}{l}\text { Type of row constraint or bounds } \\
\text { row vector (left justify, if } \\
\text { necessary). }\end{array}$ \\
\hline 2 & $5-12$ & Name 1 & Name 1 (name of row or column) \\
\hline 3 & $15-22$ & Name 2 & Name 2 (usually name of row) \\
\hline 4 & $25-36$ & value $1 / 2$ & $\begin{array}{l}\text { Value of name } 1 \text { or name } 2 \text { matrix } \\
\text { element }\end{array}$ \\
\hline & $40-47$ & Name 3 & Name 3 (usually name of row) \\
\hline 6. & - $50-61$ & value $1 / 3$ & $\begin{array}{l}\text { Value of name } 1 \text { or name } 3 \text { matrix } \\
\text { element }\end{array}$ \\
\hline
\end{tabular}

All names in fields 2,3 , and 5 must begin with an alpha character and may be up to eight characters long. Names may not contain embedded blanks and must be left justified in the field. Values in flelds 4 and 6 are 12 characters long, and the decimal point is not fixed. Numbers may also be represented in exponential form (IBM, 1971, p. 188). The organization of a MPSX data deck is as follows:

1. NAME card - Always the first card in the deck contains: 'NAME' in columns $1-4$ and the data deck name (XDATA variabled in columns 15-22. . $\mathrm{C}-2$ 
2. ROWS cards -- specifies the names to be assigned to the rows of the problem matrix and the types of constraints. The Indicator card has "Rows' in columns 1-4. The data cards are formatted as follows:

Field 1 -- type of constraint code ('N' - change or objective function row; 'G' - greater than or equal to: ' $L$ ' - less than or equal to; 'E' - equality).

Field 2 -- row name.

There must be one card for each row name in the matrix.

3. Columns cards -- specify the names to be assigned columns in the problem matrix and define for each nonzero element in a given column vector the row name and the corresponding column name/row name element value. The indicator card has 'CoLUMN' in columns 1-7.. The data cards are formatted as follows:

Field 2 - column name

Field 3 -- Row name 1

Field 4 -- Value 1

Field 5 -- Row name 2

Field 6 -- Value 2

. Fields 5 and 6 are optional in that their use allows two matrix elements to be stored on one card image instead of just one matrix element.

3. RHS cards - specifies the name of the right-hand side constraint vector (or change vectors) and the nonzero elements in that vector. The indicator card has 'RHS6' in columns' 1-4. The data cards are formatted as follows:

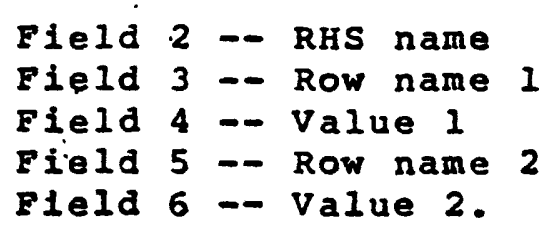

The use of fields 5 and 6 are optional.

4. RANGES cards - Used when a row constraint is to represent both a $\geq$ and $\leq$ inequality (see IBM, 1971, p. 193). 
5. BOUNDS cards -- Specifies limits to be imposed upon the values which the column variables may assume in the problem. When bounds are not specified the lower bounds are automatically set to zero and the upper bounds are set to $+\infty$. The indicator card has 'BOUNDS' in columns 1-6. The data cards have the following format:

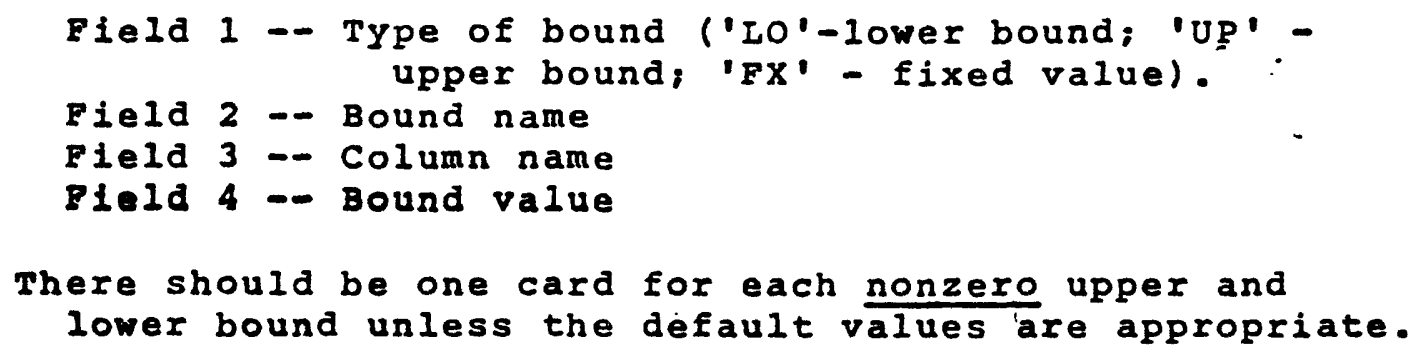

There should be one card for each nonzero upper and

lower bound unless the default values are appropriate.

6. ENDATA card - The ENDATA card signals the end of the input data and must be the last card in the deck.

'ENDATA' is punched in columns 1-6.

In addition to these control cards a mixed-integer program requires two MARKER cards to signify the beginning and ending of a group of integer column variables. They have the following format:

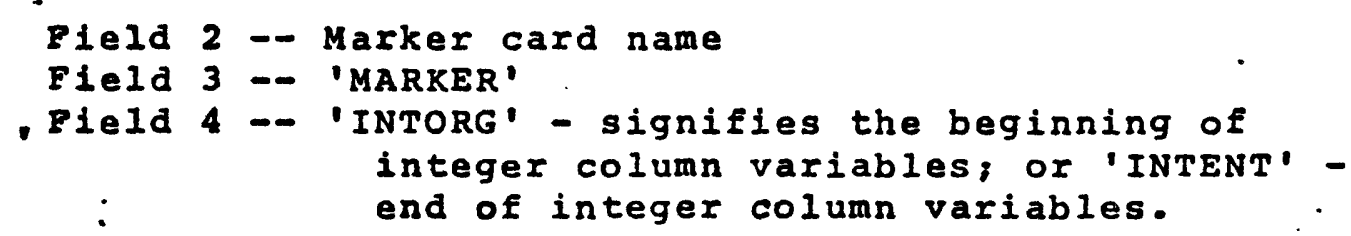

The two marker cards must have different names. More detailed information on the formats of these cards and other option avallable to the user of MPSX may be found in MPSX program description (IBM, $1971 \mathrm{a}$ and 1971b). 


$$
\begin{aligned}
& \text { Appendix D. - Examples of MODCOP input } \\
& \text { data, MODCOP output tables, and MPSX } \\
& \text { output for a two-region planning model }
\end{aligned}
$$




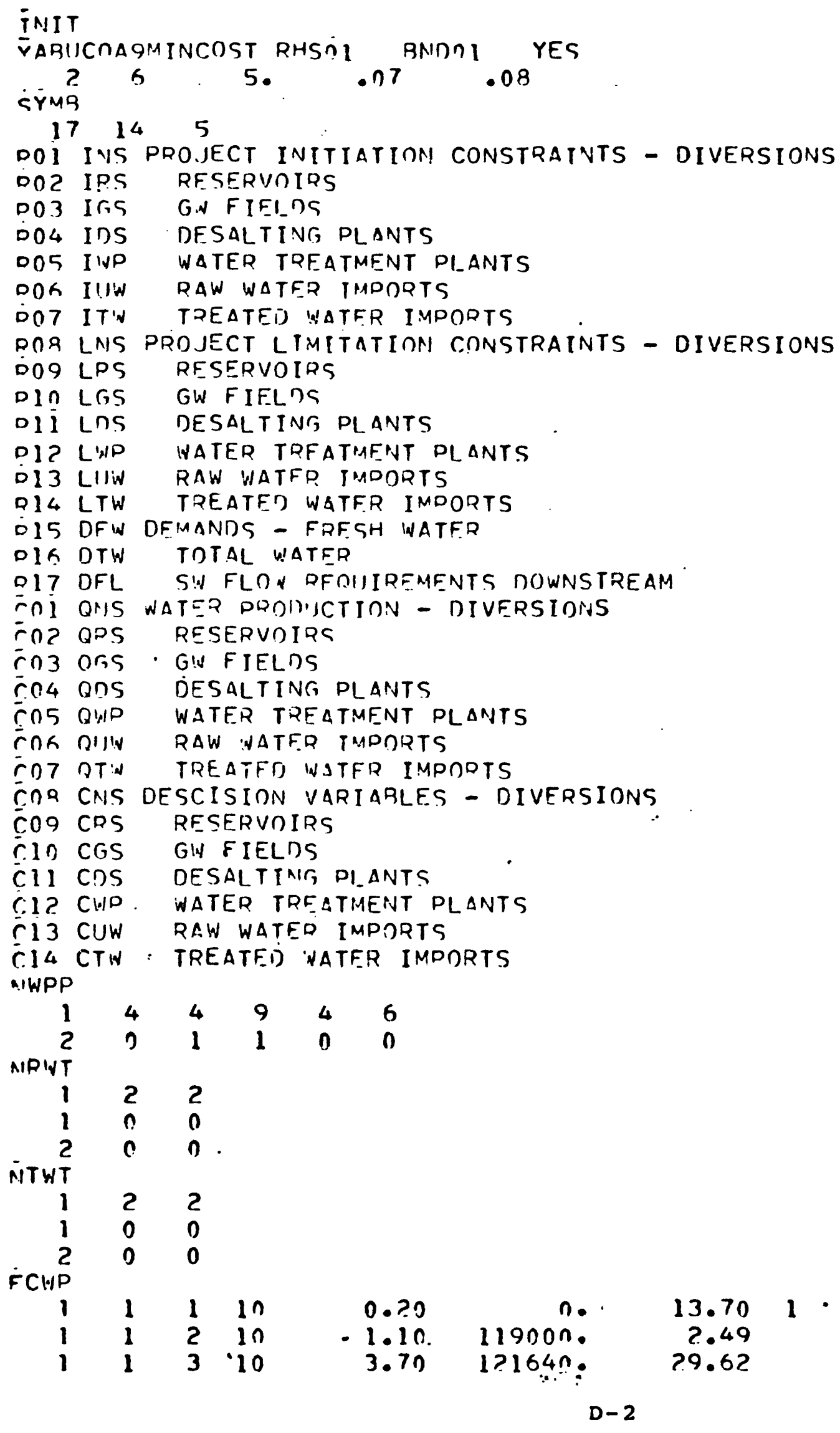




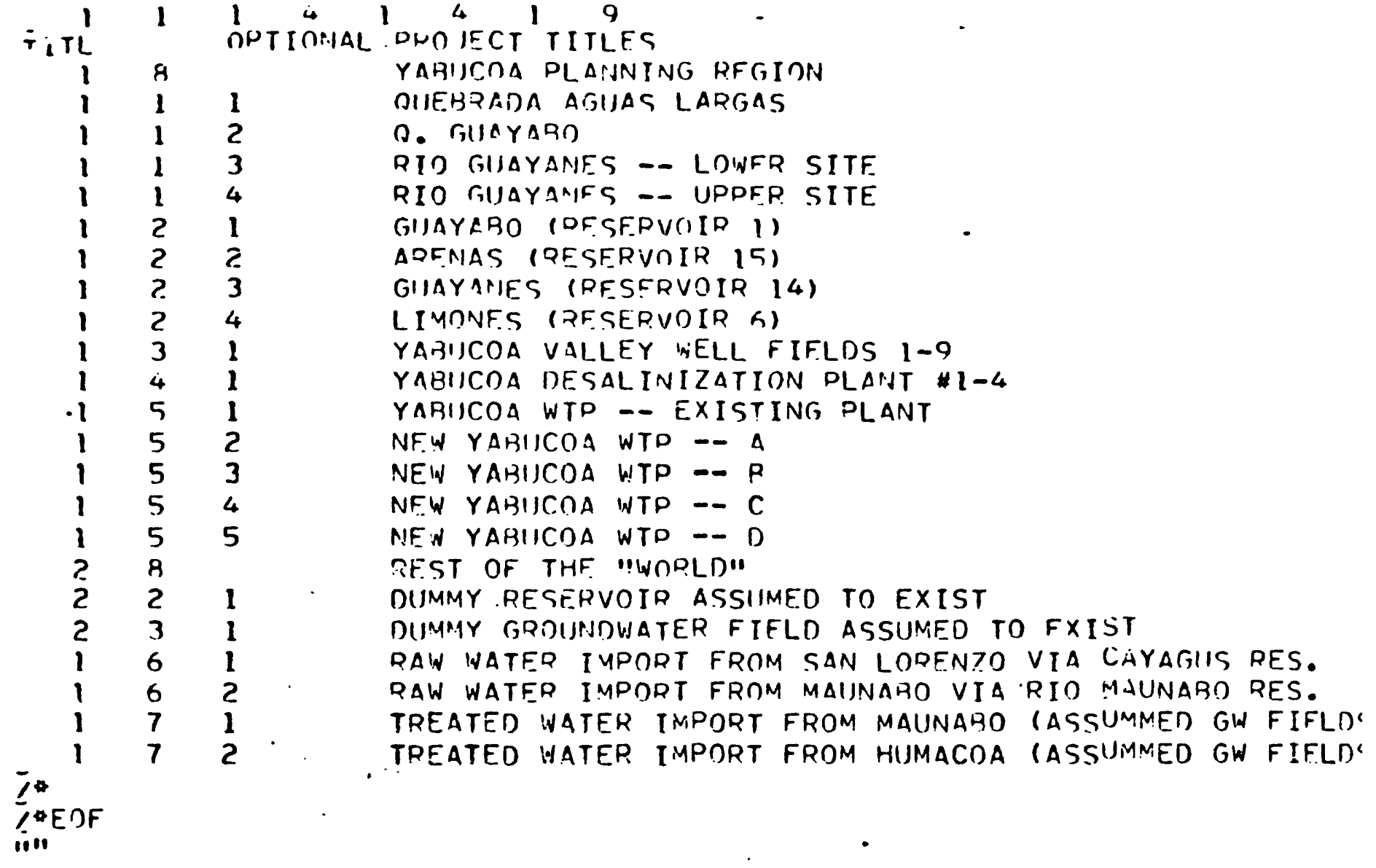


MODCOP OUTPUT DATR

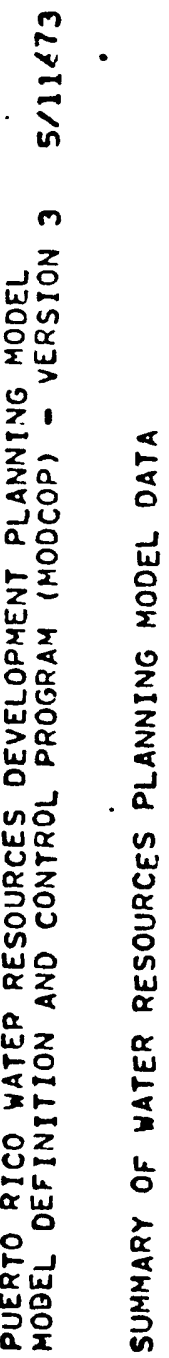

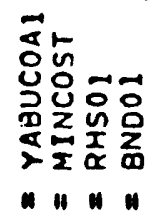

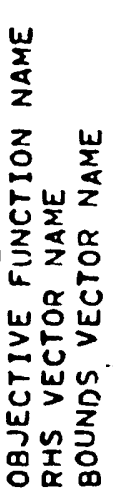

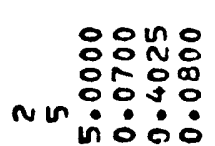

"<smiles>[10BH]</smiles>

วoㅇำw

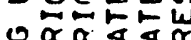

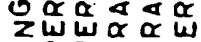

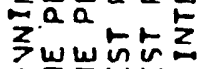
a $\sum w \omega$

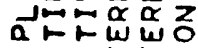

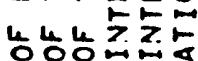
$\alpha \alpha I+0 \stackrel{N}{\alpha}$ w山心

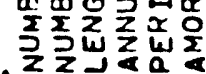

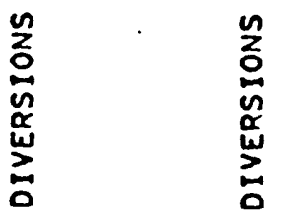

1.2

$\sum_{\frac{1}{\alpha}}^{n}$

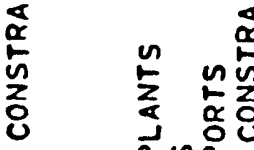

$z \quad n^{a} n \frac{a}{x}$

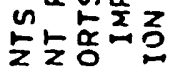

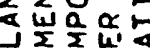

a $\sum_{0} \sum_{0}$

绎

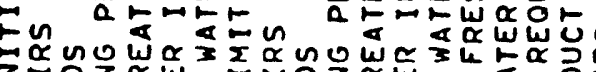

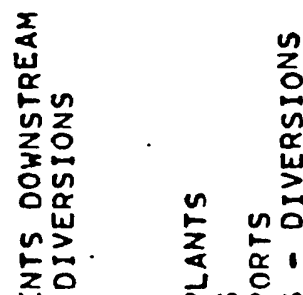
an

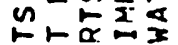

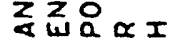

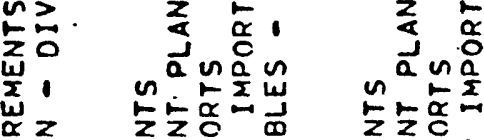

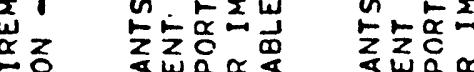

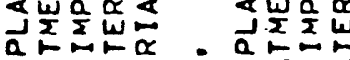
z

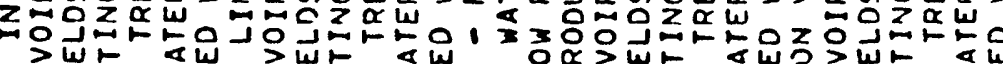

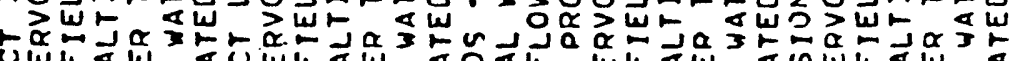

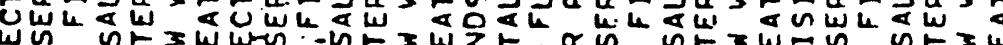
w n上

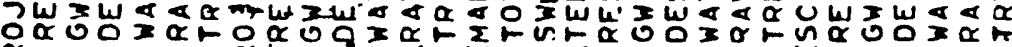
$\stackrel{\alpha}{a}$

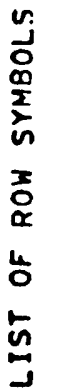

$a$

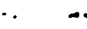

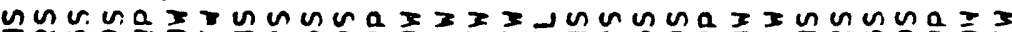

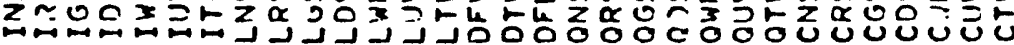

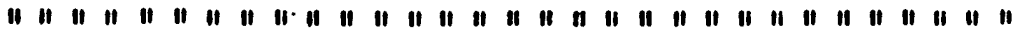

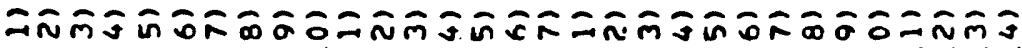

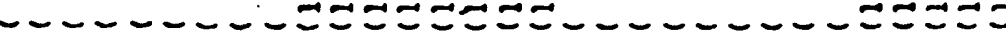
m

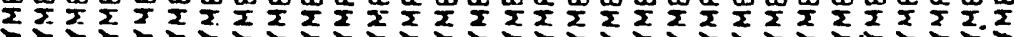

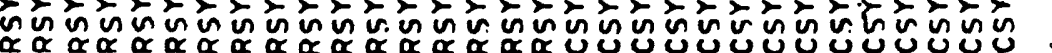




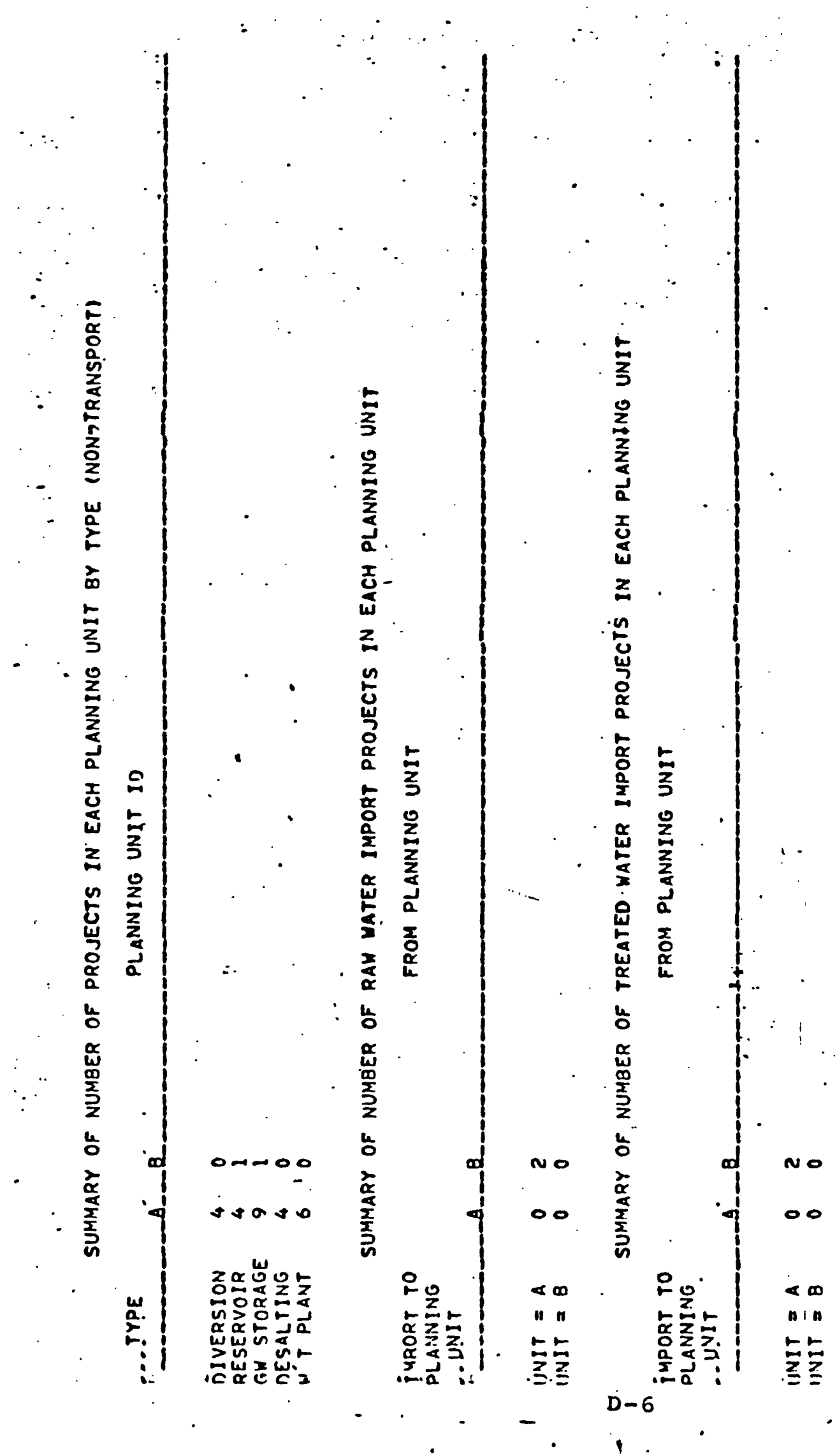



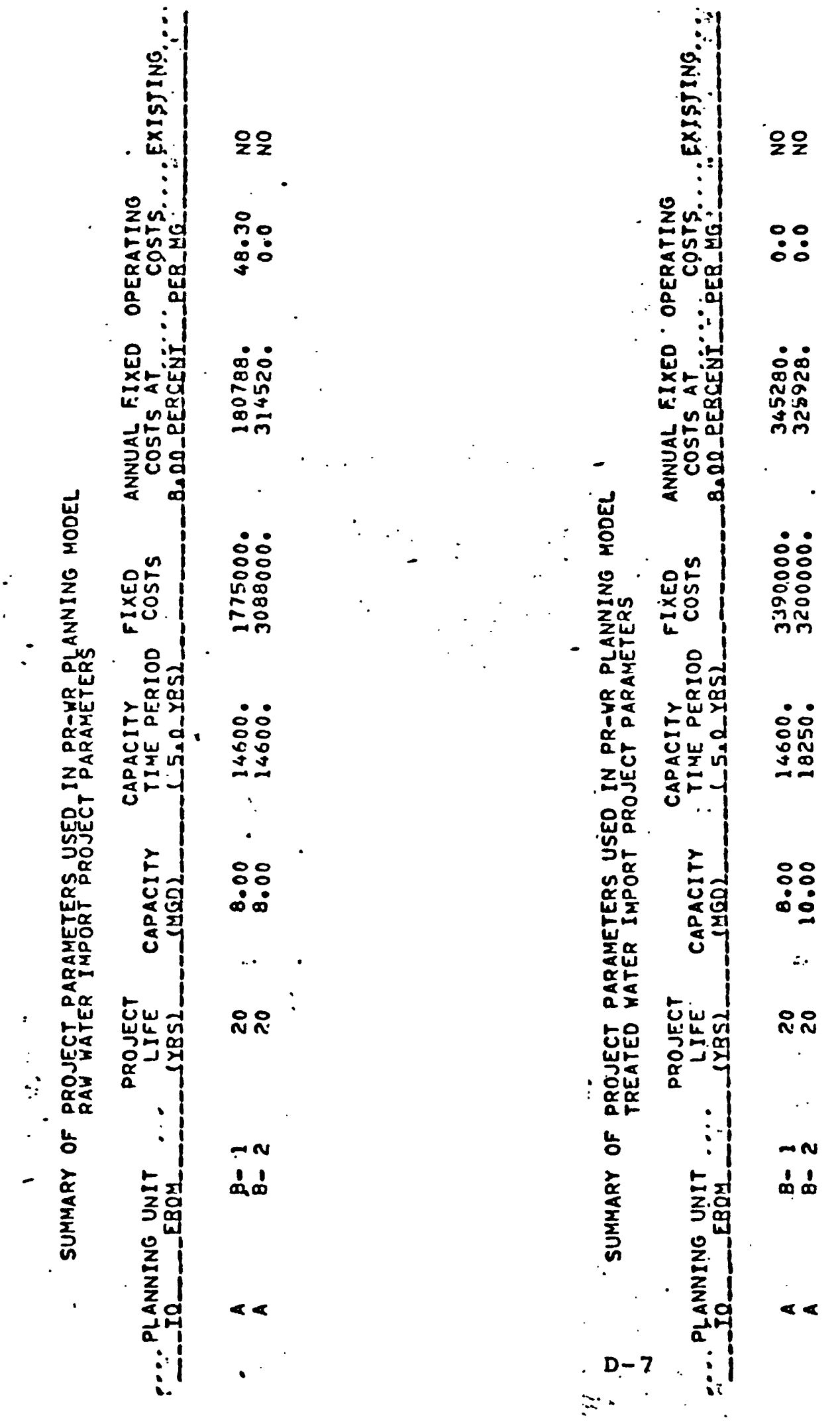


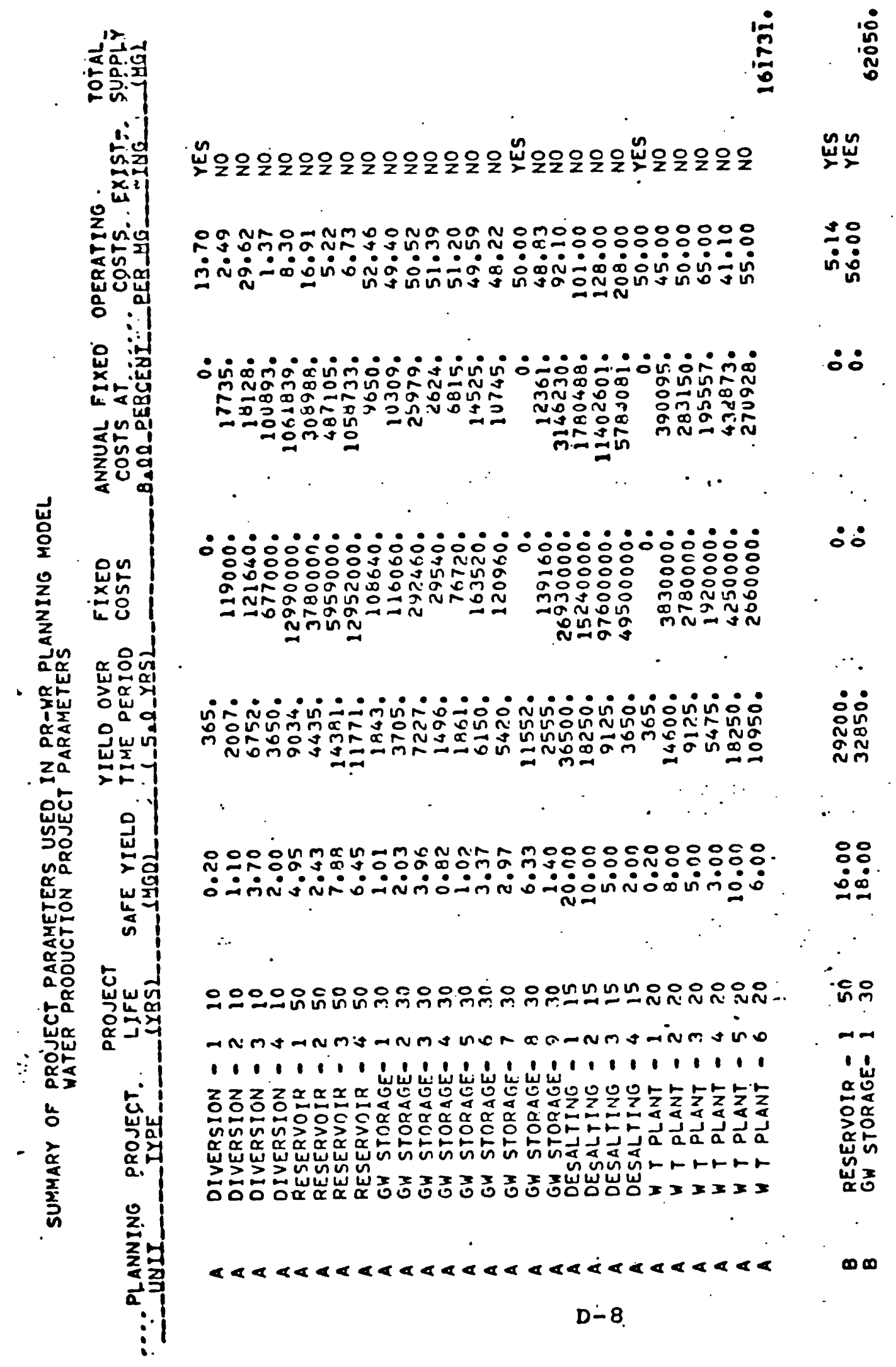




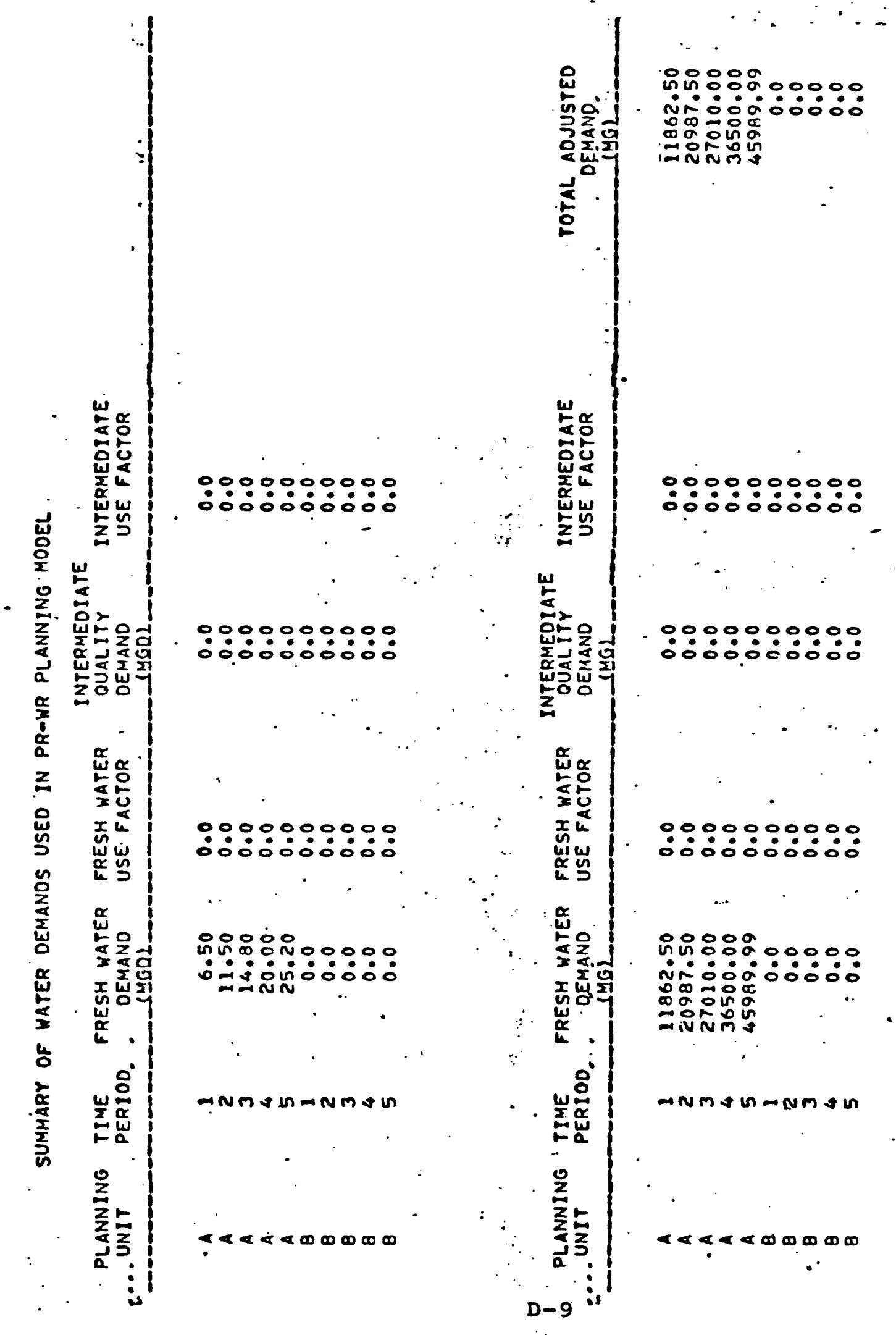




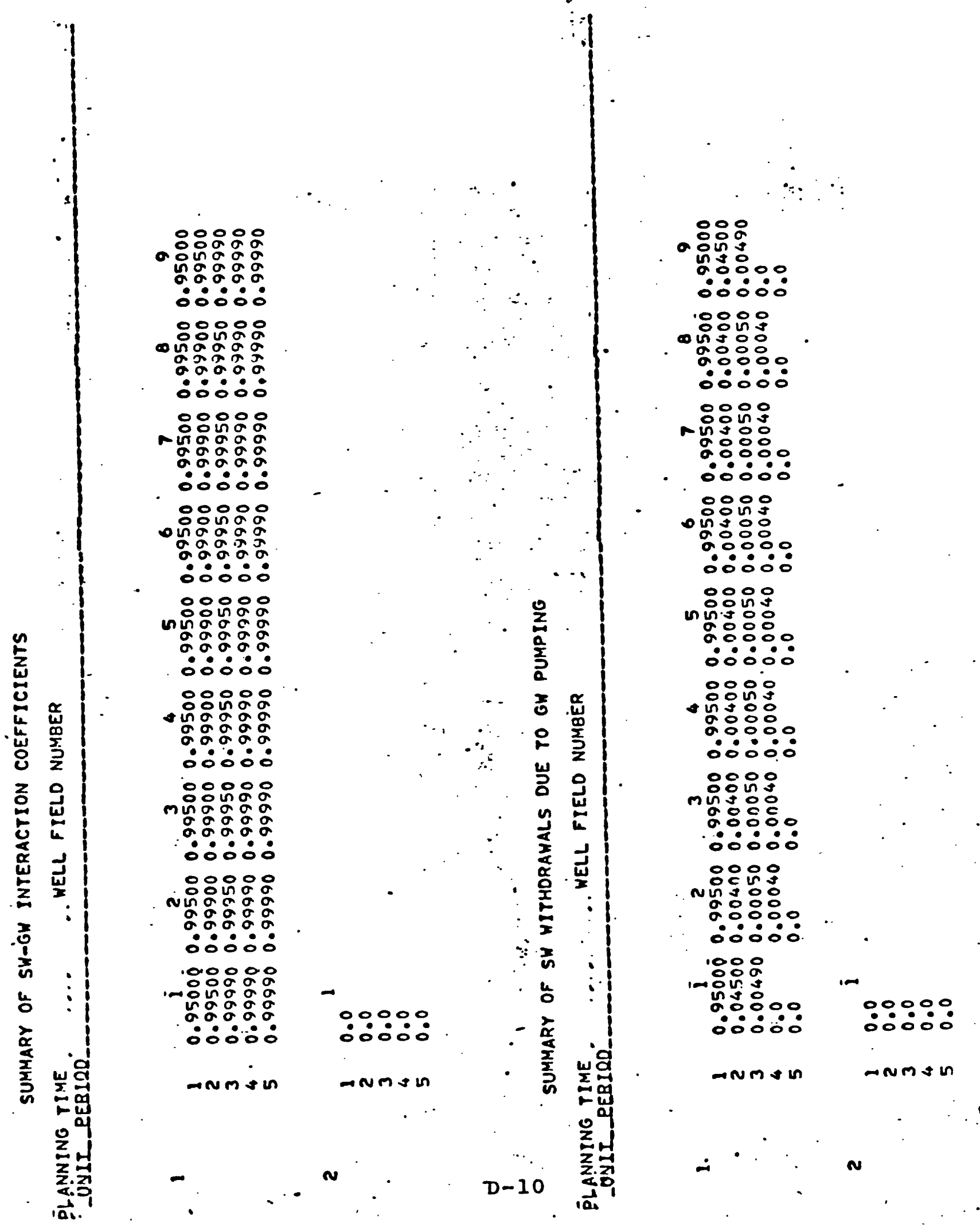




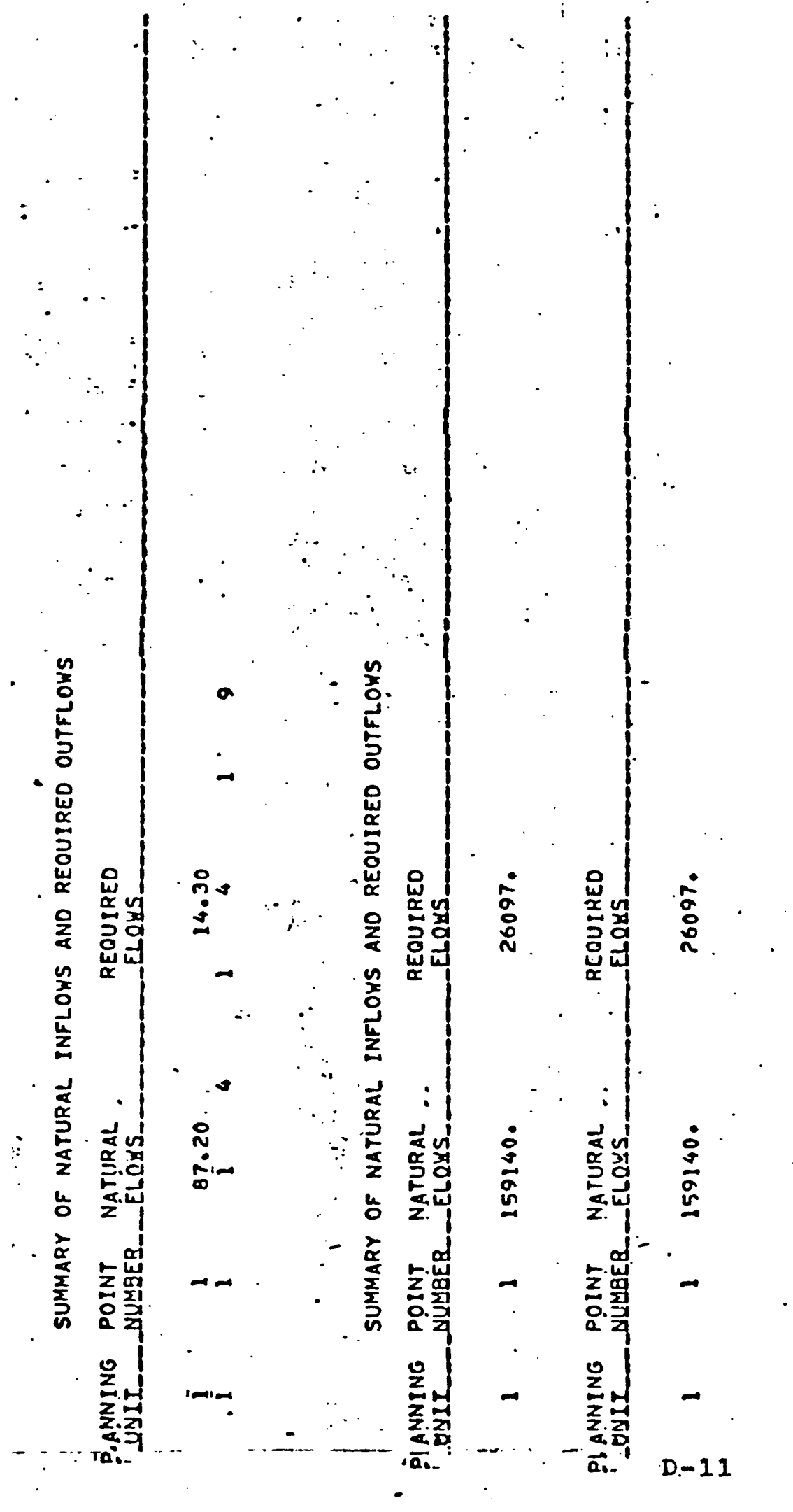


MPSX PROGRAM

:PSX-PTF1? CONTROL PROGRAM COMPILER. MPSX RELEASE 1 MOD LEVEL 3

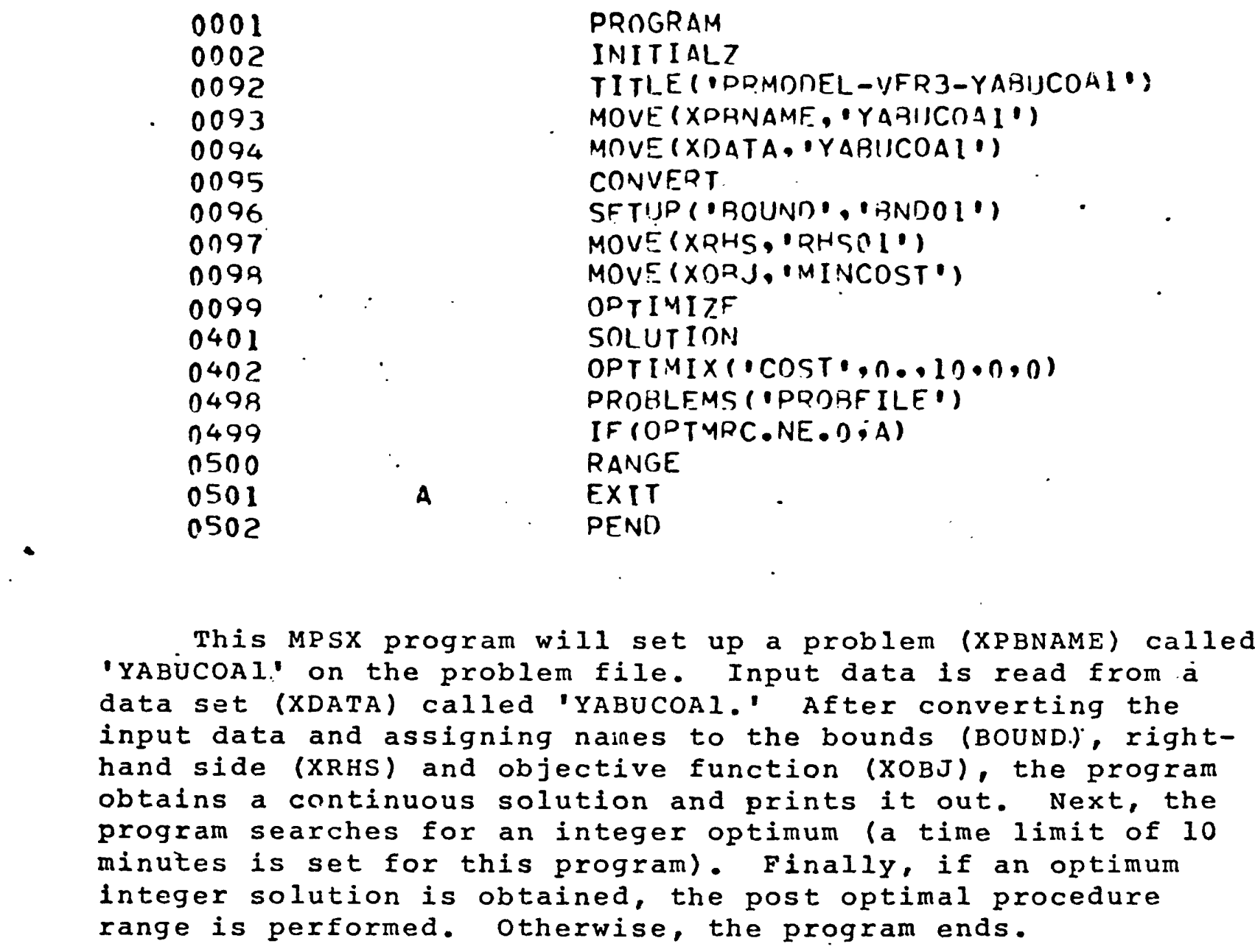




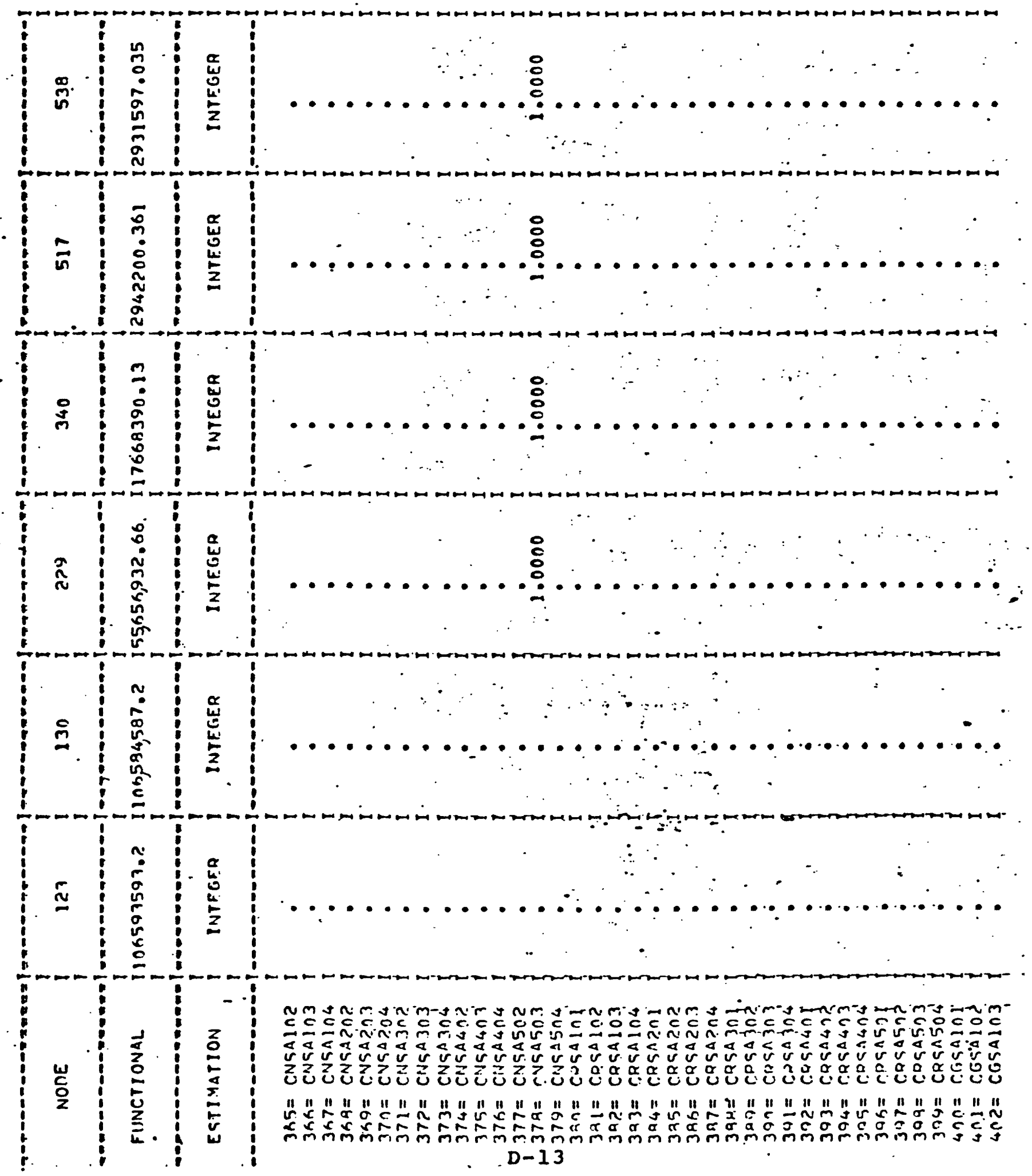


3
0
0
0
0
0

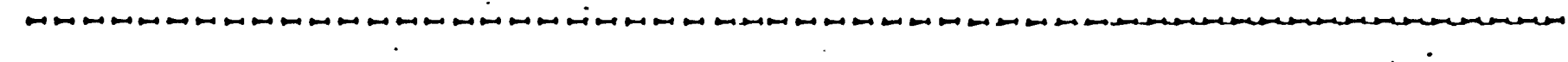

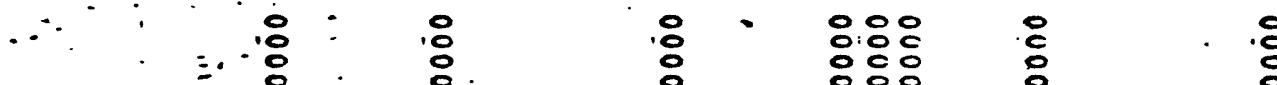

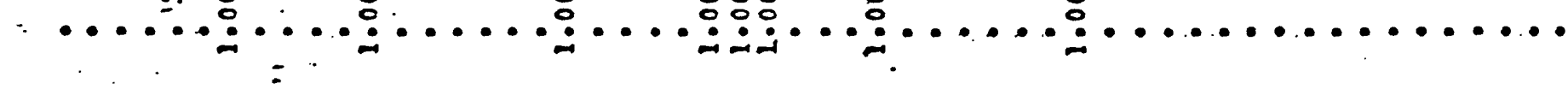

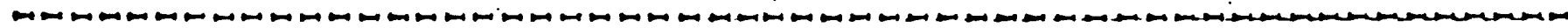
$\because$

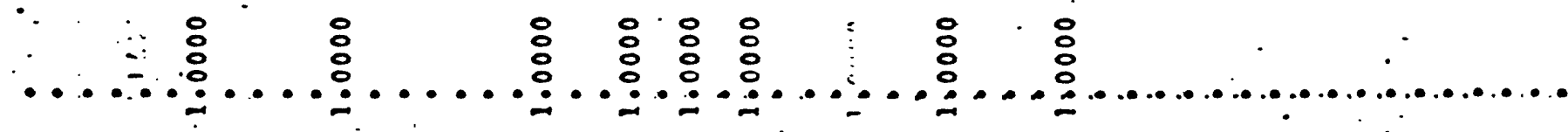
$\vdots \cdot \cdots$

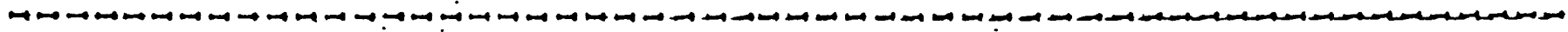

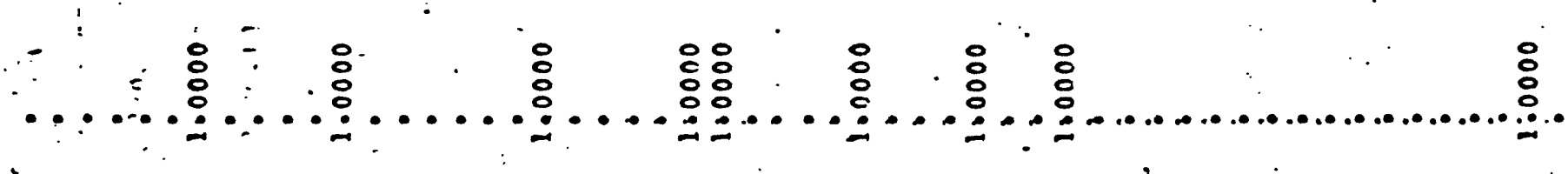
ఏ一ั

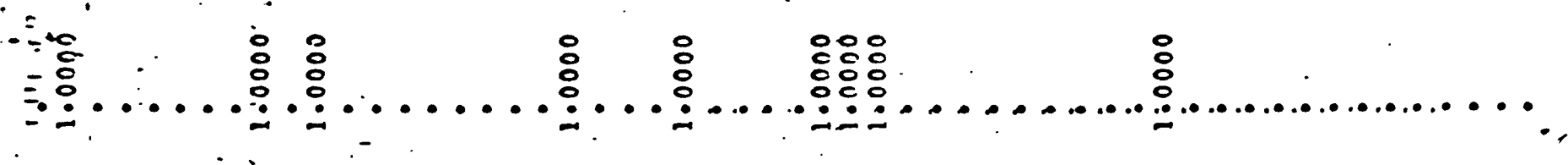

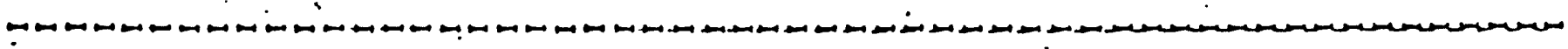

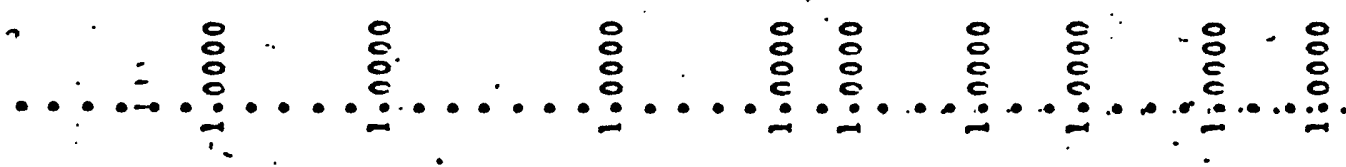

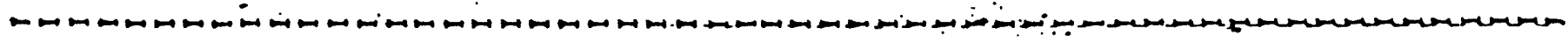

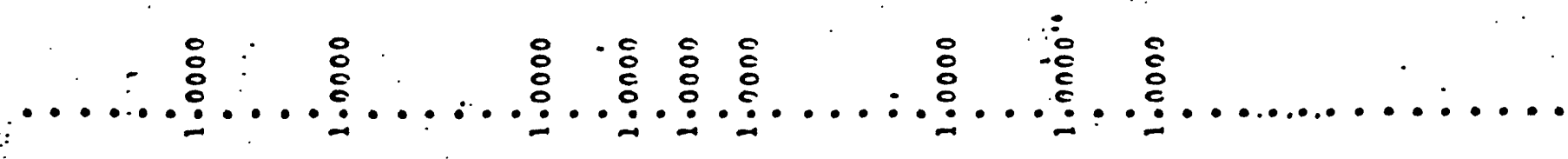

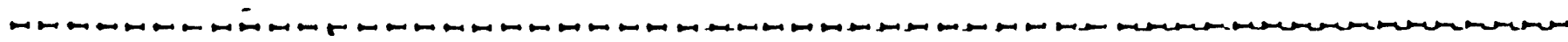

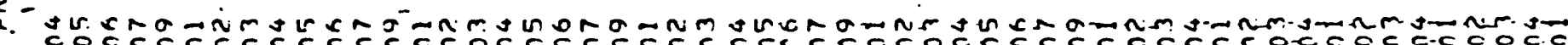

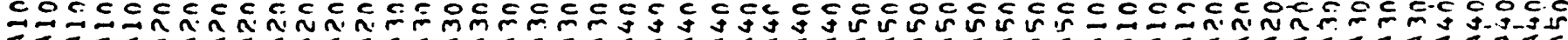

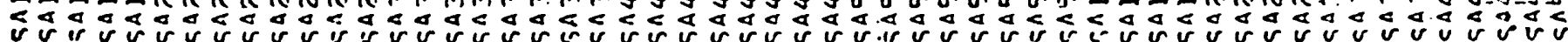
○ L " " " " " "

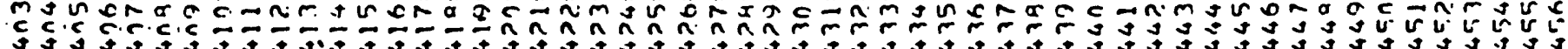




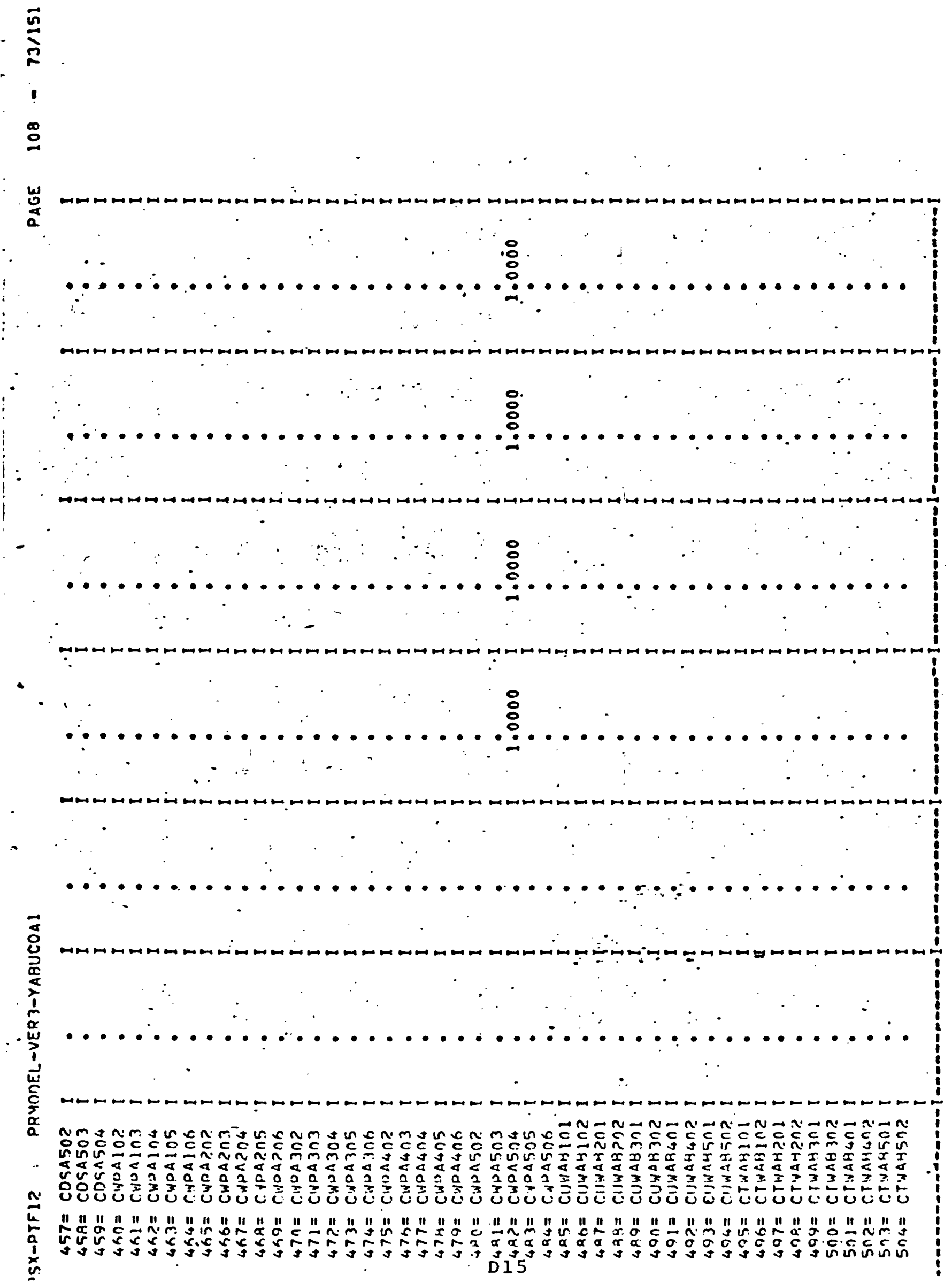




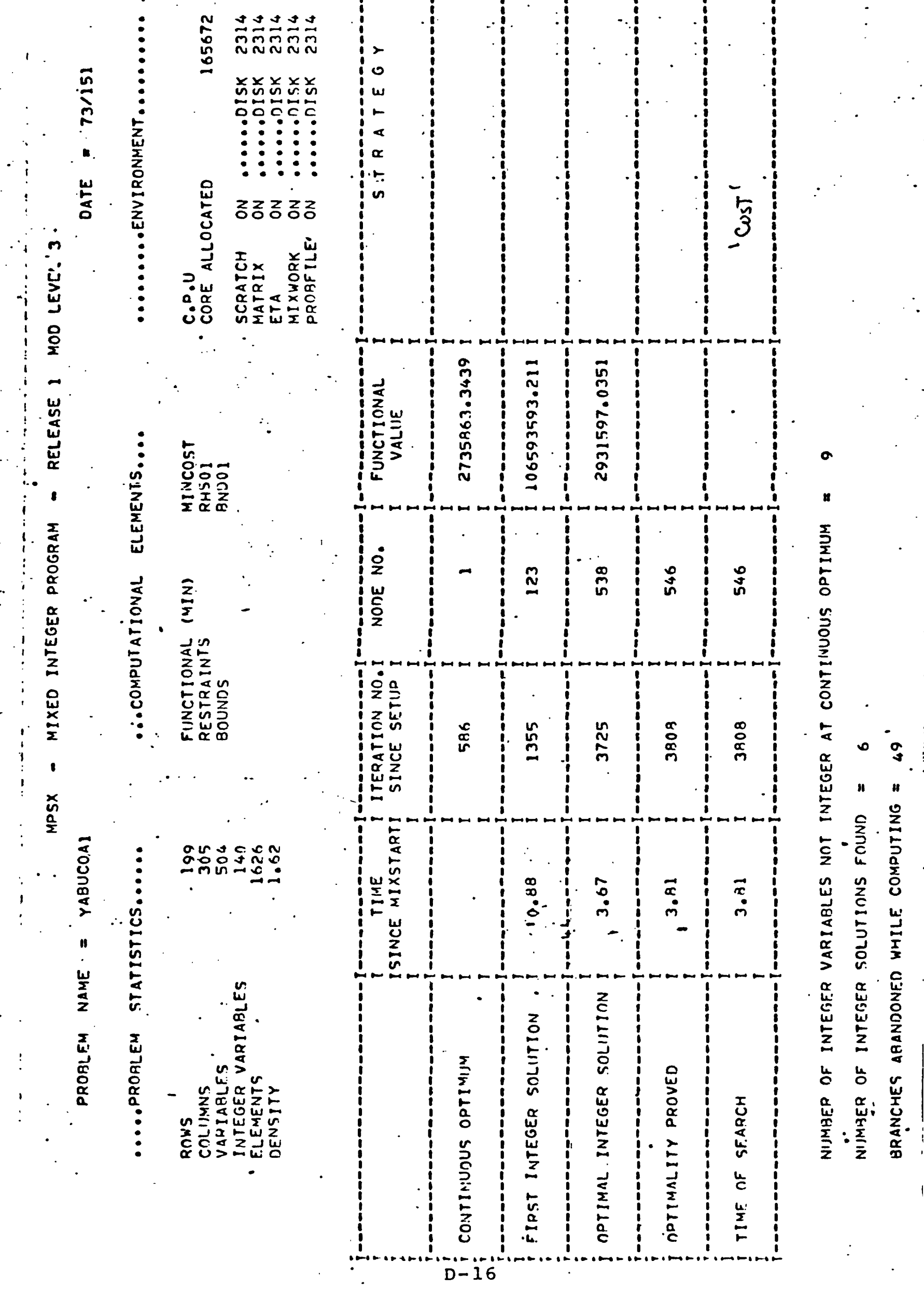


Appendix E. -- Source listing of MODCOP. (version 3).

$E-1$ 
응

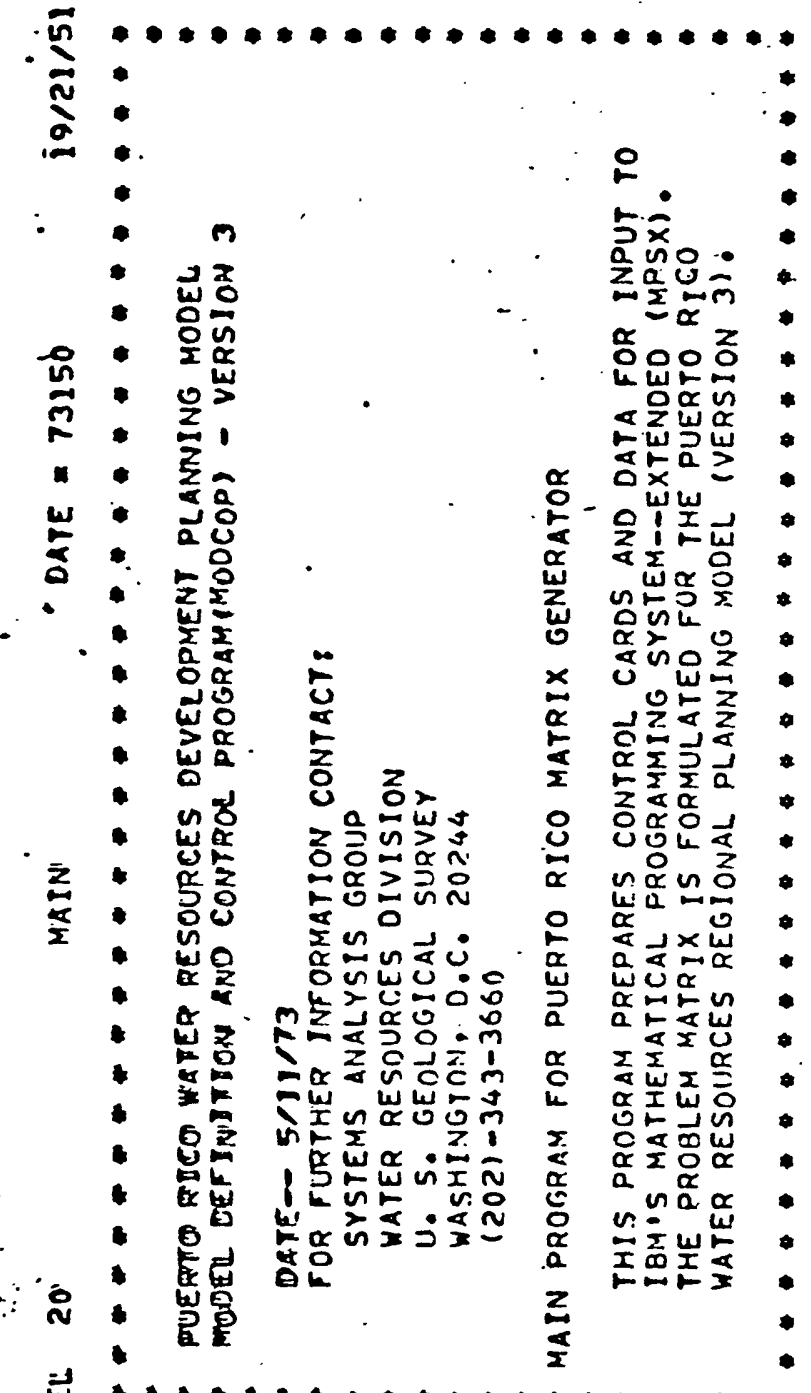

$\underset{\leftarrow \infty}{\vec{x}}$

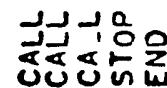

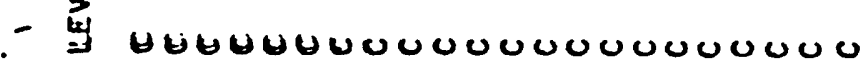

b

2

$z$
$\alpha$
$\alpha$
$\alpha$
$\alpha$
0
0

mam $n$

:응응응

ione E-2 
.0

w

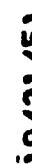
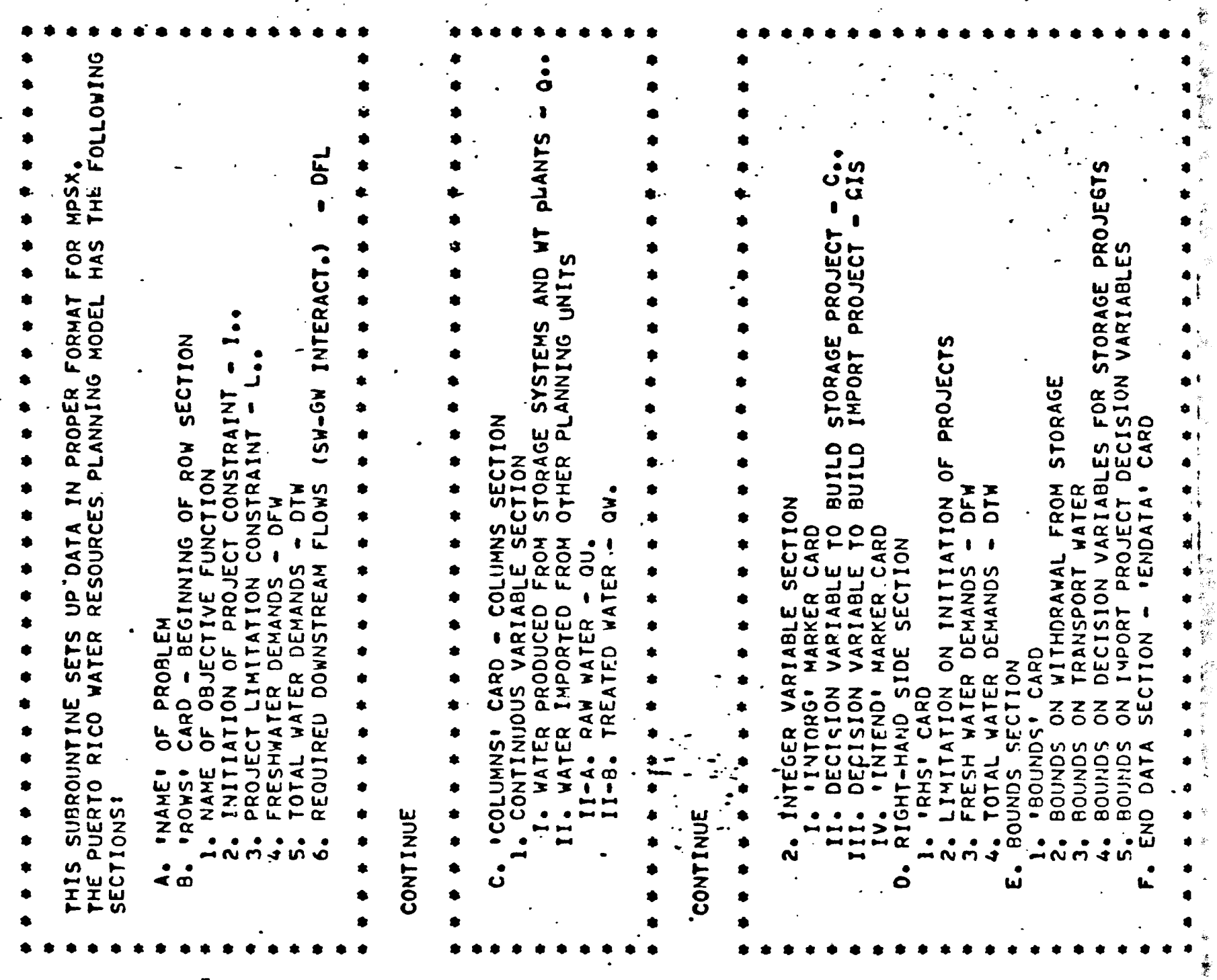

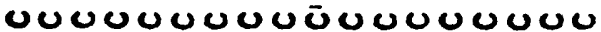

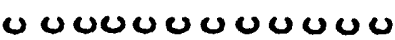

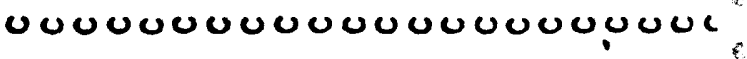



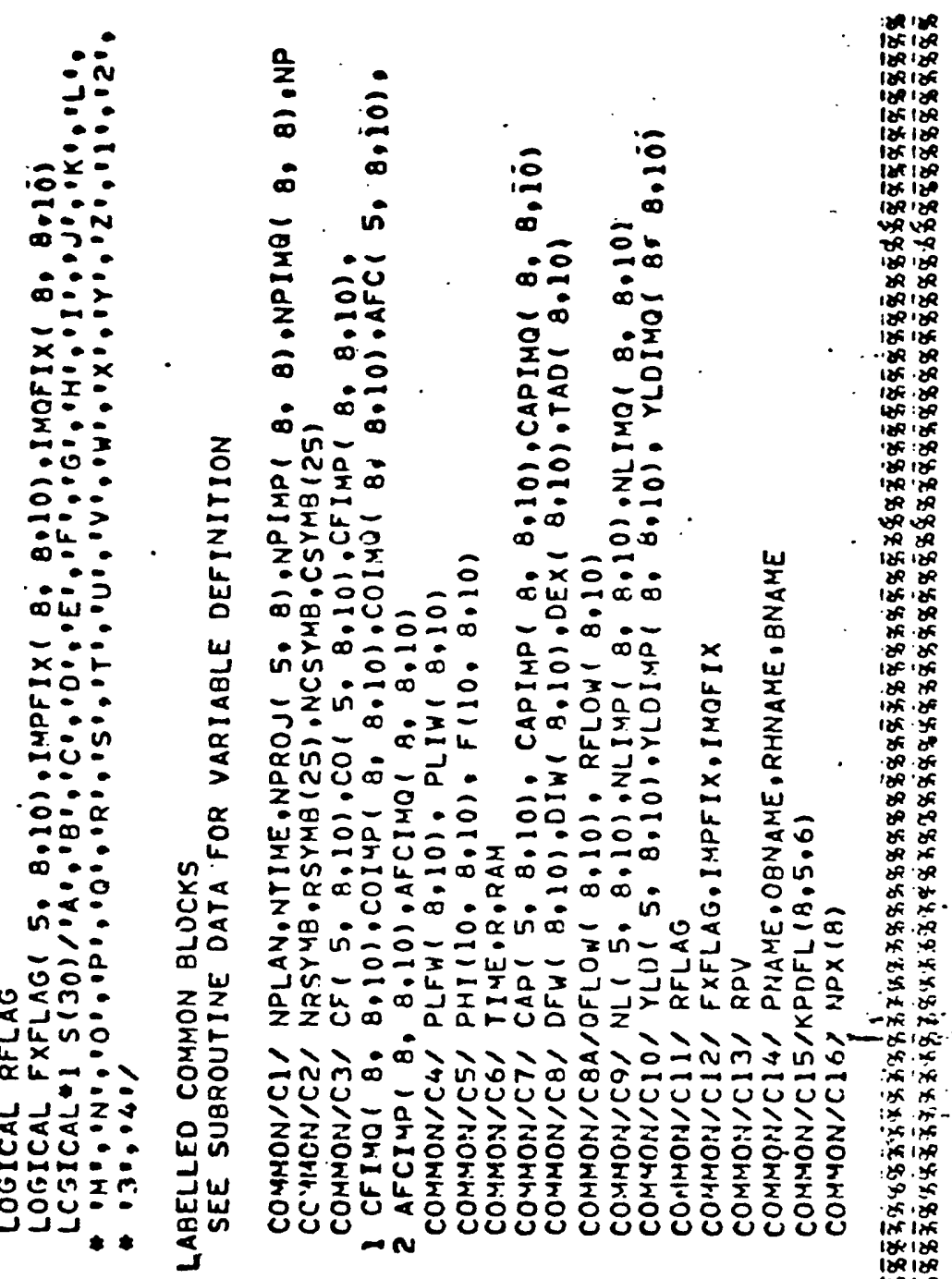



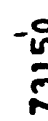

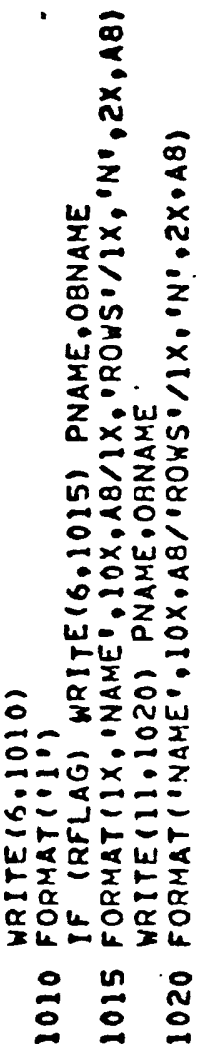




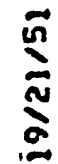

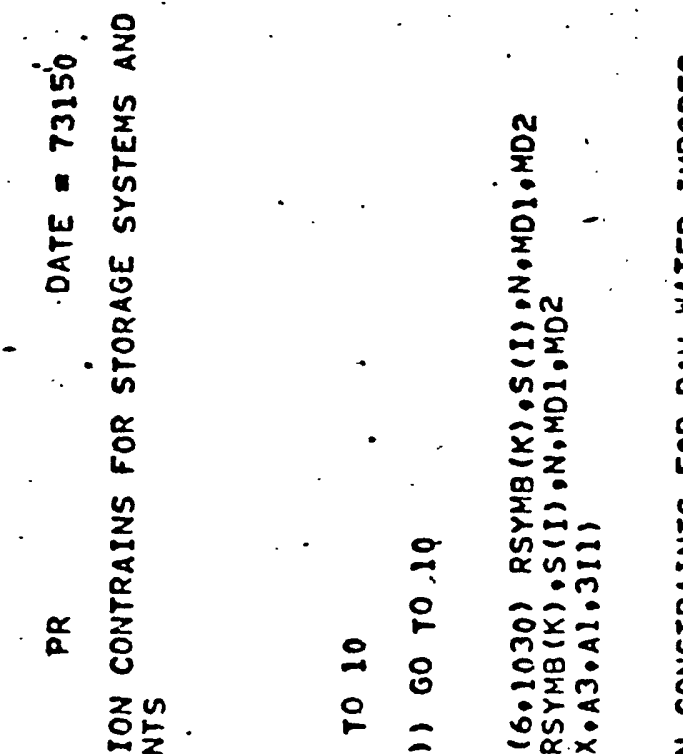

$0^{\circ} \quad \cdot \quad+\cdots$ 
0
8
0
0
0
0

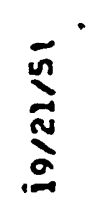

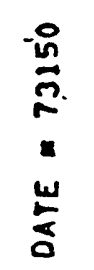
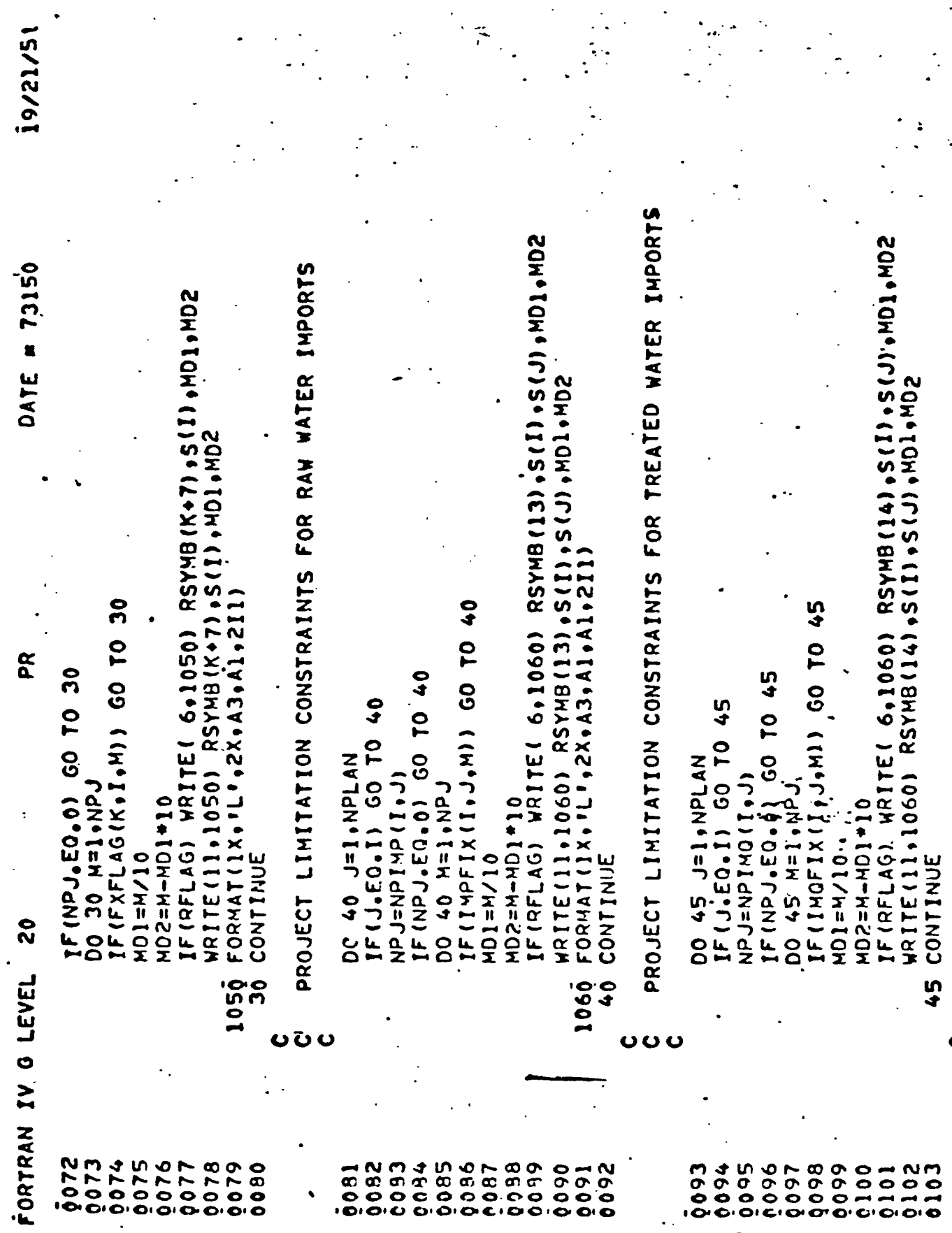

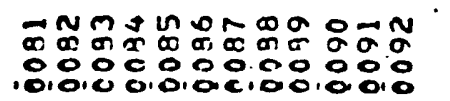

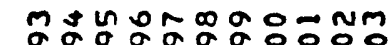
웅ㅇㅇㅇㅇㅇㅇㅇㅇㅇㅇㅇ응 E- 6

ㄴำ 오웅ㅇㅇㅡ 
2
8
0
$y$
0
0

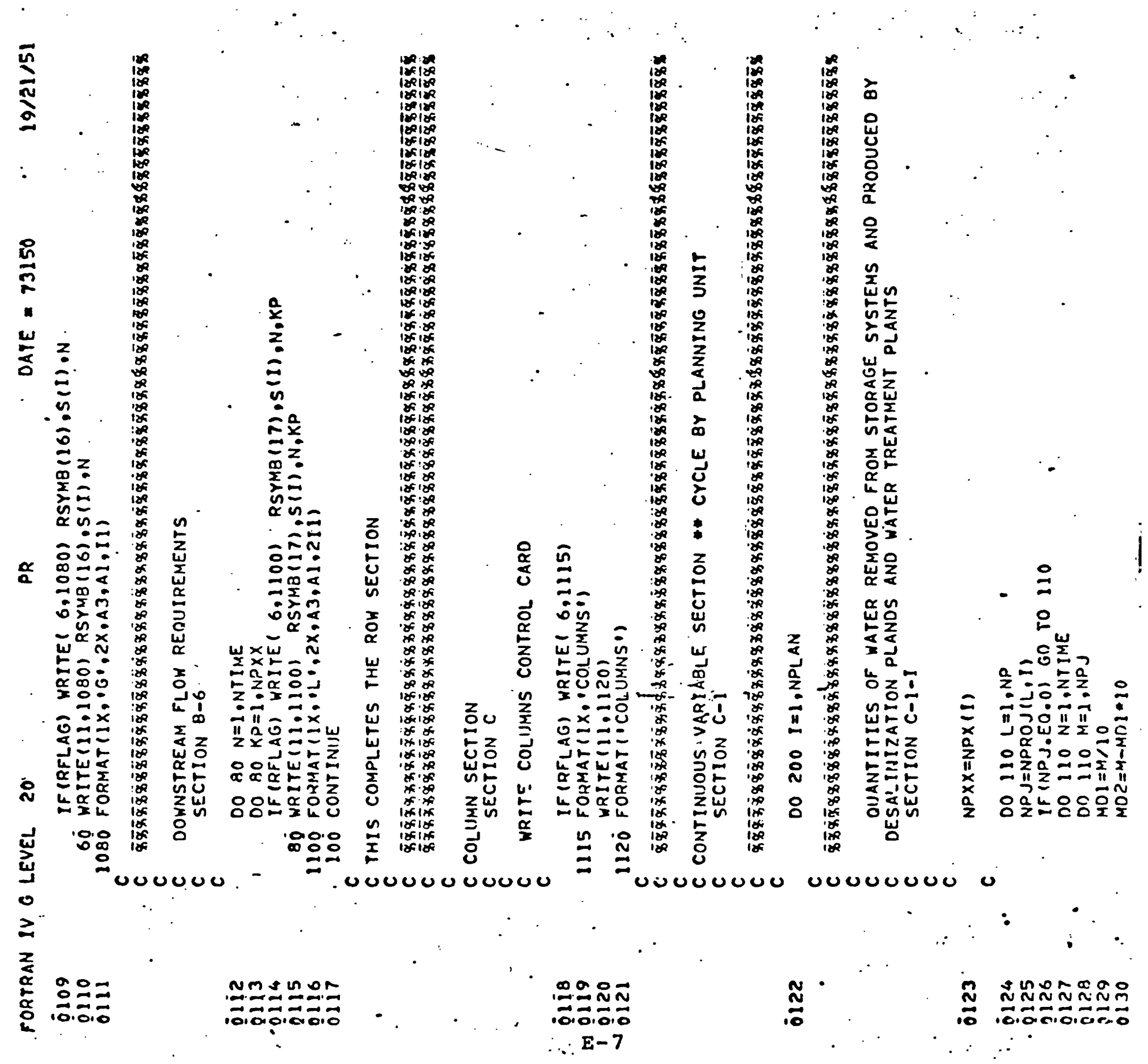




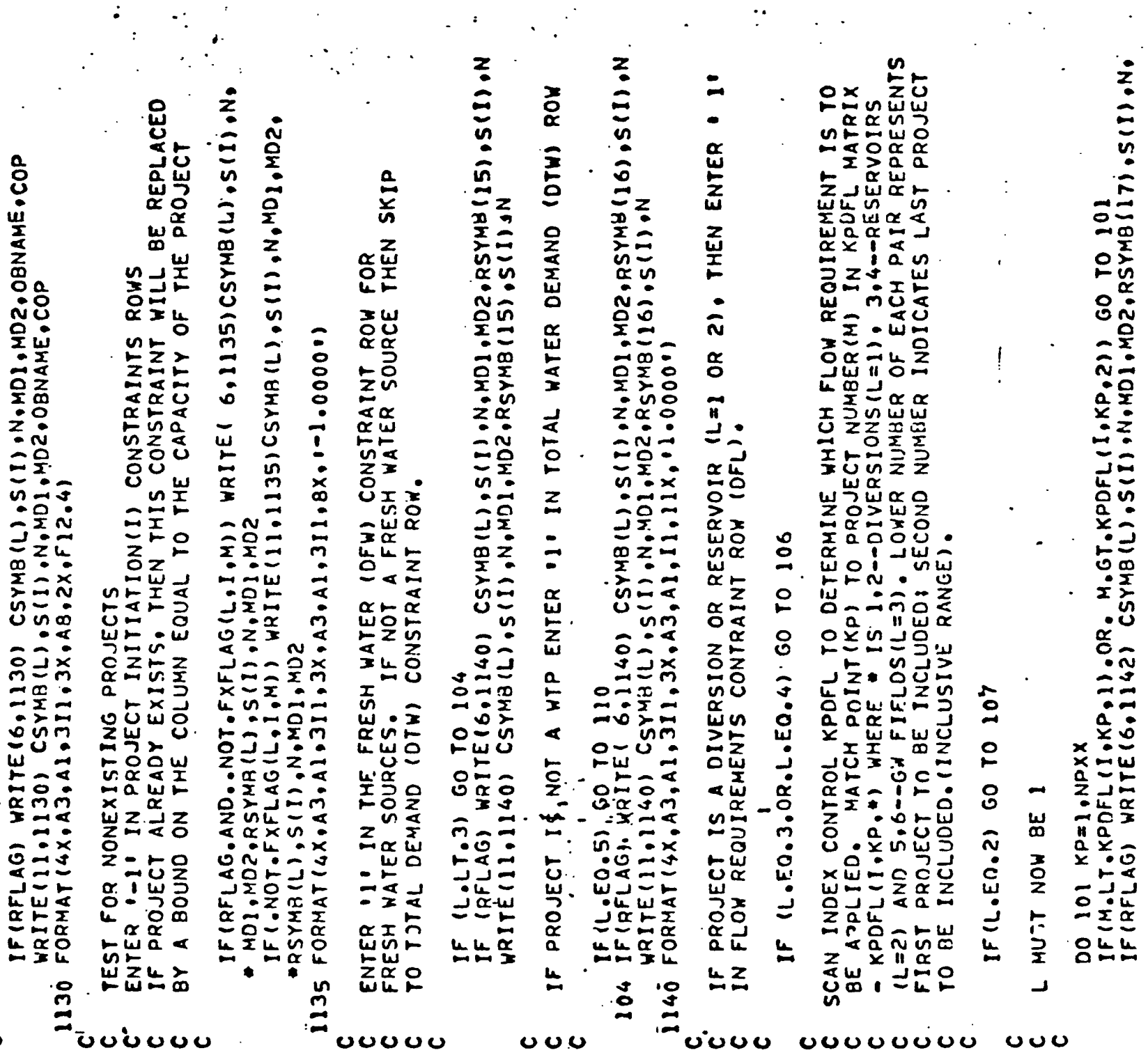

2

uno vuo

uviugo

$$
\text { ט }
$$




\section{$1 \mathrm{KP}$}

WRITE (11,114?) CSYMB(L:,S(I),N,:1D1,MD2,RSYMB (17),S(I),N,KP

1142 FORMAT $(4 X, A 3, A 1,3 I 1,3 X, A 3, A 1,2 I 1,9 X, 11.0000 \cdot)$

101 CONTINUE

GO TO 110

c

L MUST NOW BE 2

$10700102 \mathrm{KP}=1$. NPXX

IF $(M \cdot L T \cdot K P D F L(I, K P, 3), O R \cdot M \cdot G T \cdot K P D F L(I, K P, 4))$ GO TO 102

IF (RFLAG) WRITE $(6,1142) \operatorname{CSYMB}(L), S(I), N, M D I, M D Z, R S Y M B(17), S(I), N$, $1 \mathrm{KP}$

- HRITE(11,1142) CSYMB(L),S(I),N,MOI,MD2,RSYMB (17),S(I),N,KP

$10 \overline{2}$ CONTINUE

GO TO 110

IF PROJECT IS A GH FIELD, THEN ENTER INTERACTION COEFFICIENTS (F)

IN FLOW REQUIREMENTS (DFL) CONSTRAINT ROWS FOR PRESENT T.IME

PEPIOD ANO ALL SUCCEDING TIME PERIODS.

IF PROJECT IS A DESALTING PLANT $(L=4)$ GO TO END OF LOOP,

C

106 IF $(L \cdot E O .4)$ GO TO 110

$N 2=0$

DO $109 \mathrm{NI}=\mathrm{N}, \mathrm{NT} I \mathrm{ME}$

$N^{2}=N 2+1$

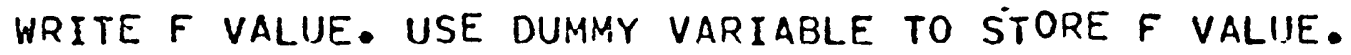

$G=F(N ? \cdot I, M)$

DO $103 \mathrm{KP}=1, \mathrm{NPXX}$

IF (1.LT.KPDFL (I,KP,5).DR.M.GT.KPDFL $(I, K P, 6))$ GO TO 103

IF (RFLAG) HRITE $(6,1144) \quad \operatorname{CSYMB}(L), S(I), N, M 01, M D 2, R S Y M B(17), S(I), N 1$ s

$1 K P, G$

URITE(11,1144) CSYMB(L),S(I),N,MD1,MOZ,RSYMB(17),S(I),N1,KP,G

1144 FORMAT $(4 X, A 3, A 1,3 I 1,3 X, A 3, A 1,2 I 1,4 X, F 12,4)$

103 CONTINIJE

109 CONTINUE

110 CONTINUE

c

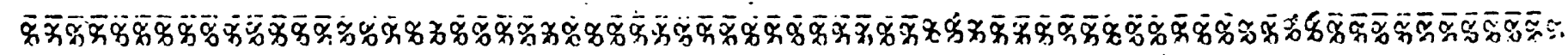

C

C QUANTITIES OF RAH WATER IMPORTED

C SECTION C-I-II: :

C

$:$

DO $120 \quad j=1, N P L A N$

IF (J.EQ.I) GO TO 120

$N P J=N P[M P(I, J)$

IF (NPJ.EQ.0) GO TO 120

DO $120 \mathrm{~N}=\mathrm{I}$, NTIME

DO $120 \quad M=1$, NPJ

$M D !=M / 10$

$M O 2=M-M O I * 10$

c

C

C

ADJUST .OPERATING COSTS TO PRESENT VALUE

$$
\text { E-9 }
$$


:

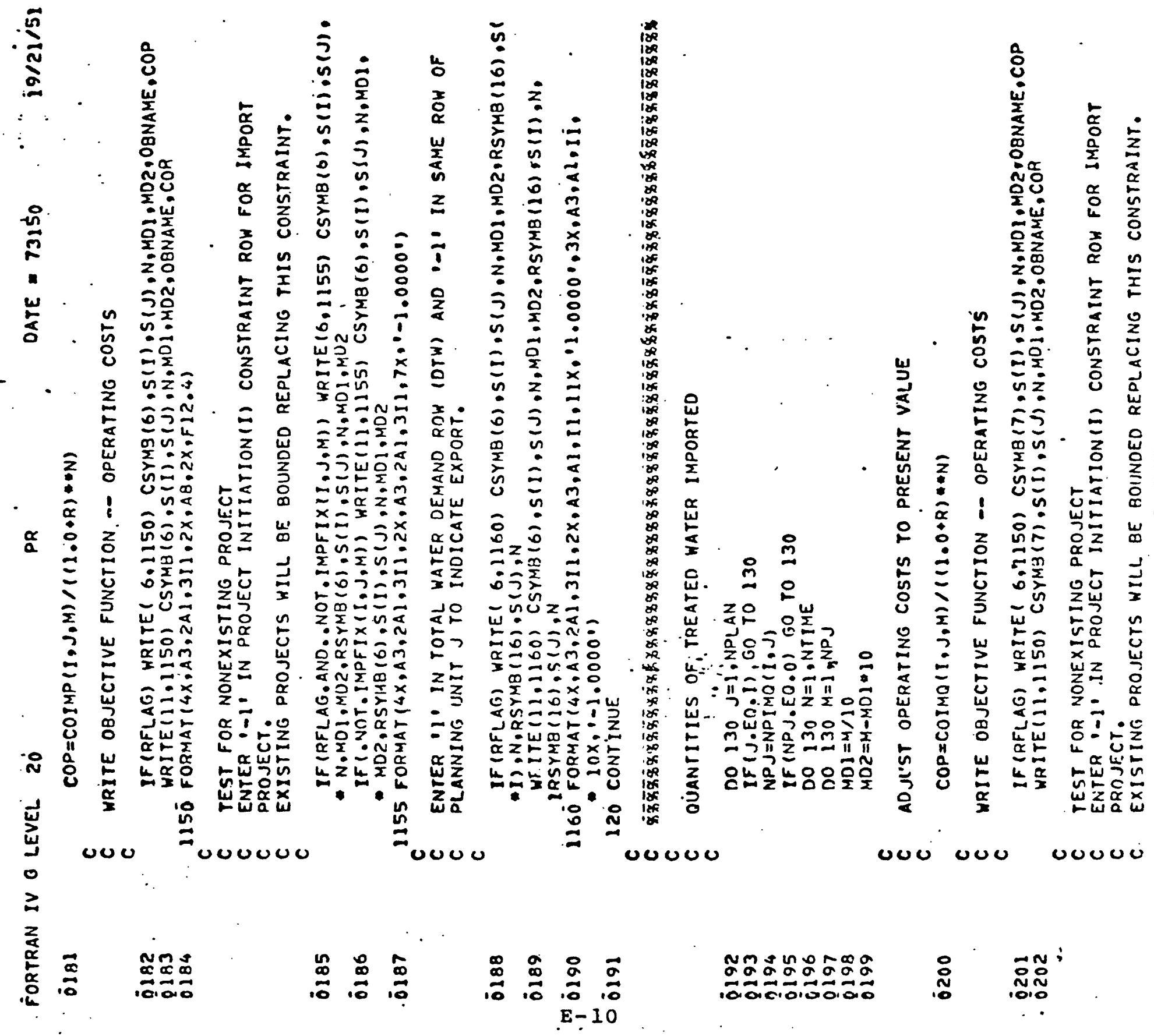




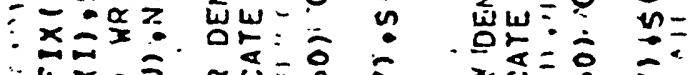

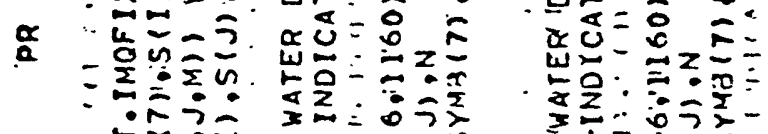

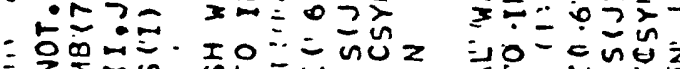

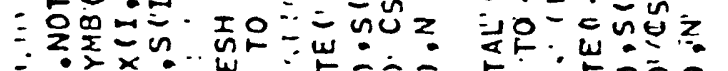

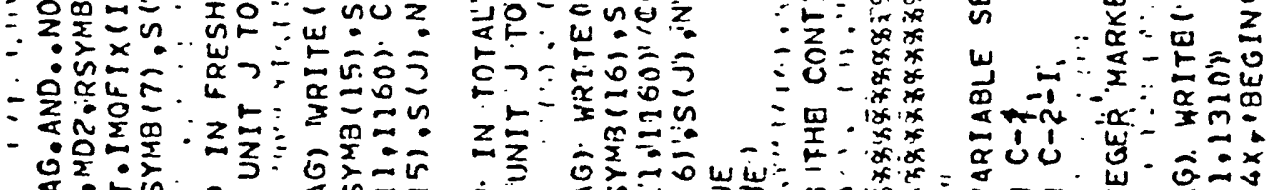

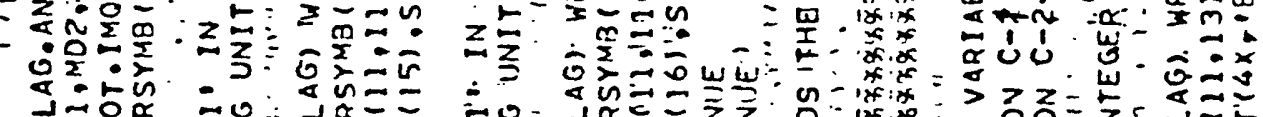

-

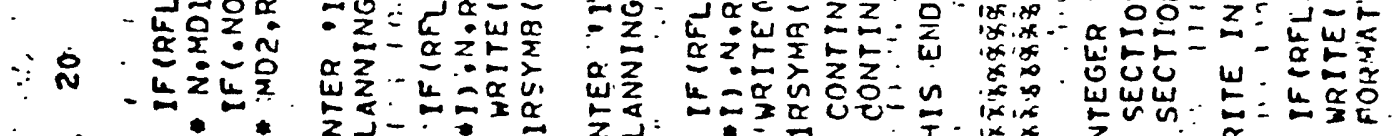

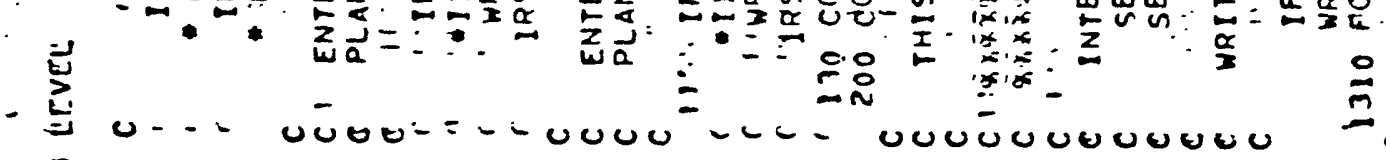

טu

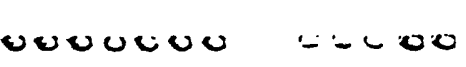

$\geq$

$\underset{\substack{z \\ \alpha}}{\substack{\alpha \\ \alpha}}$

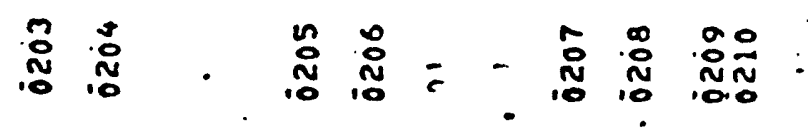

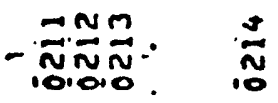

$$
\begin{aligned}
& \therefore E-11 \text { (roporge E12) }
\end{aligned}
$$


0
0
0
0
0
0
0
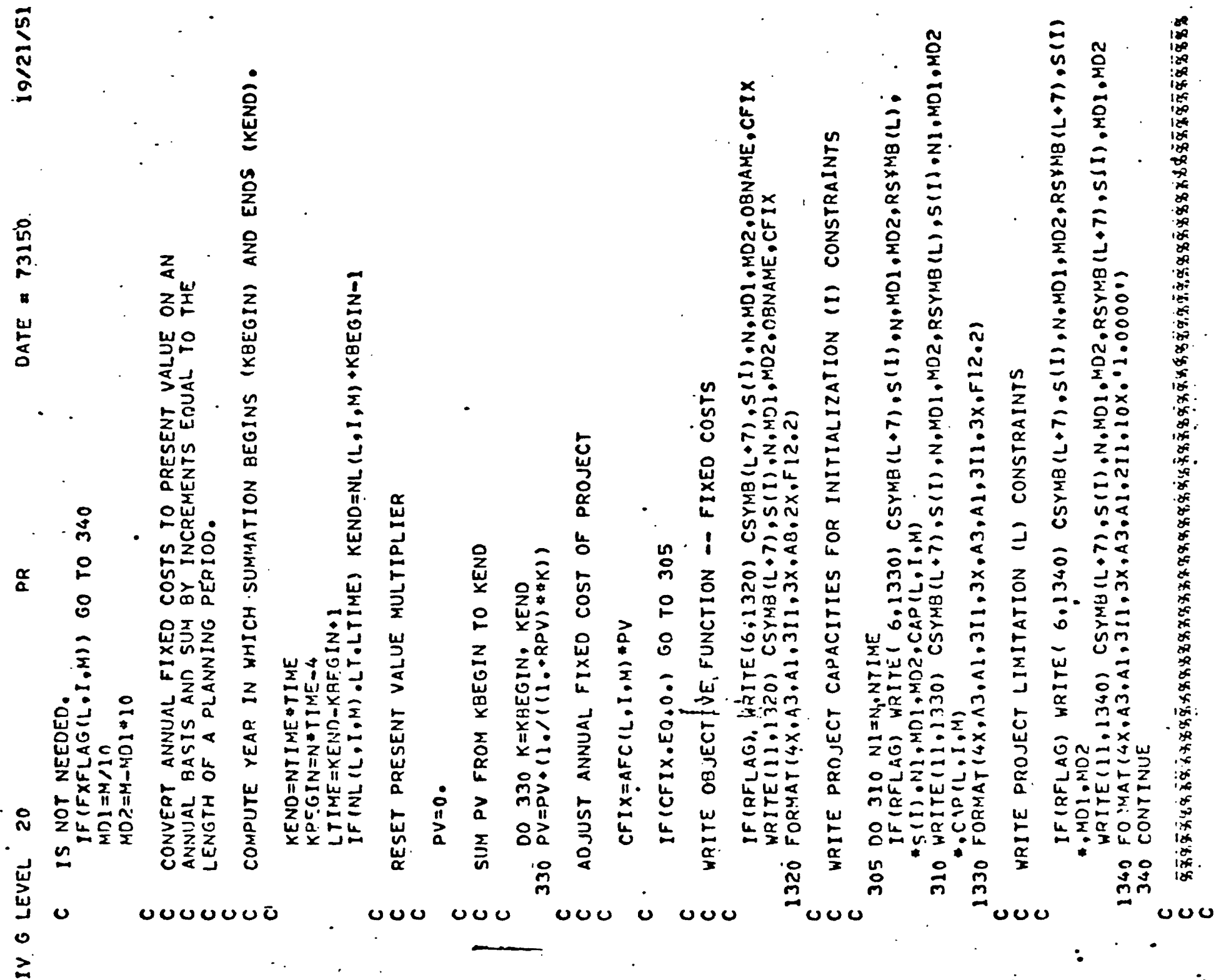

퓨

$\underset{N}{N} \mathbb{N}$

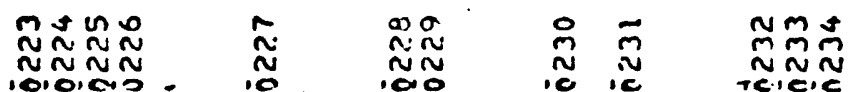

TC.C.C

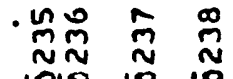

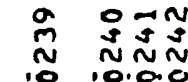

$\therefore$ E-13 
$1=$
0
0
0
0

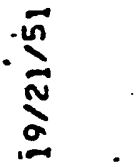

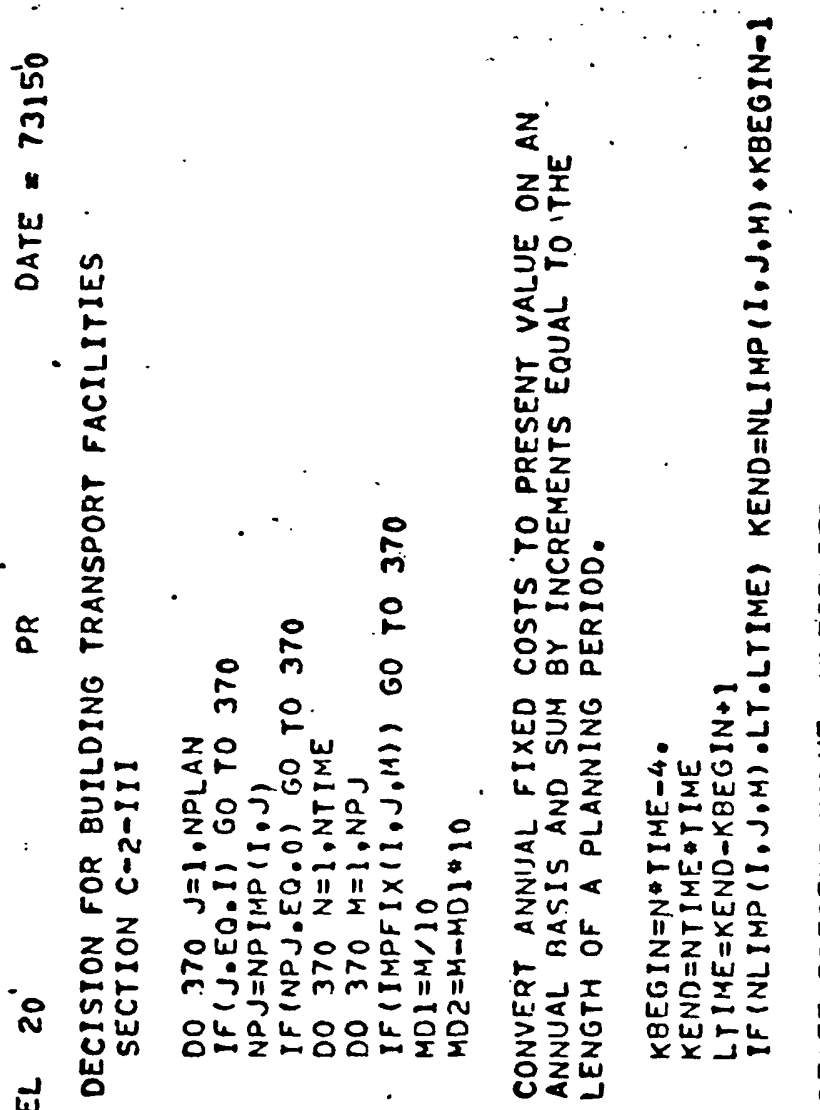

UU טoses ous

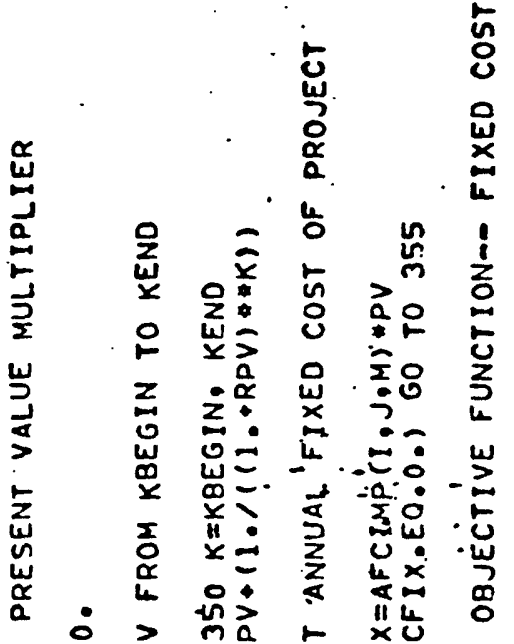

上

a $\sum_{\text {a }}^{5}$ : 'ू

2

0
2
2
2
$\vdots$
0
0
0
0
0

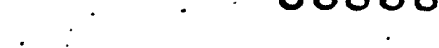

000
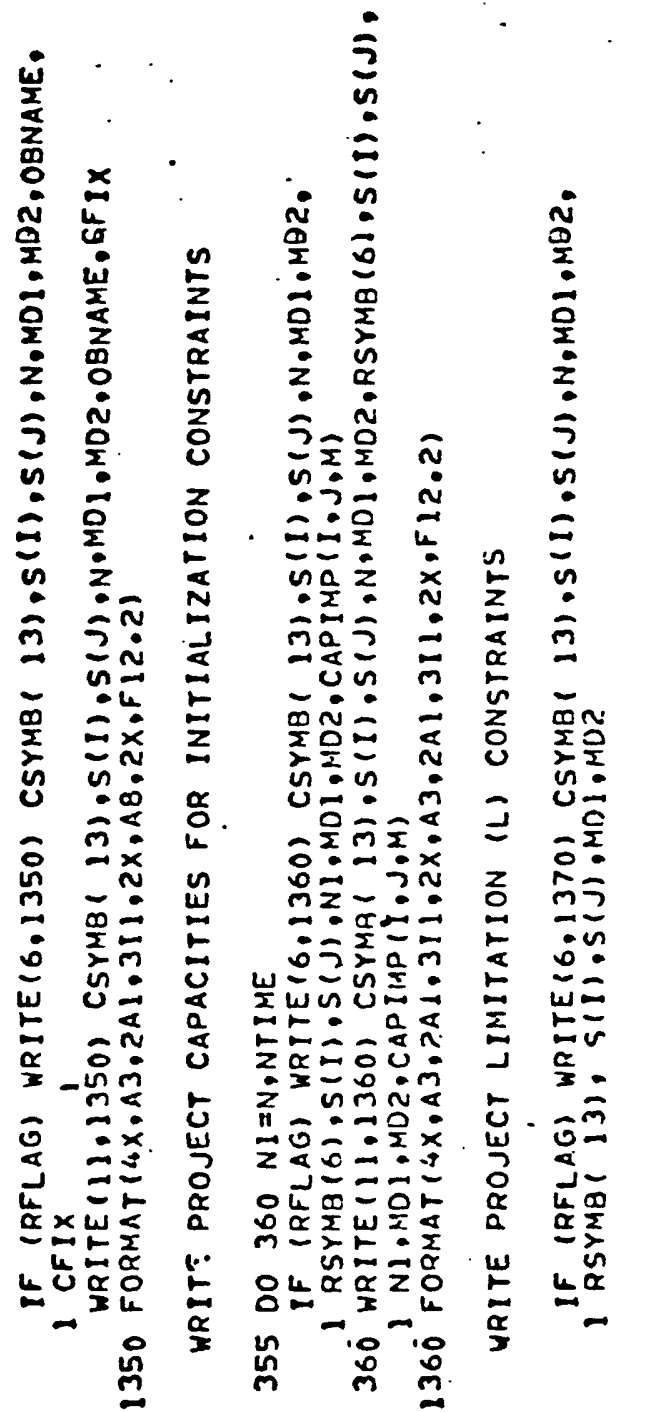
กำ
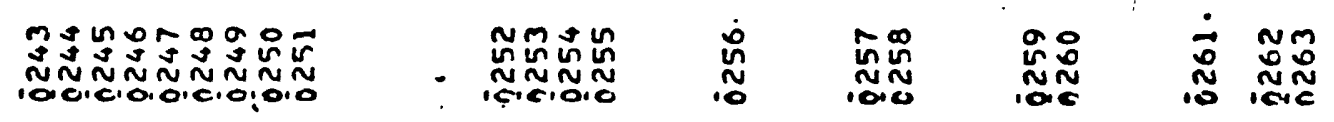

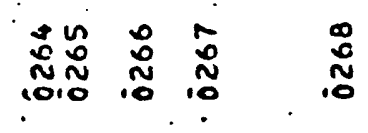
E-14 
0
0
0
0
0
0

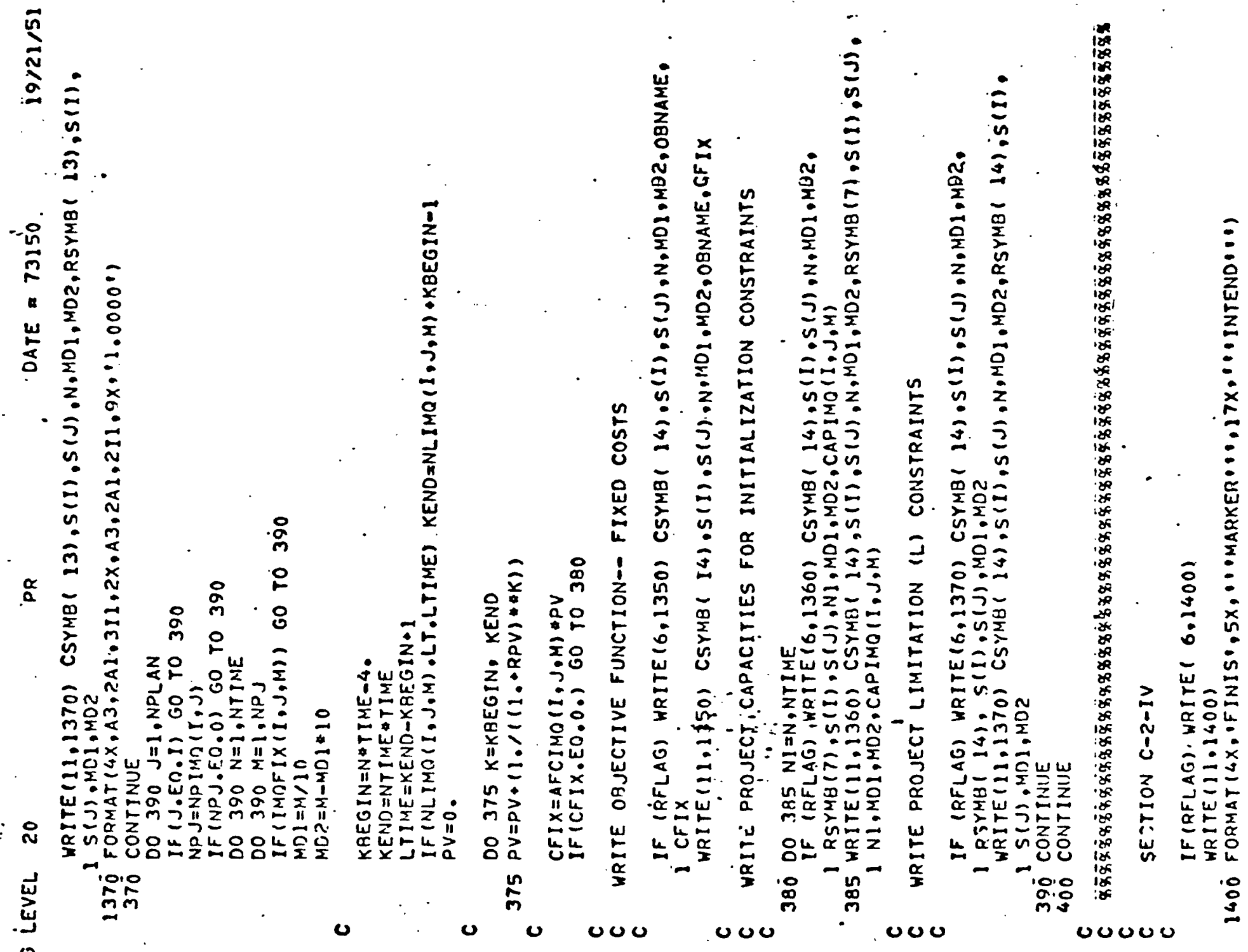

0

2

za

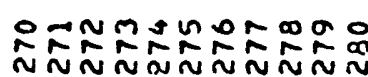

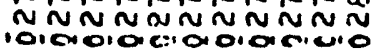

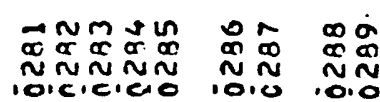

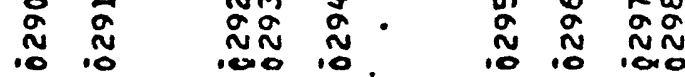

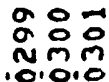
E- 15 
$m$
0
0
$w$
0
0
$a$

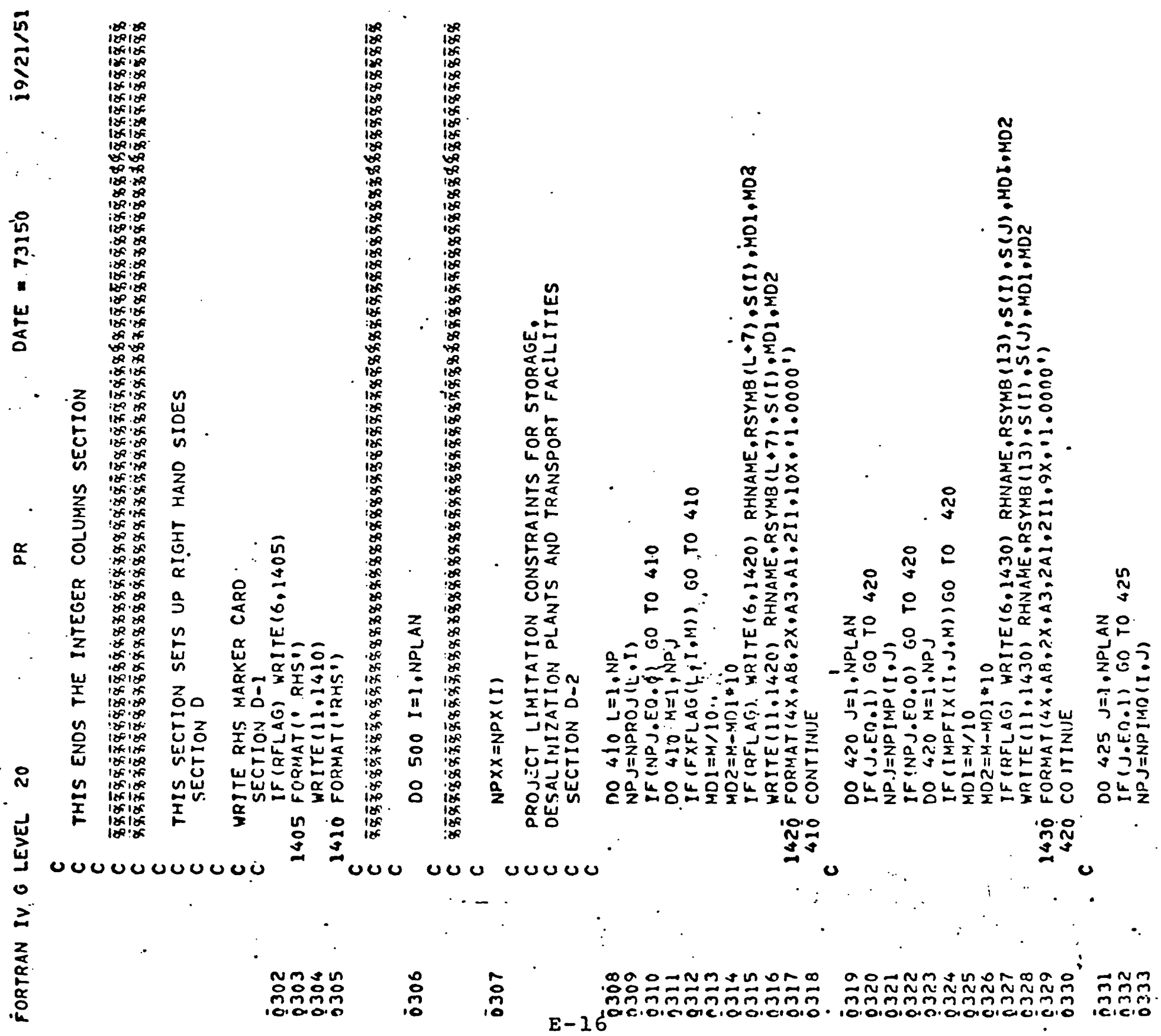


$\$$
0
0
0
0
0

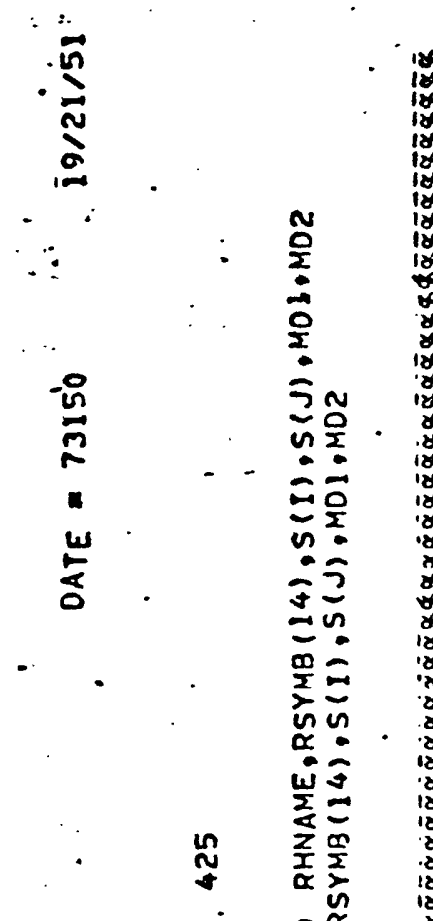

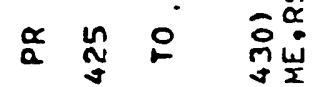

은 主竞

o, $\sum_{\text {. }}$

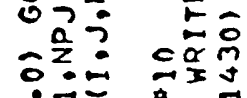

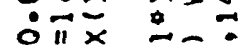

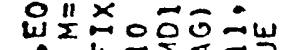

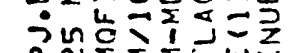

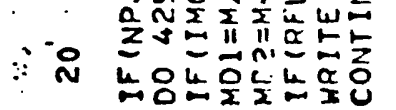

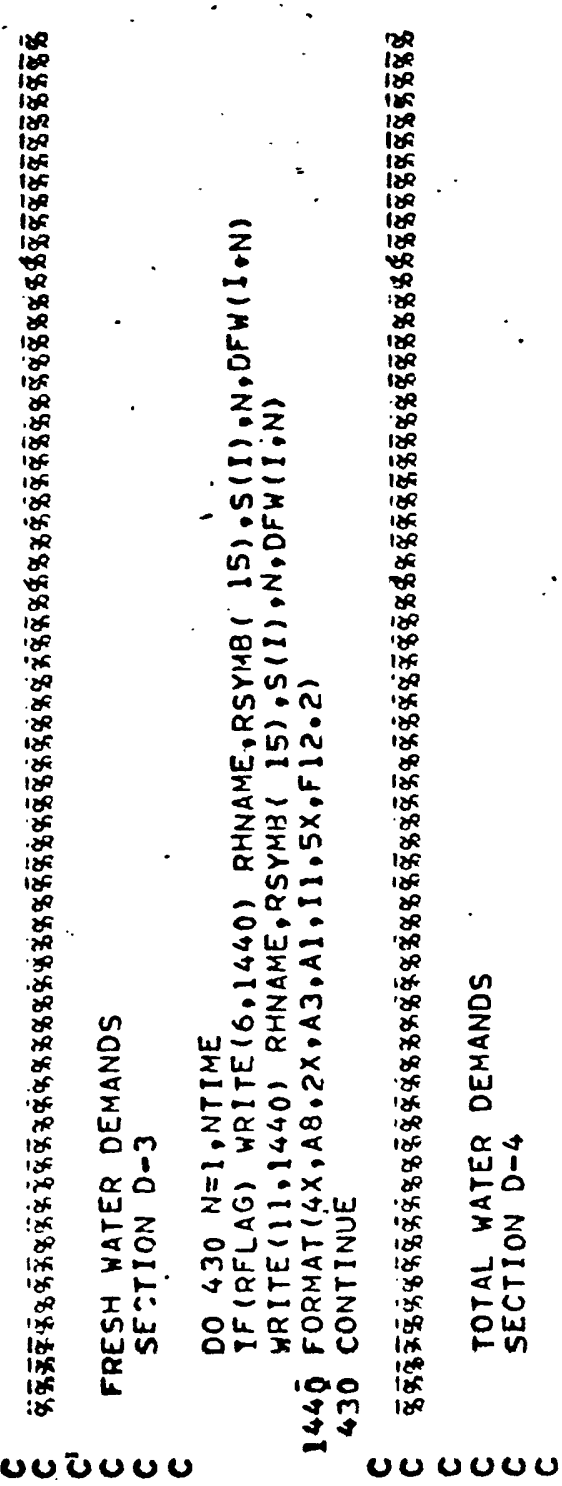

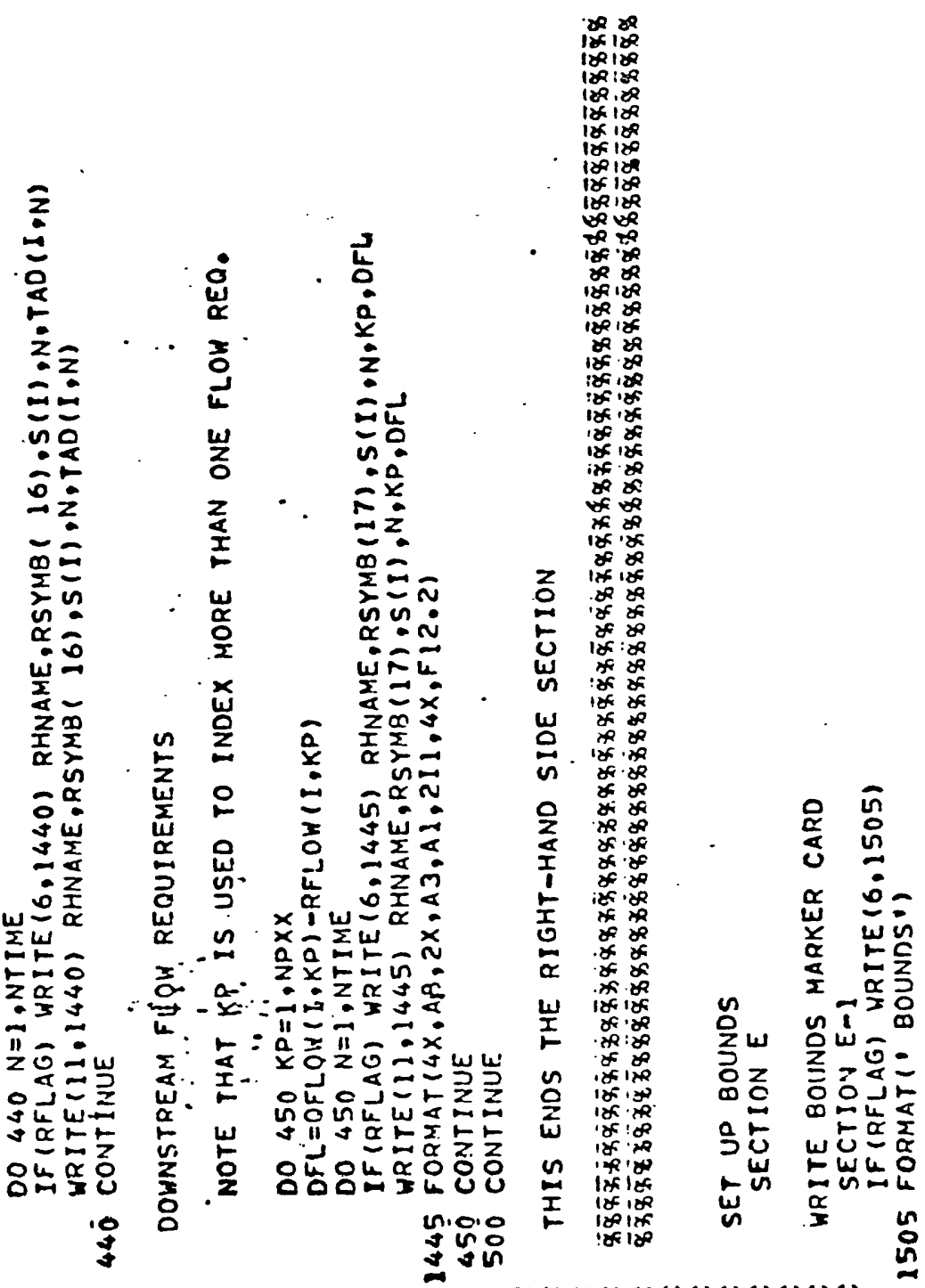

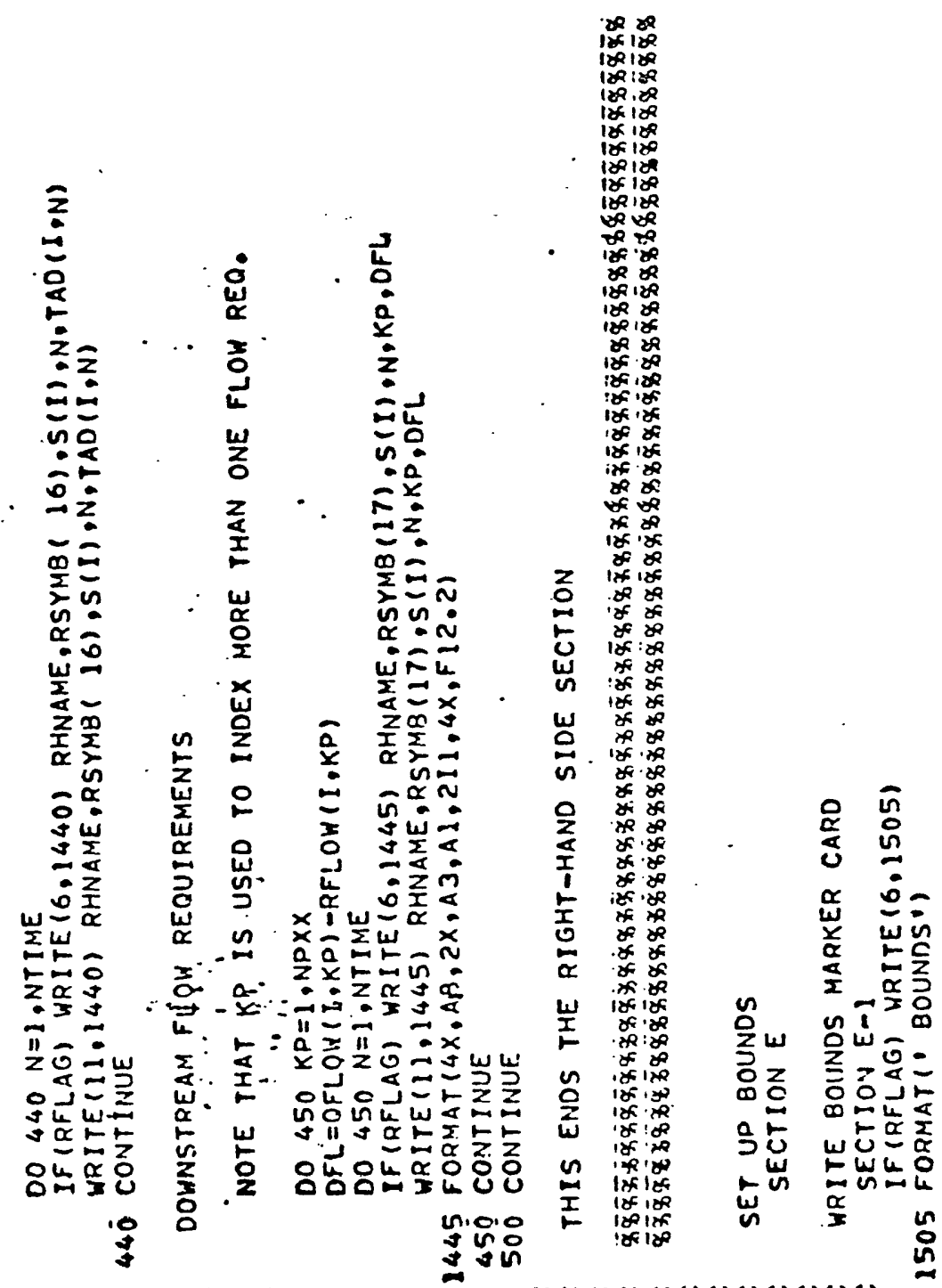

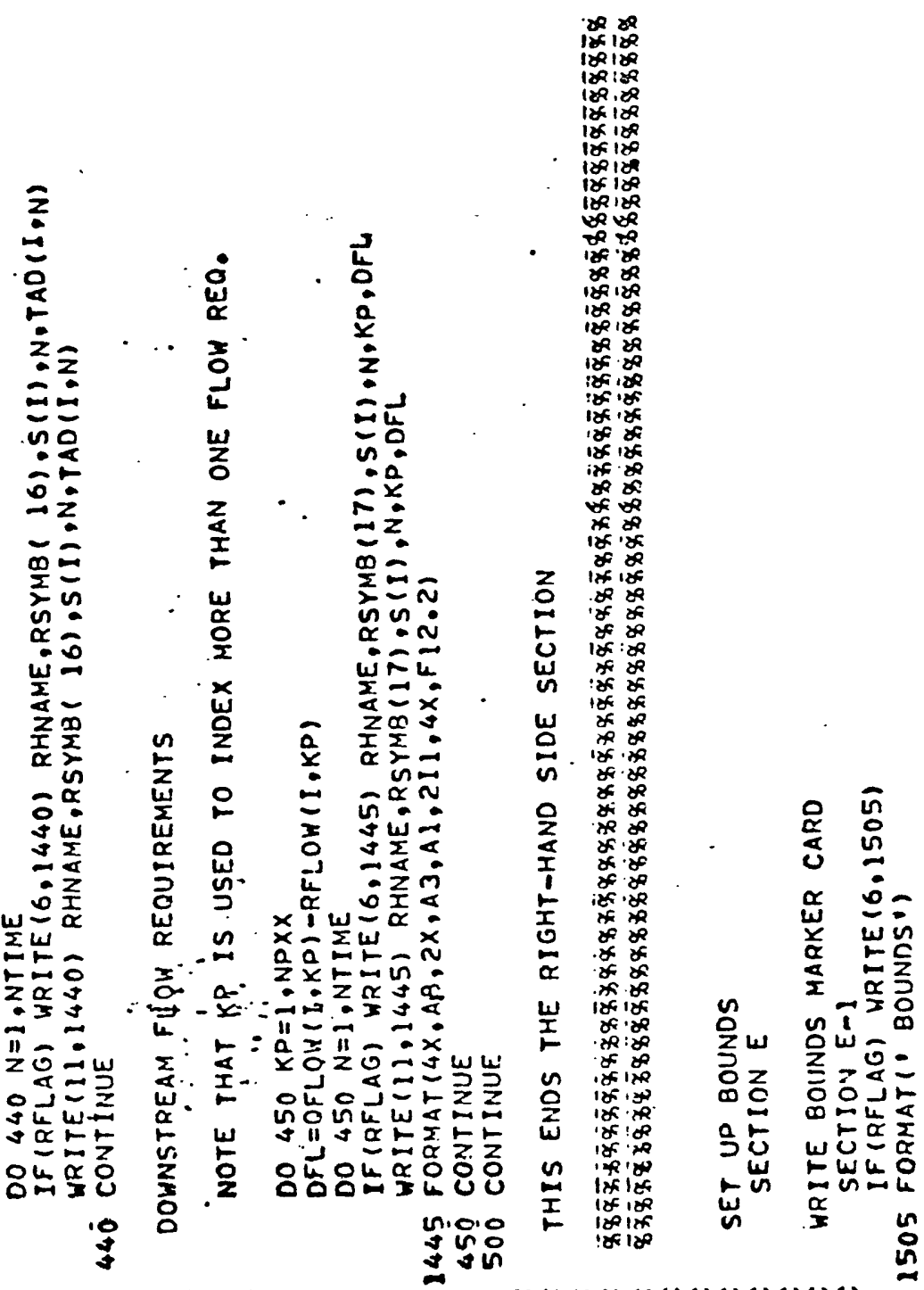

vutuou

vouvou

טuOUo

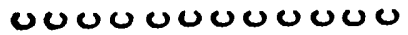

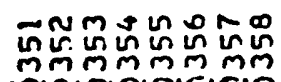

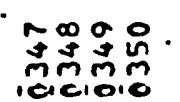

acisonicio 
$\frac{n}{8}$
$: 8$
$y$
0
$a$

$\sum_{2}^{\frac{1}{2}}$

出

$a$

品

$\therefore$

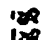

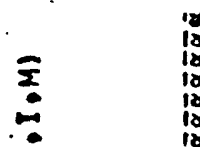

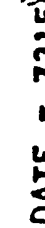

.

$ㅇ$

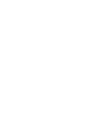

管。

ที่ง

in

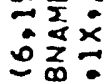

w口-

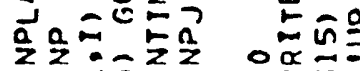

过年.

을드

$\Xi \tilde{1}$

"चวँ

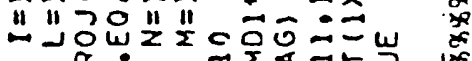

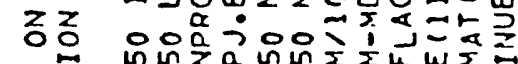

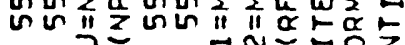

⿰纟:

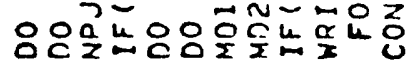

$$
\text { 员 }
$$

ที่⿺辶⿱

ñuvuou

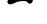

Que

\section{$i_{10}^{\infty}$}

טuouou

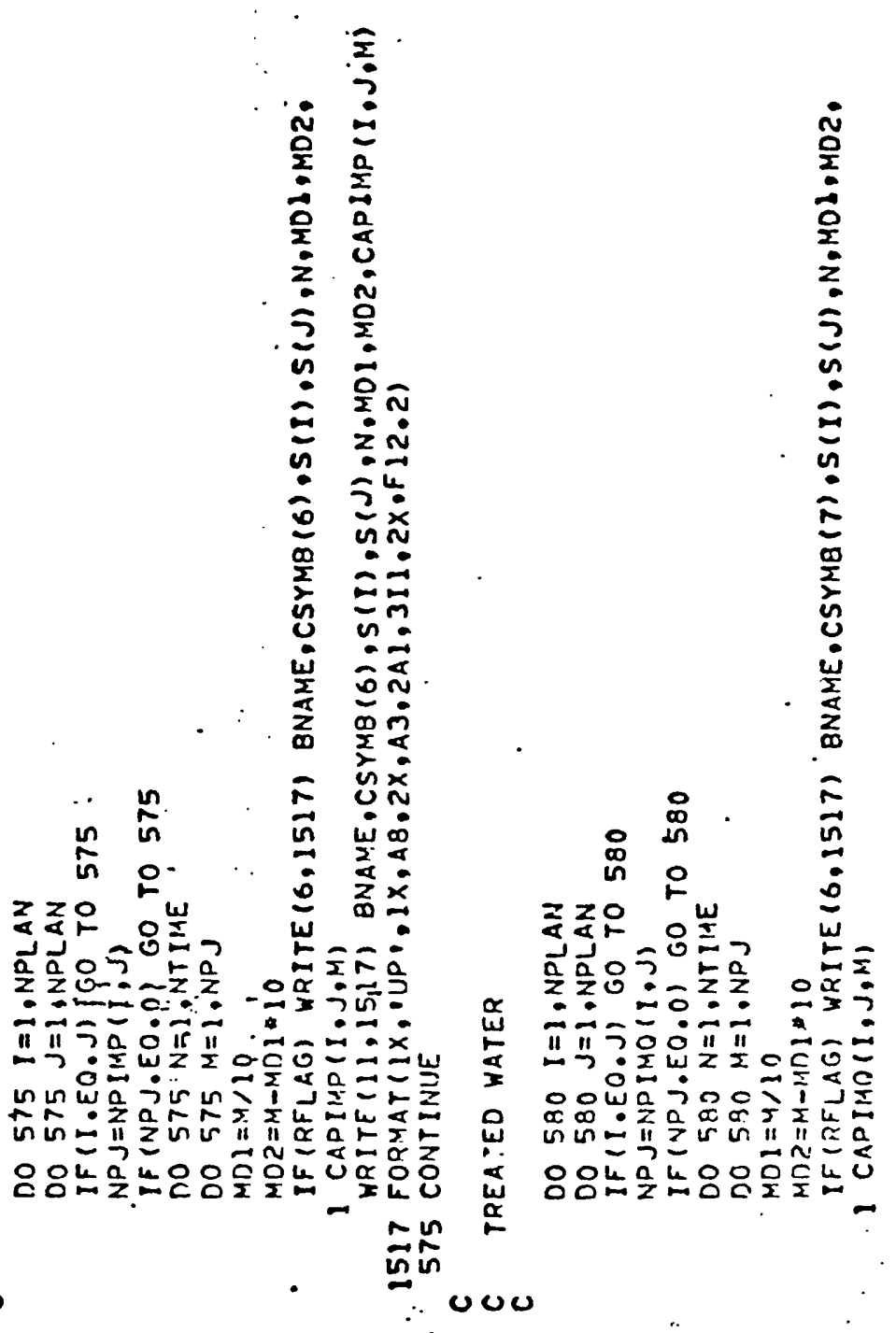

0

$\geq$

$z$

2

$\overrightarrow{0} \mathfrak{0}$

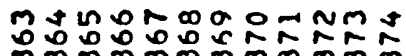

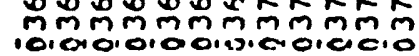

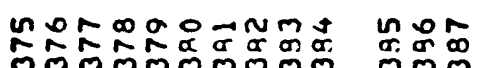

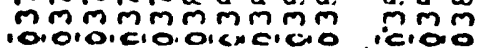

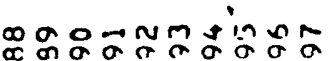

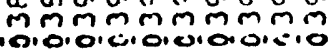


0
0
0
0
0
0
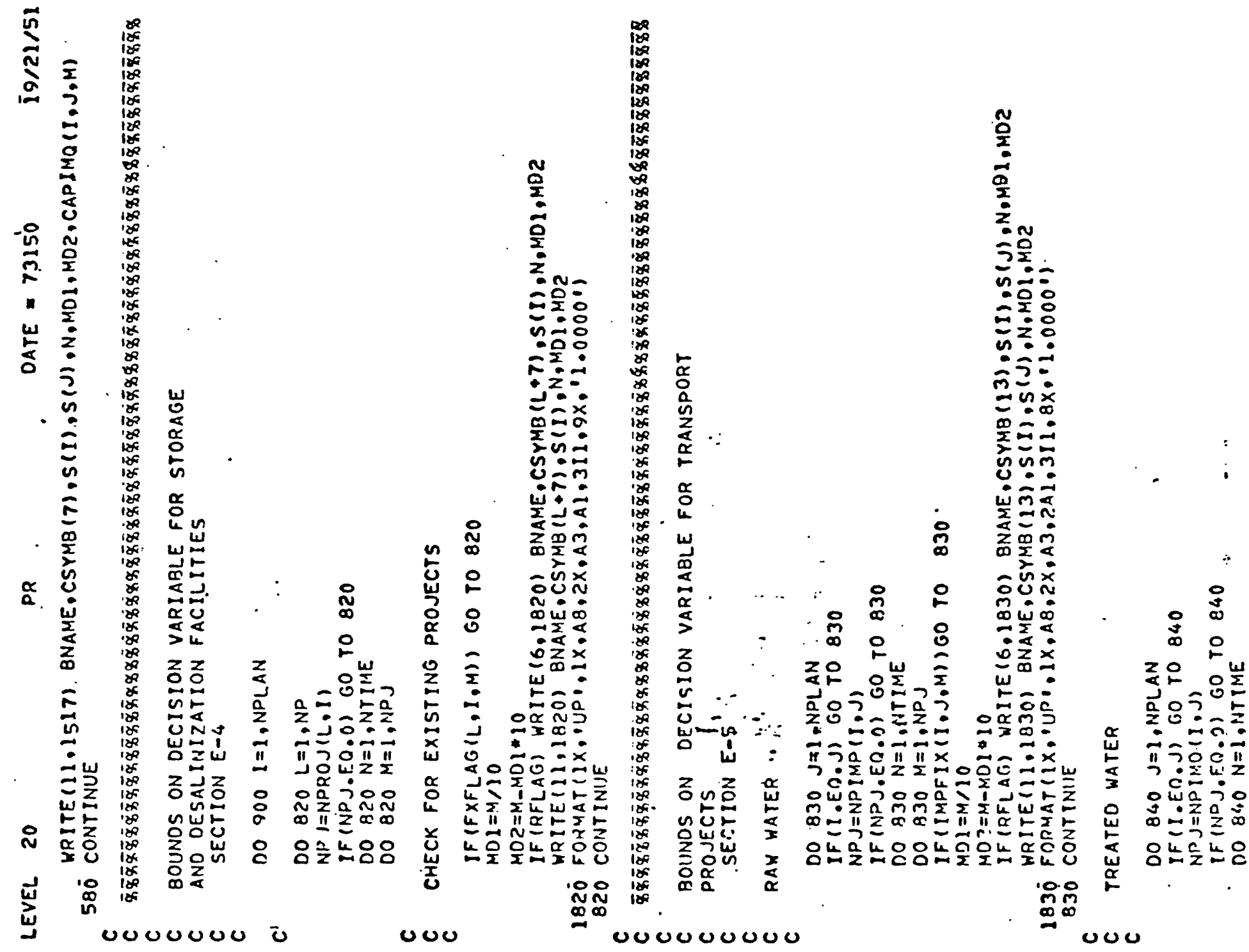

0

vouvuno

000

0uvucuuno

טOU

2

$\infty$
$\substack{\alpha \\ 0}$
$\substack{\alpha \\ 0.0}$

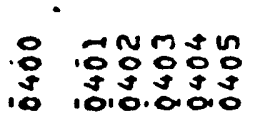

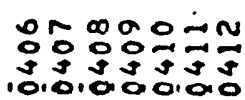

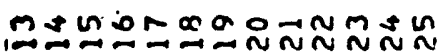

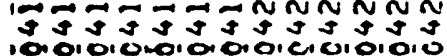

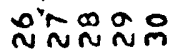
E-19 
:

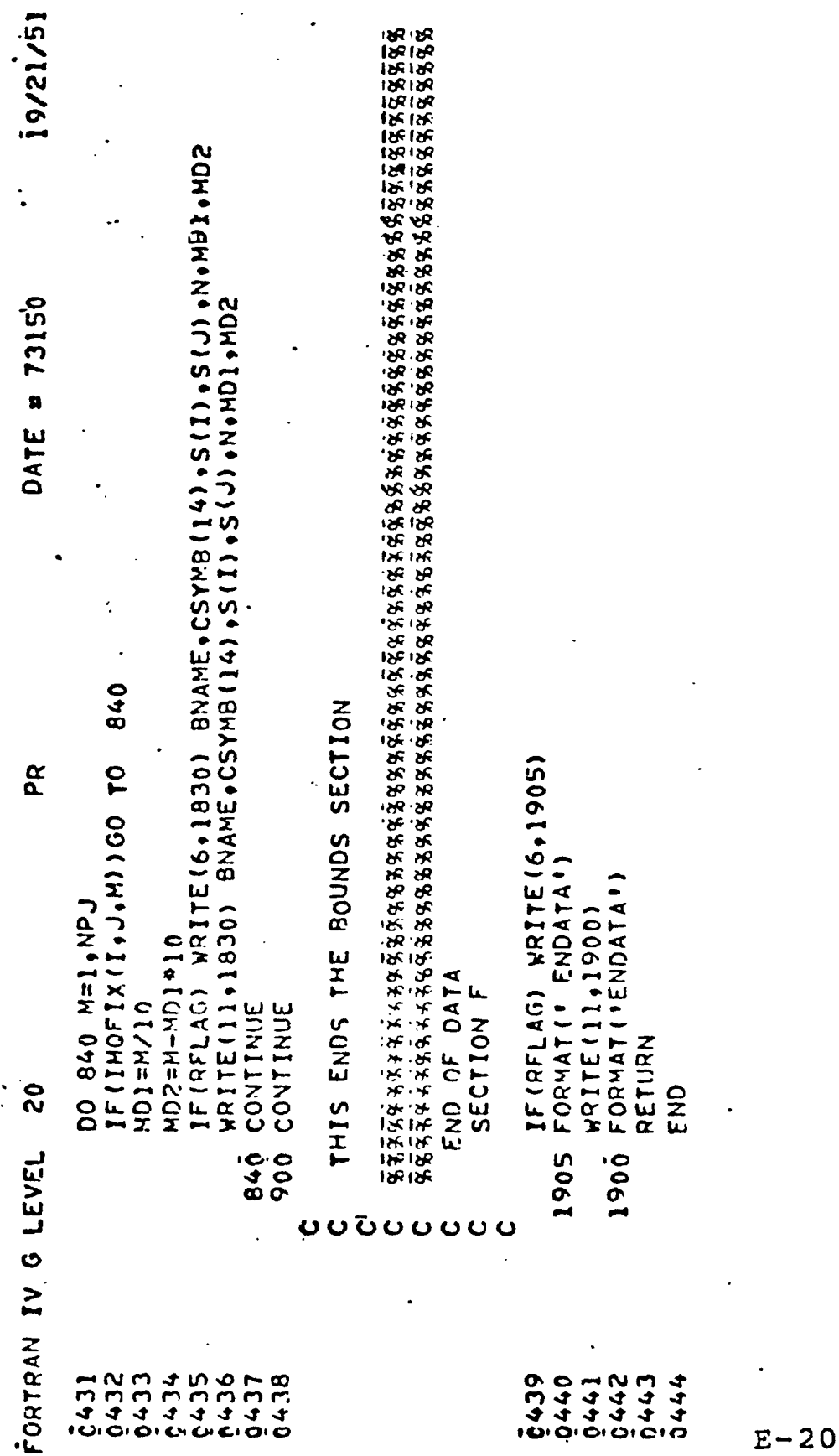


0
0
0
0
0
0

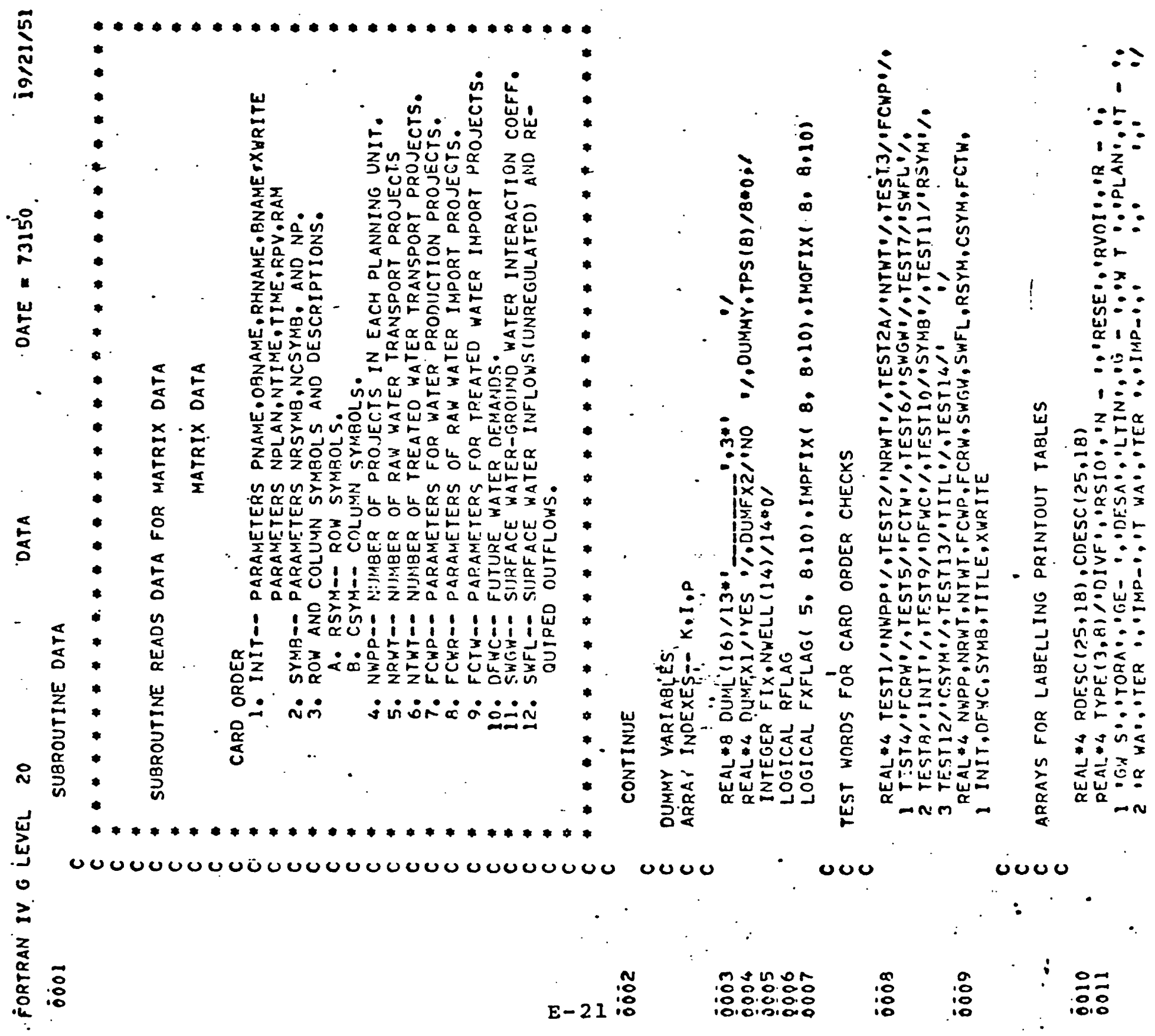


.ั.

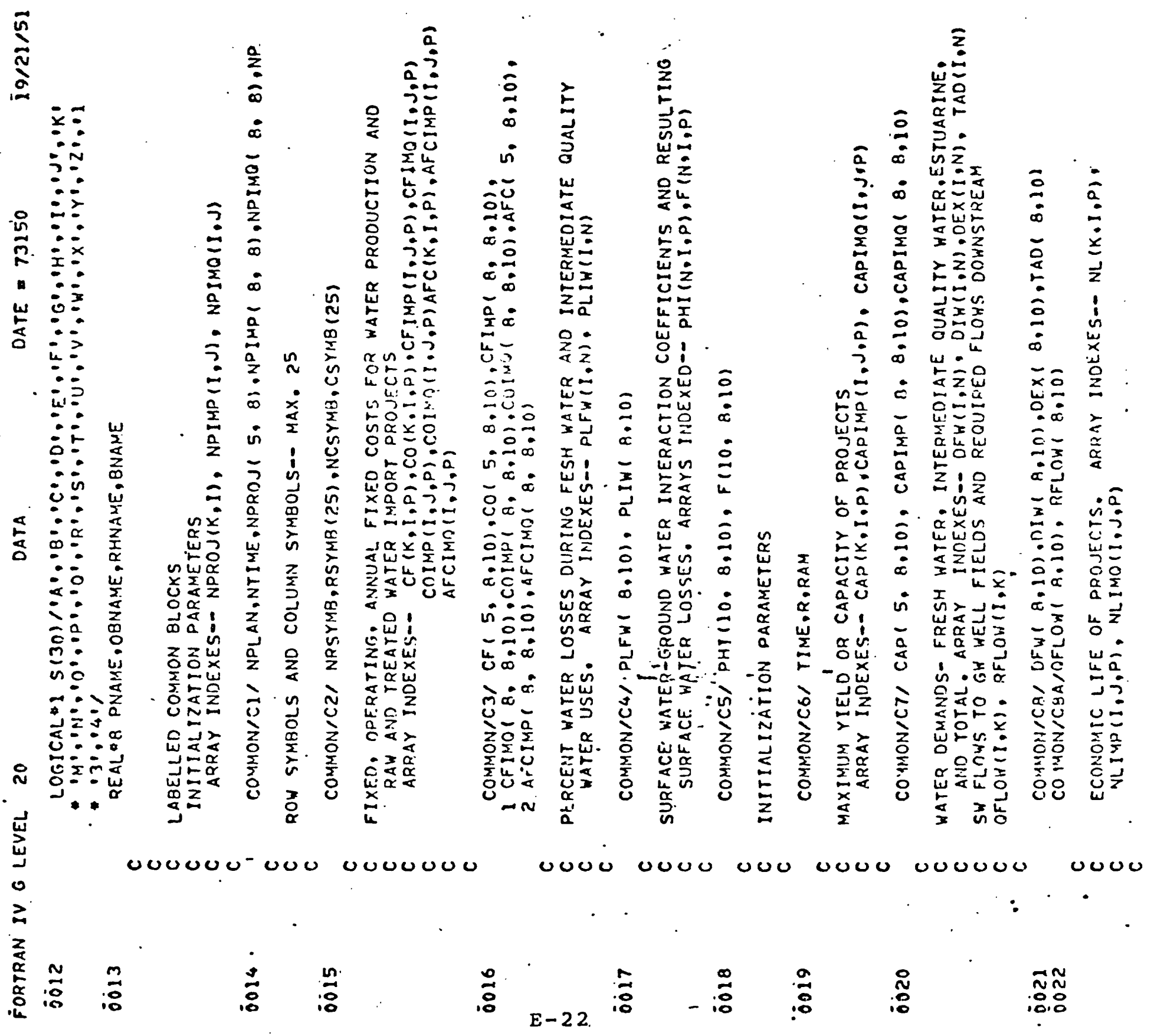


m
0
10
0
0
0
$a$

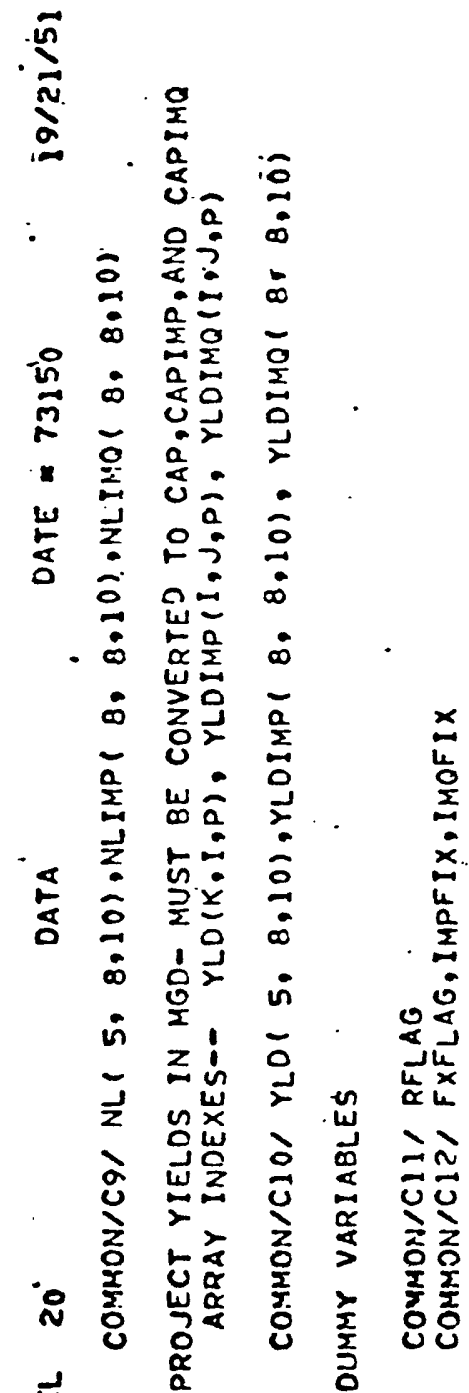

טugu ưo

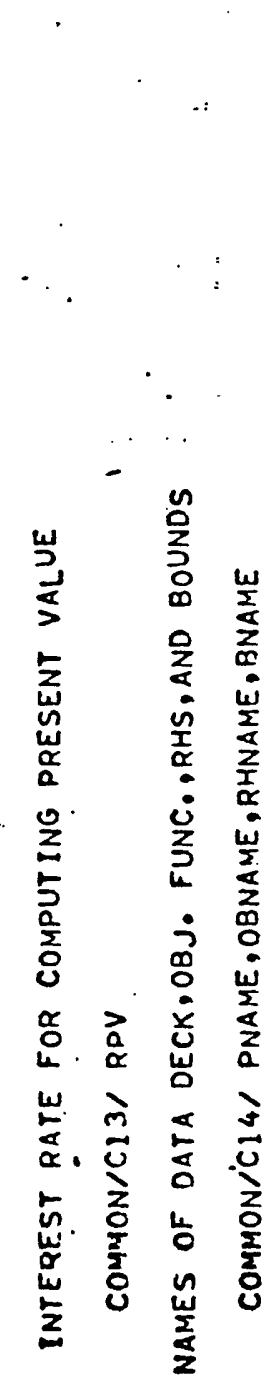

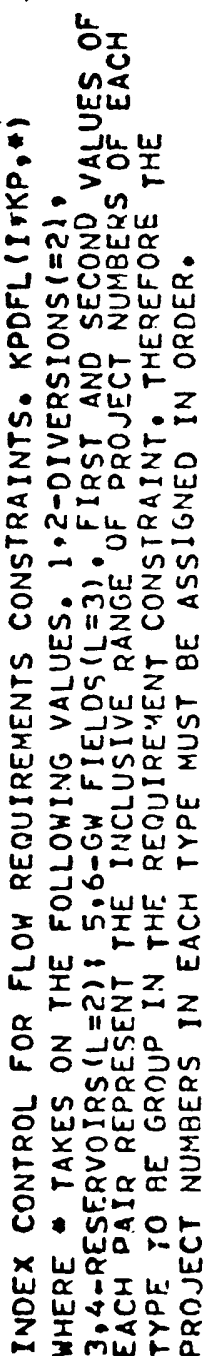

- ous ouo

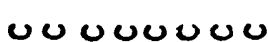

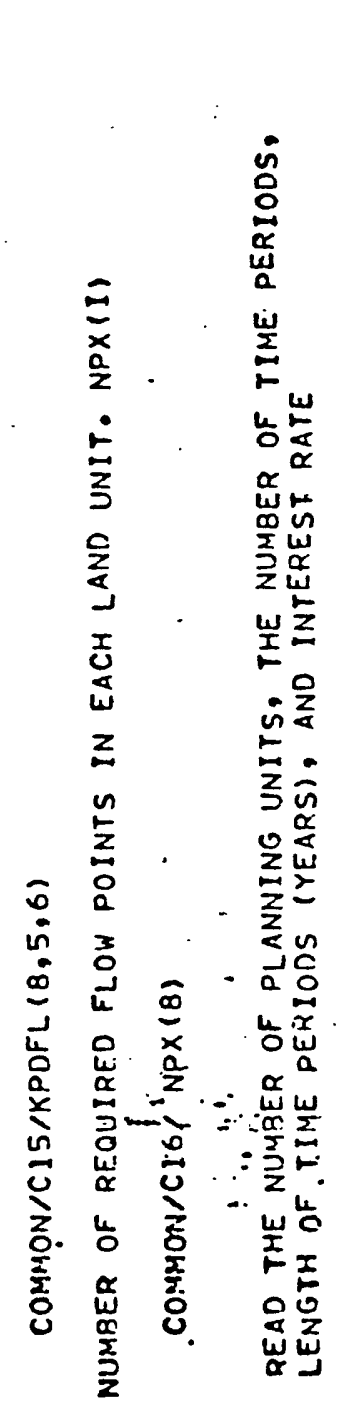

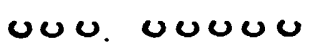

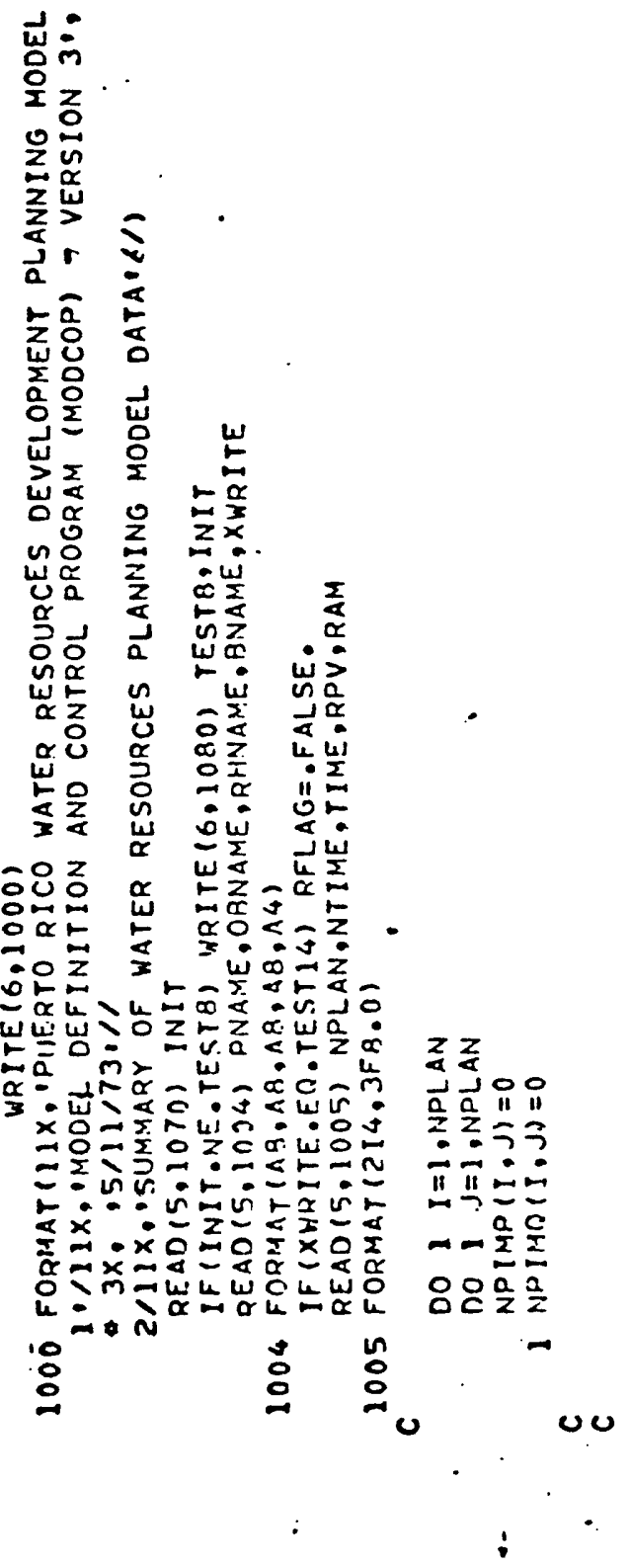

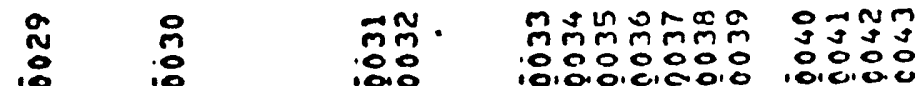




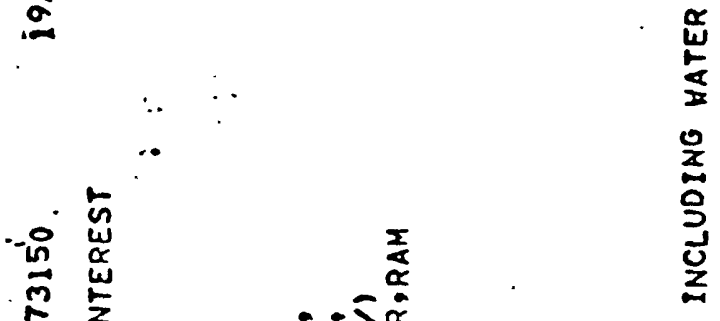

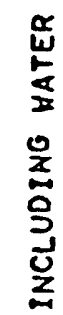

$$
\text { 造 }
$$

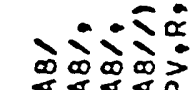

造 $\quad \begin{aligned} & \infty \\ & 0\end{aligned}$

es $\sum^{\infty}$

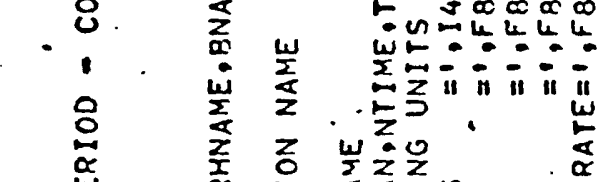

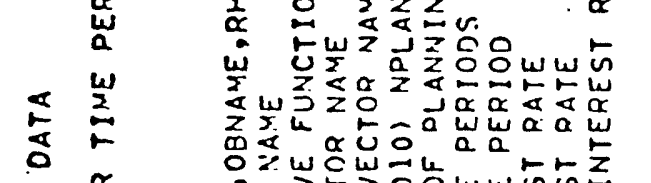

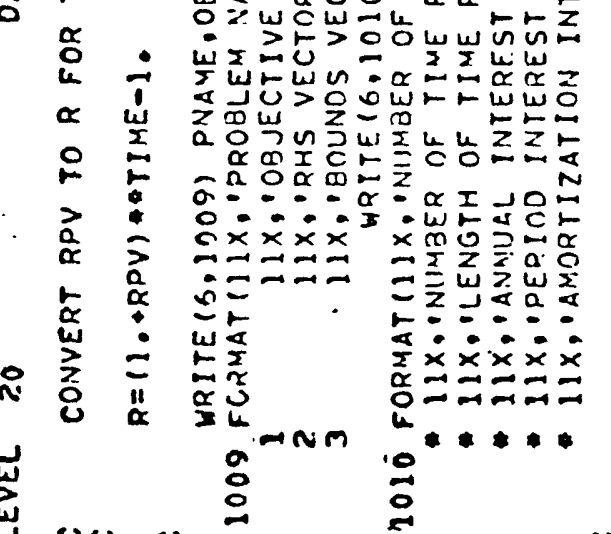

u 0 잉

0

$>$

$\sum_{\alpha}^{2}$

\section{ใ.}

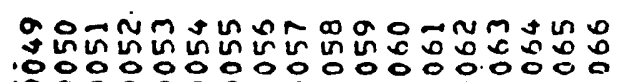

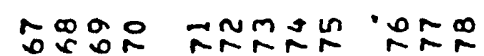

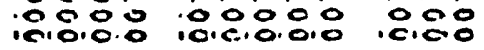


0
.0
0
0
0
0

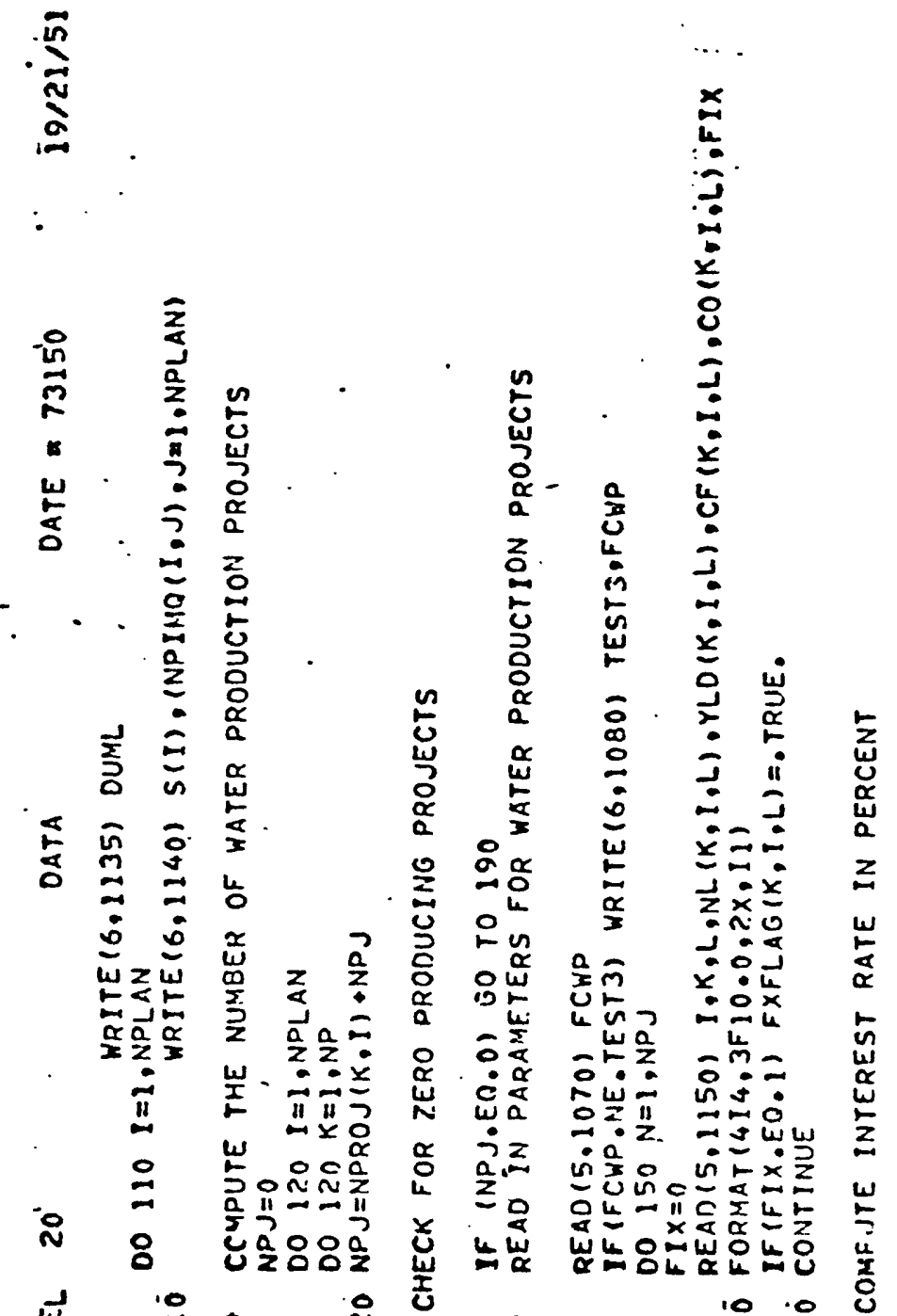

w

인 인

.00

욝 윽

ưo

究它:

岁过舟

a웅용

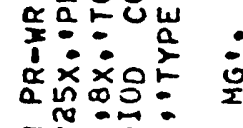

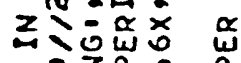

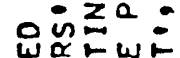

ज出运在

ว5品可

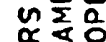

w出这文

फ़ة

岁岗和

崖它wa

a

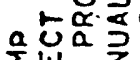

$\sum_{\alpha} \sum_{2} z_{2}$

xᄋㅇㅊ

wa

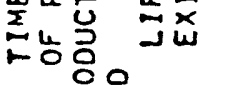

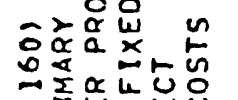

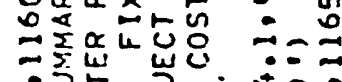

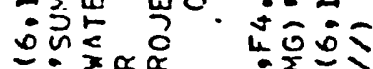

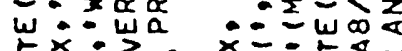

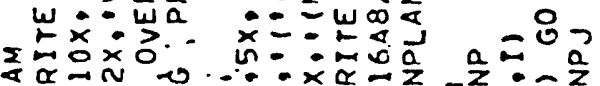

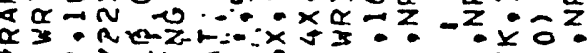

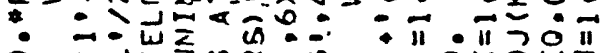

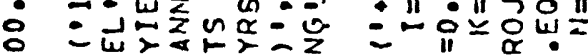

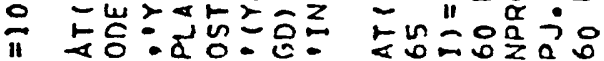

줄운언:

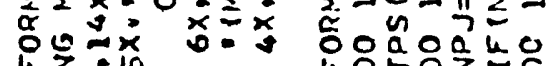

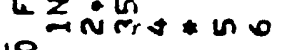

':
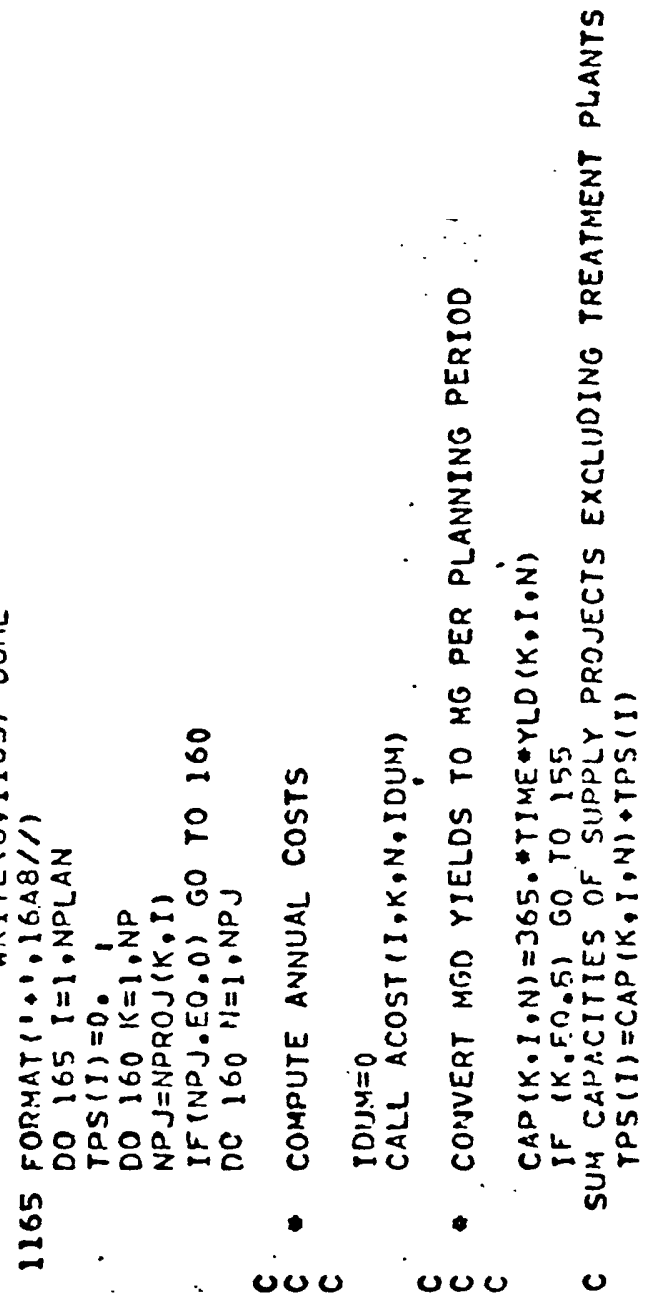

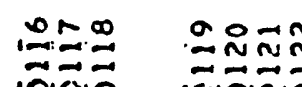

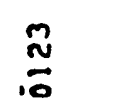

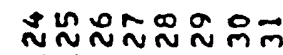

บำำ

Nmm

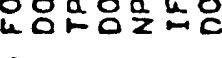

告

000

000

$\boldsymbol{U}$

: 
1
0
0
0
0
0
0

2

高文

일

管

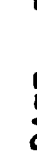

- 웡.

崖

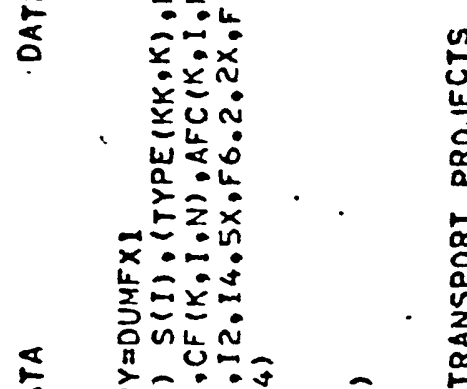

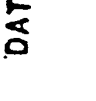

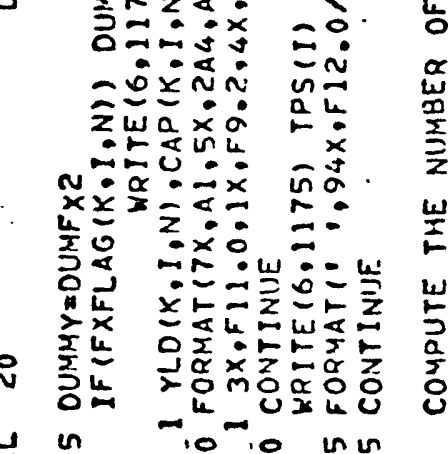

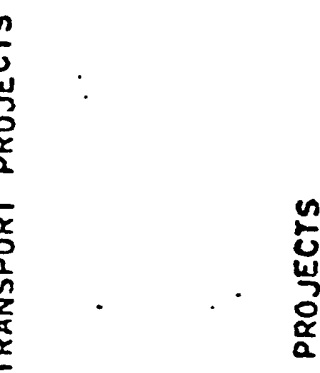

安:

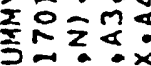

$\sum_{\omega}^{\infty}$

0

uUu

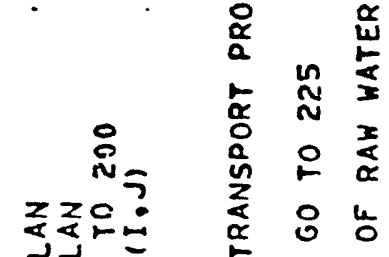

물은둘

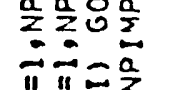

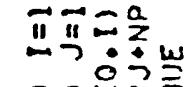
0 응놀

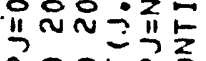

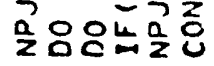<smiles>[CH-]1[CH-]CC1</smiles>

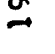

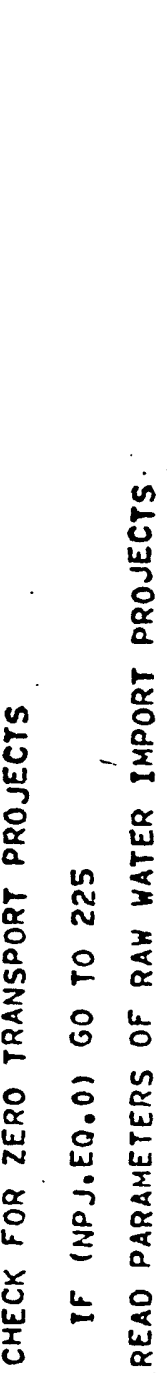

UU⿺ 000

ơ

这

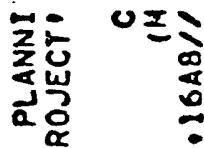

乎跑:

更:

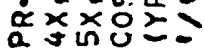

$z \mathfrak{y}-\because \frac{1}{2}$

넝ㅇㅇ중

o in $z$

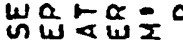

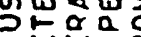

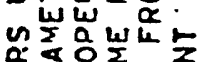

하

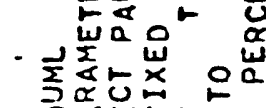

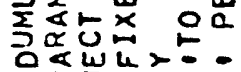

a a

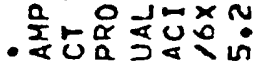

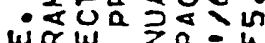

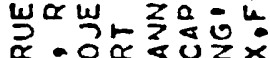

- $\alpha$ iิ웅

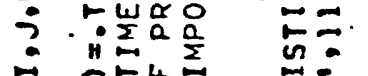

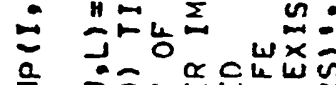

a jor

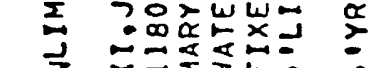

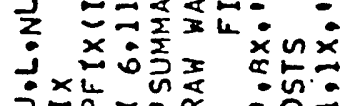

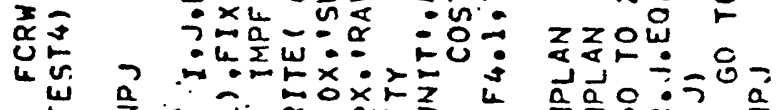

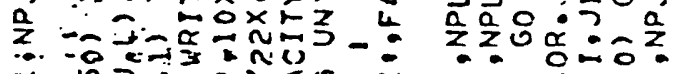

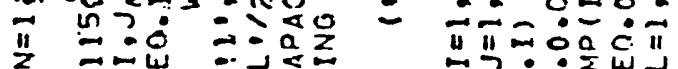

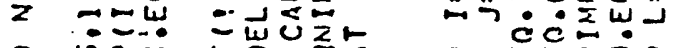

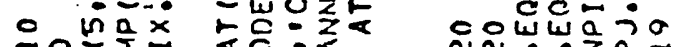

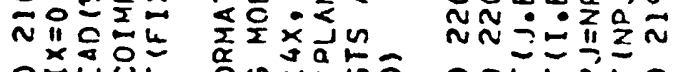

으의.

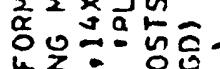

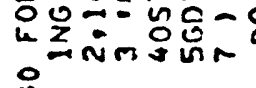

$\frac{5}{2}$

¿

능 눈

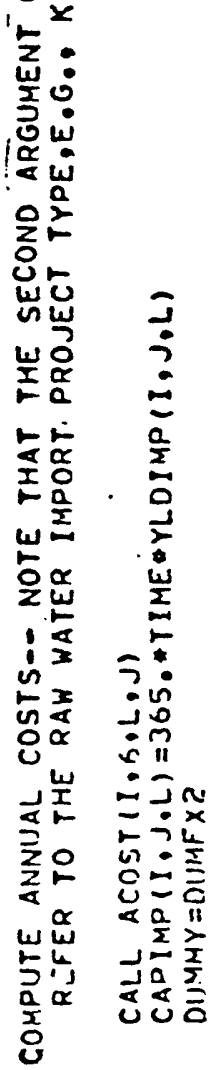

טuט

$\geq$

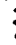

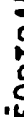

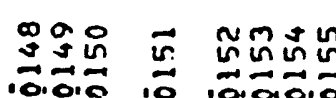

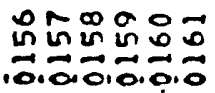

2

$\cong$

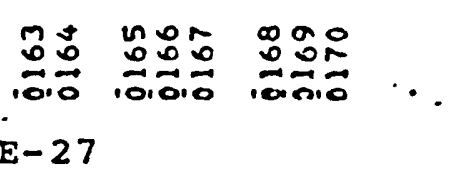

TNMENON

뭉요

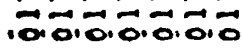
ज्ञात 
0
0
10
0
0
0
$a$

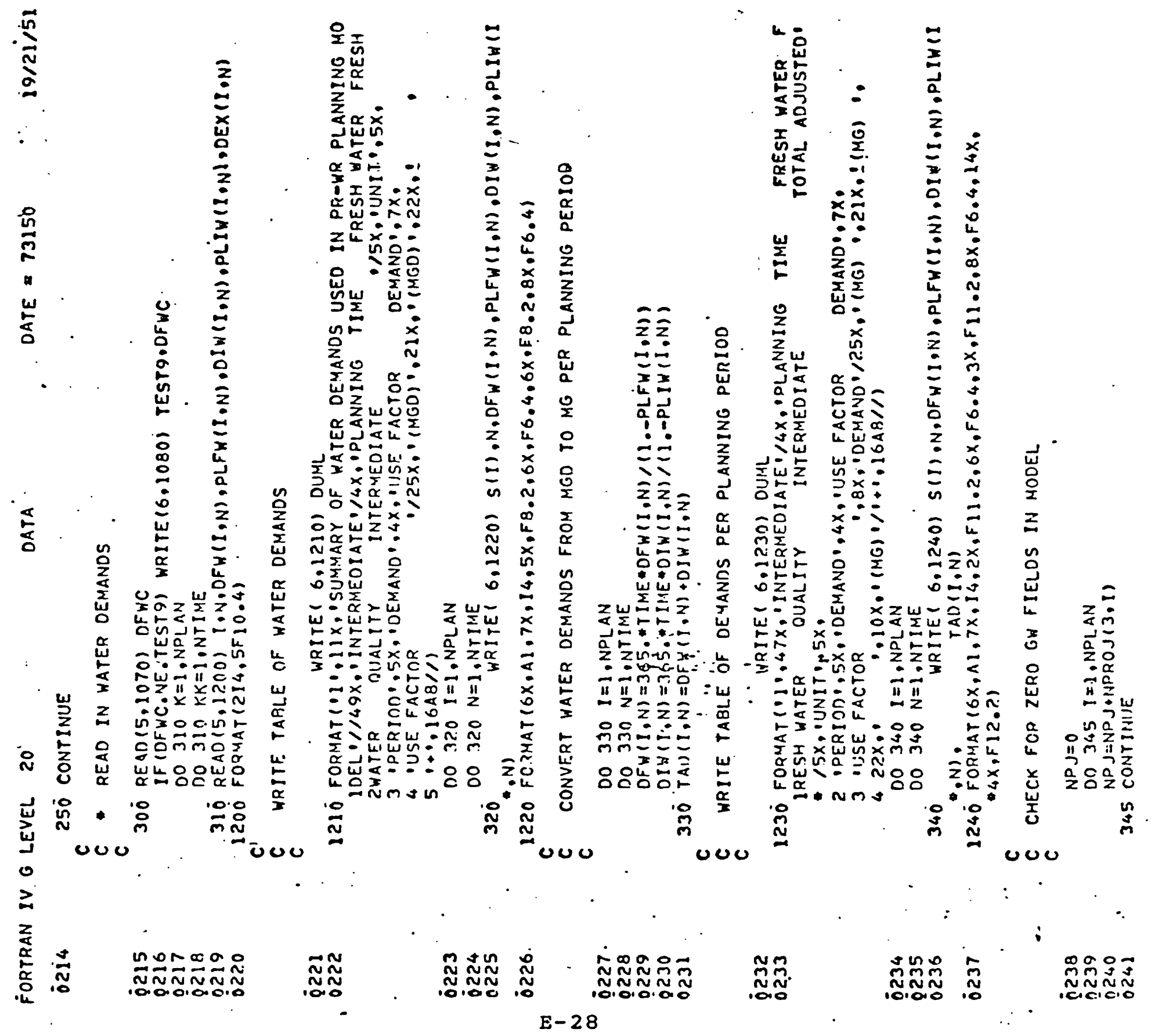


0
0
0
0
0
0
0
0

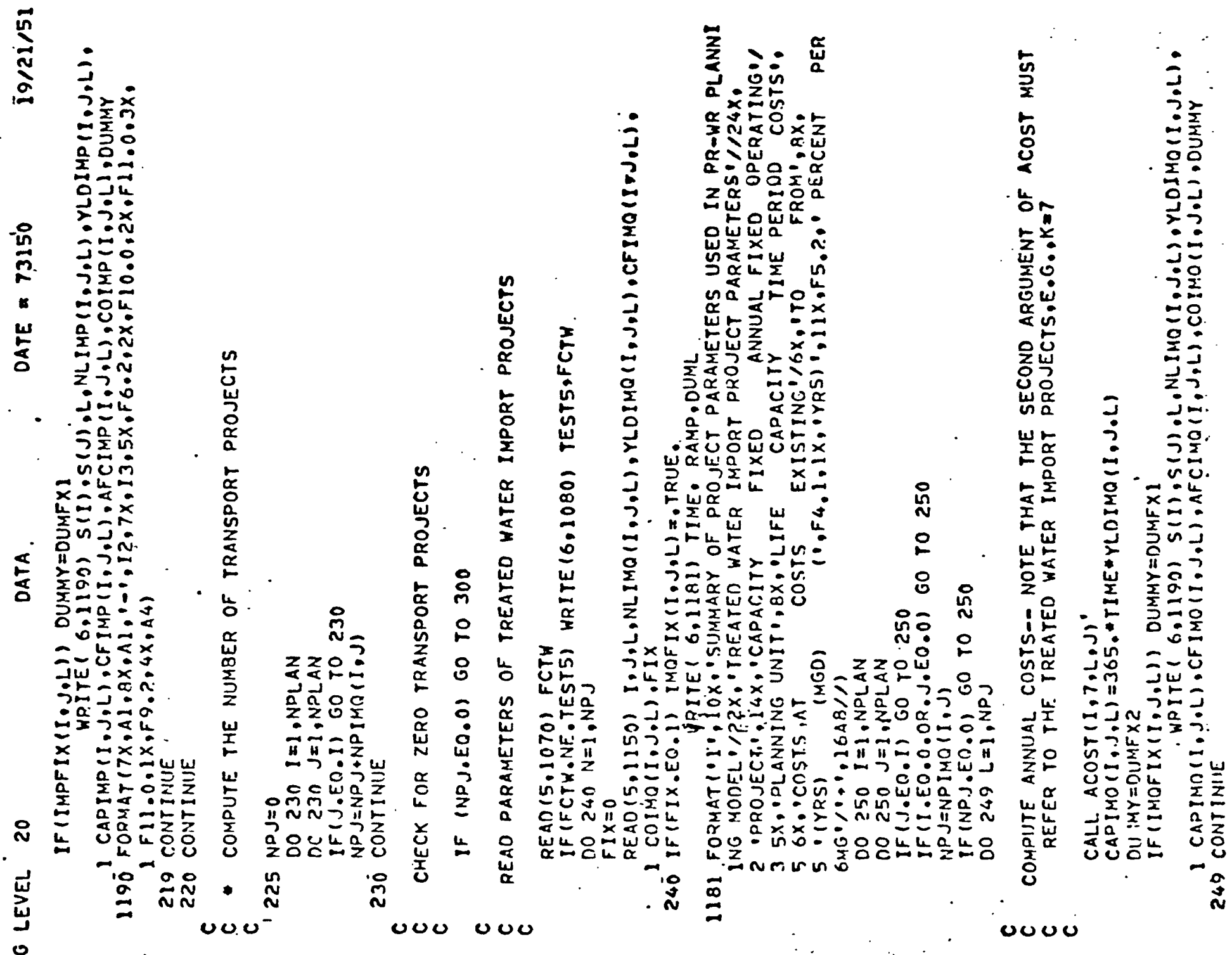


บบบ טบ̃o

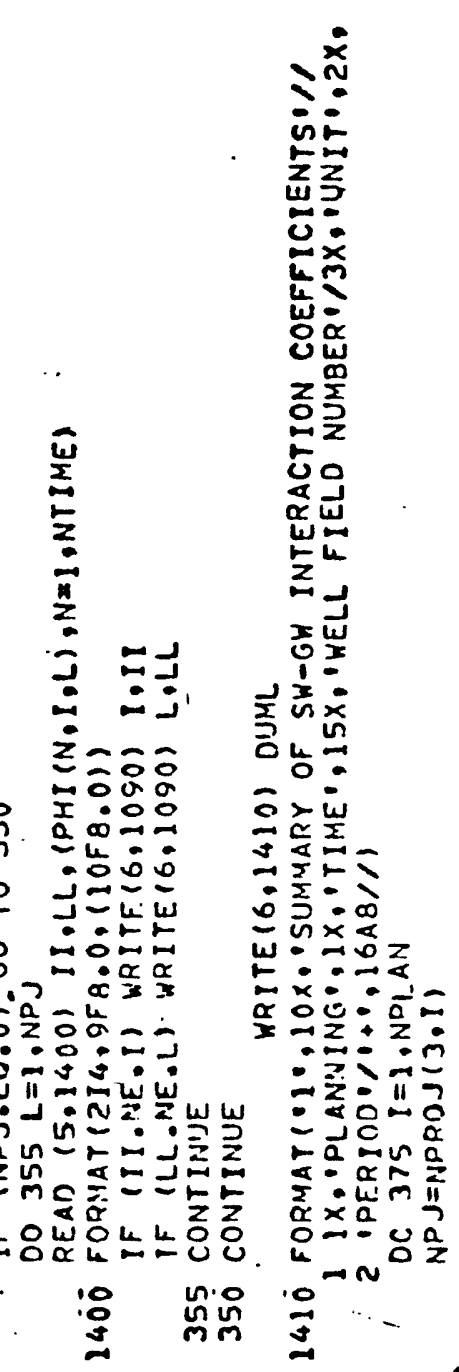

OUO
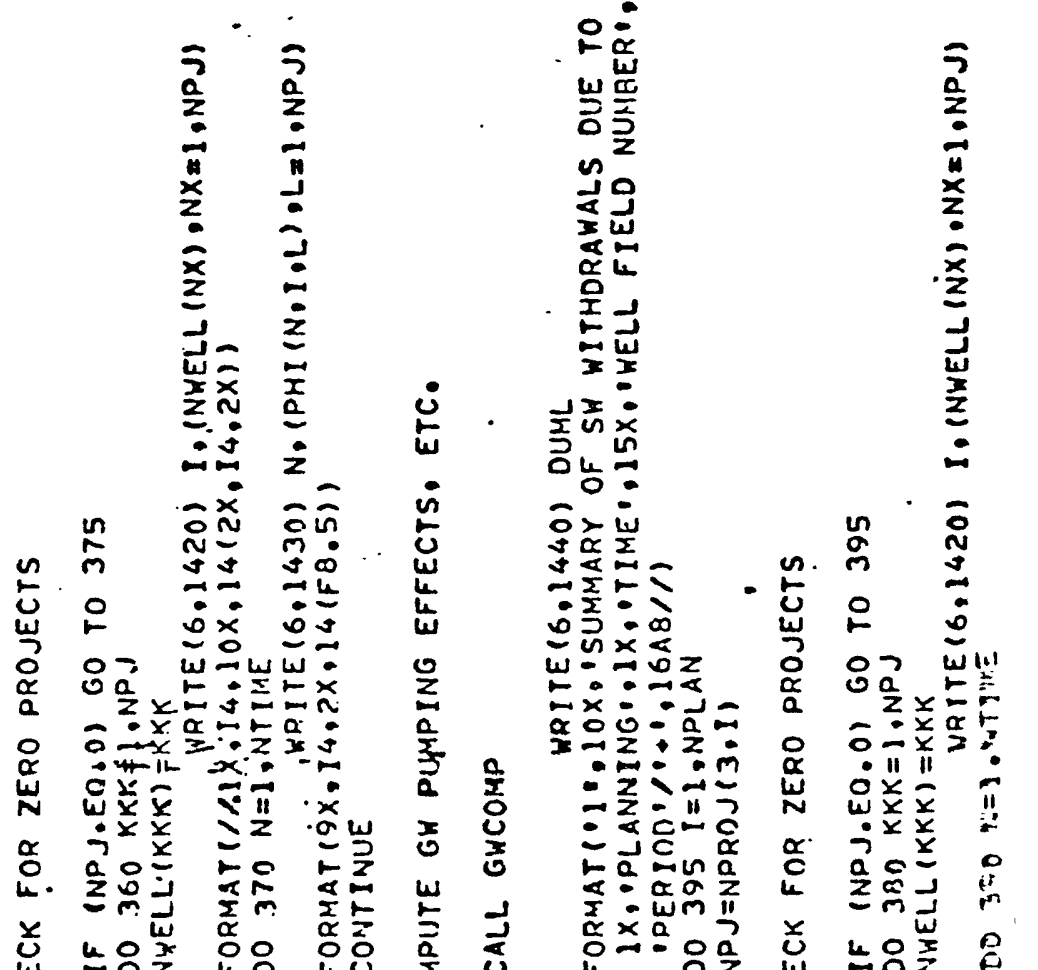

0

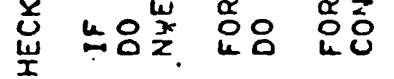

0

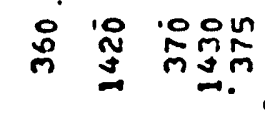


ia

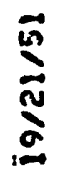

$\therefore \quad \frac{20}{2}$

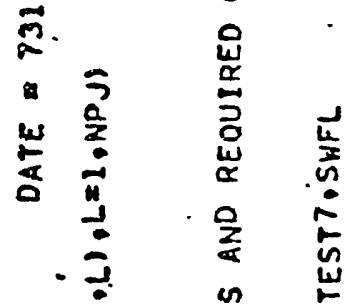

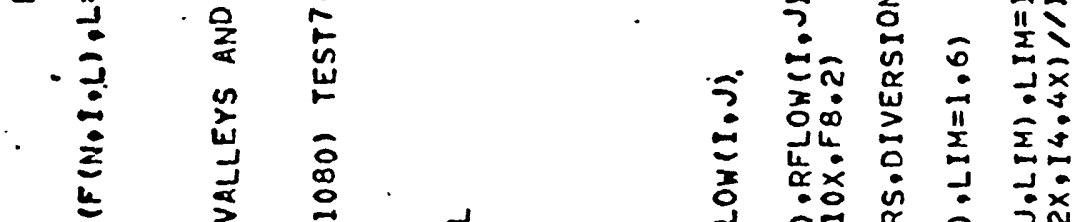

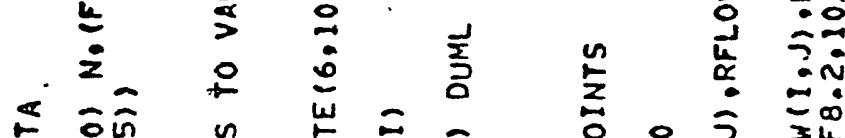

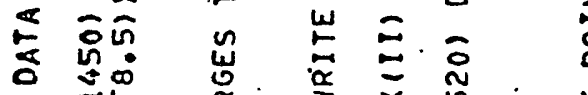

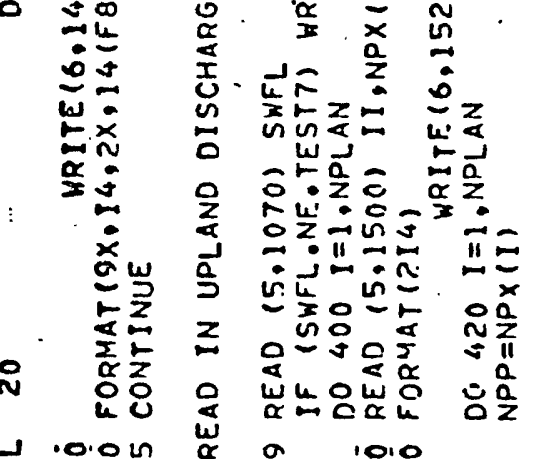

$\underset{\substack{\mathrm{w} \\ 0}}{\vec{\omega}}$

용요요

U 10 n

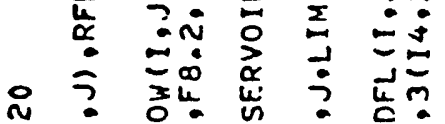

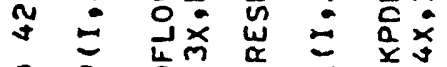

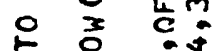

눙 ? 0

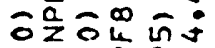

$0 \div \bar{n}$ ?

แn

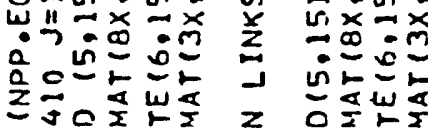

继尗

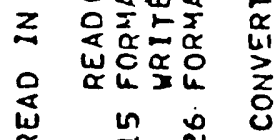

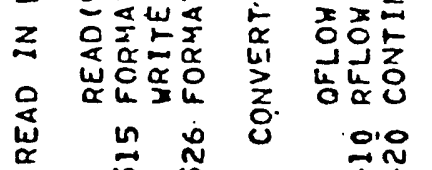

ㄴ. 농ㅎㅇ

io in

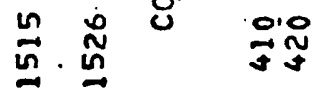

产

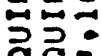

w山

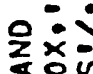

$n \div \overline{0}$

중

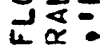

$z$

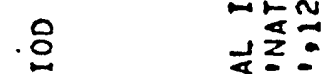

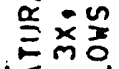

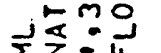

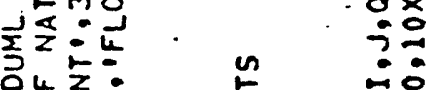

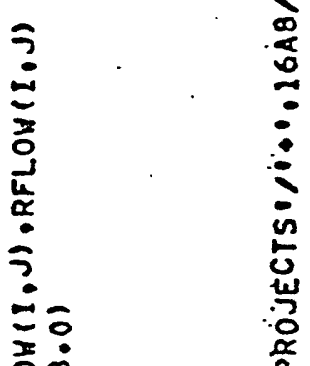

$\geq$

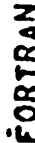

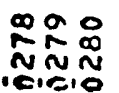

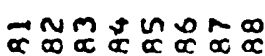

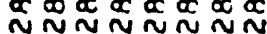

uou

Uuo $\rightarrow$ uvo

这文

Ẽo:

in $\frac{x}{4}: 0$

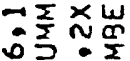

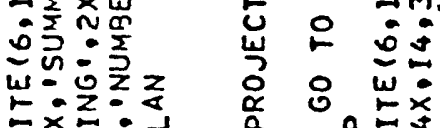

三

w $\sum_{\Sigma}^{m}$

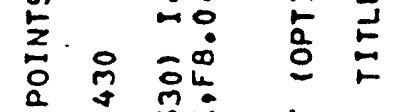

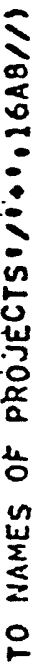

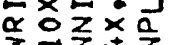

次走?

シずオニ

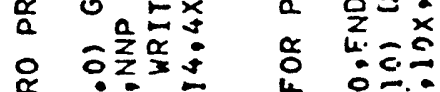

$\therefore=k$ 웅

แI $x_{w}$ u $0 \div$

$=:-\frac{1}{x}$

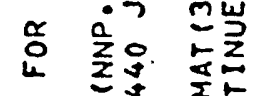

in

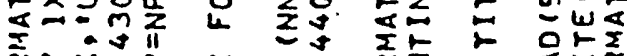

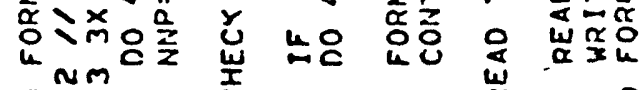

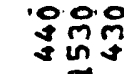

400

$\frac{0}{0}$

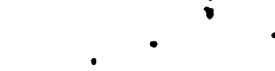




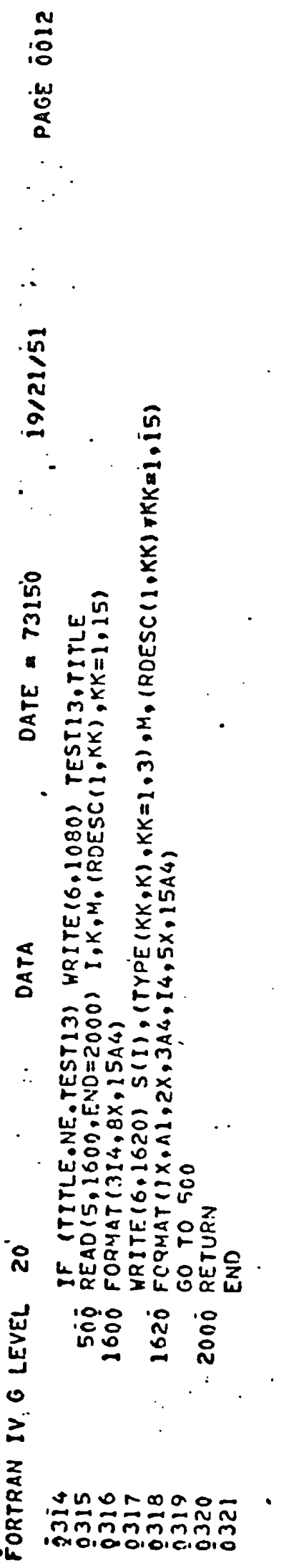


ניב:

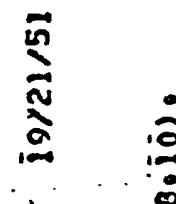

$\therefore 0$

-

ก

w

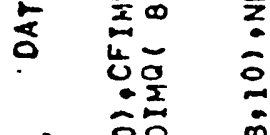

-

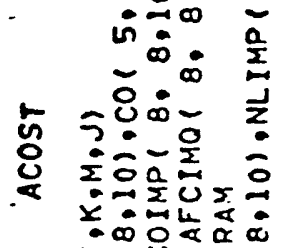
$=0 \div \dot{0}$

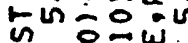

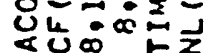

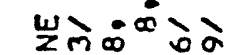
넌-0ํำ

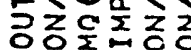

$\approx$

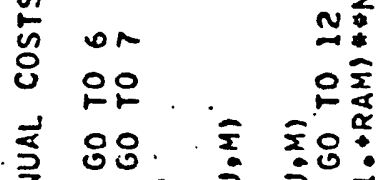

₹ $\sum_{0}$

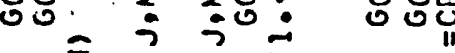

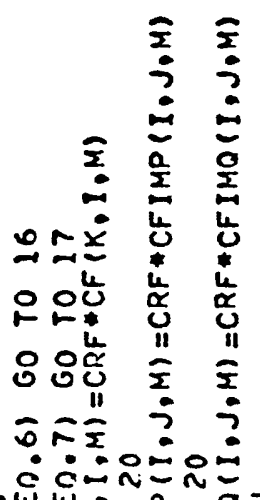

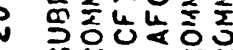

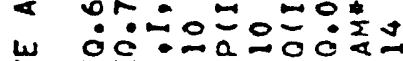

w

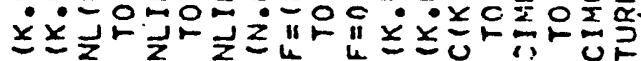
高 $\leq x \leq 2$

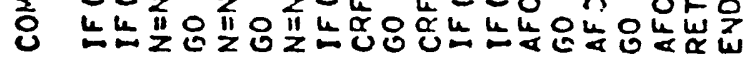

$\sum_{-\infty}^{0}$
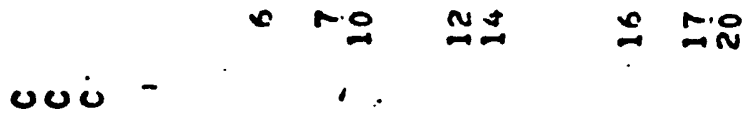

0

2.

$\frac{z}{\alpha}$

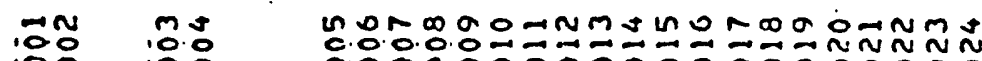
0.00.0.0000000000000000

in (3) 
8
8
0
0

$\stackrel{\text { กิ }}{\text { ก } . . \infty ~}$

욜 立

w a

d $\frac{\pi}{\frac{a}{2}}$

- $\frac{20}{\infty}$

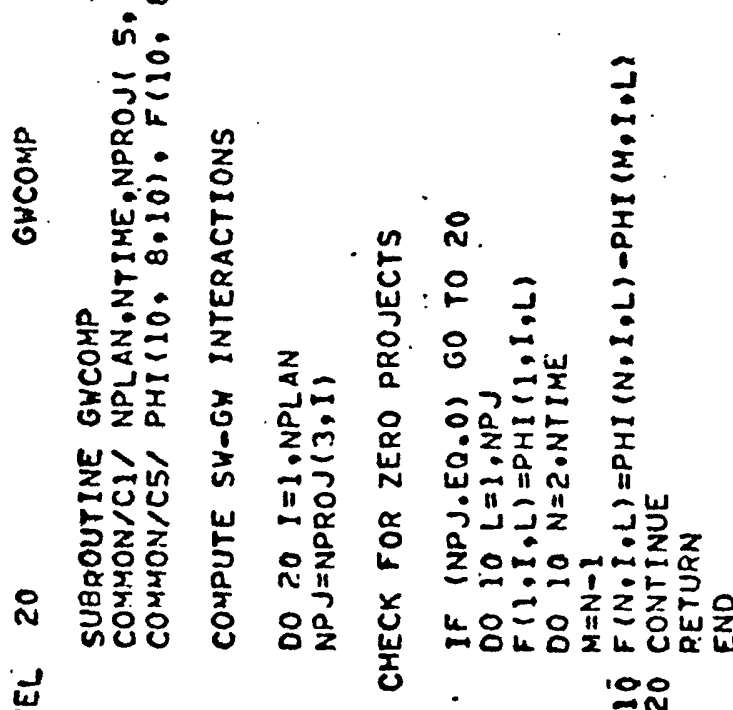

vou vōo

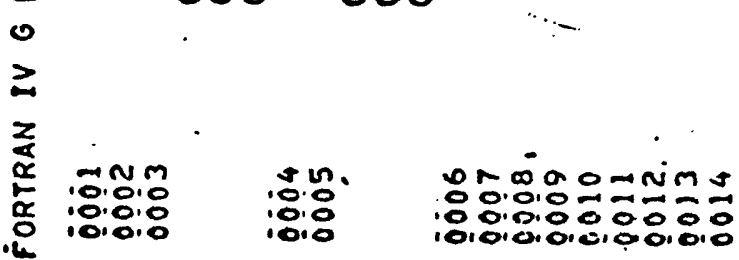

. E- 34 
'a

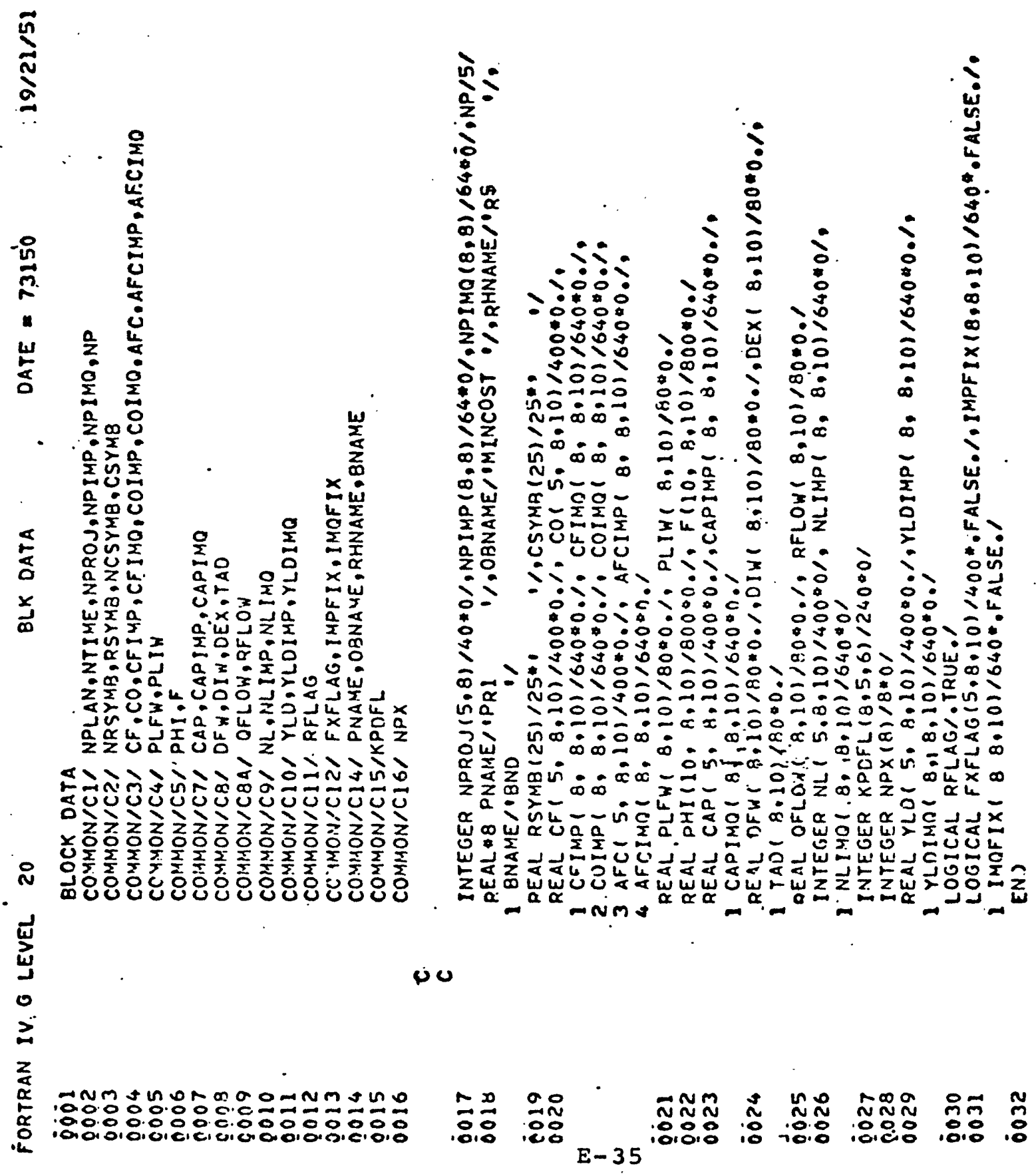


$\frac{w}{2}$

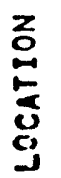

:

$\frac{w}{2}$

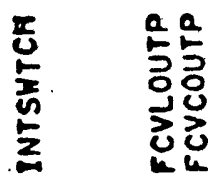

豙.

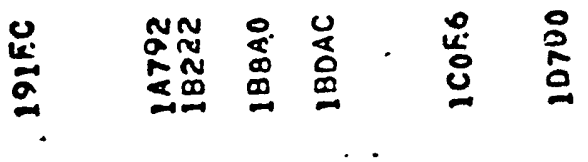

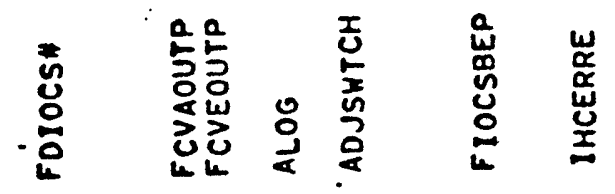

葛

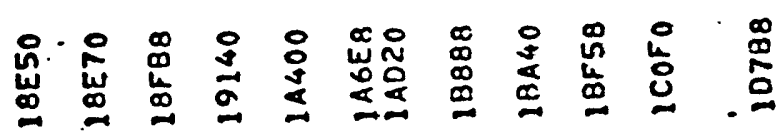

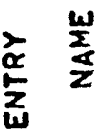

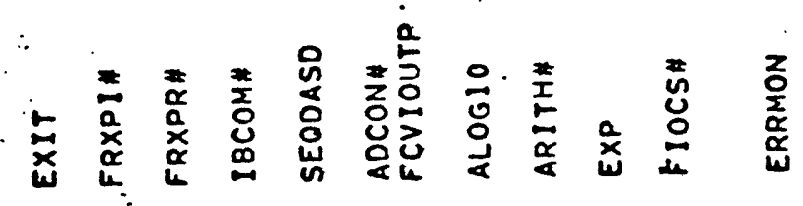

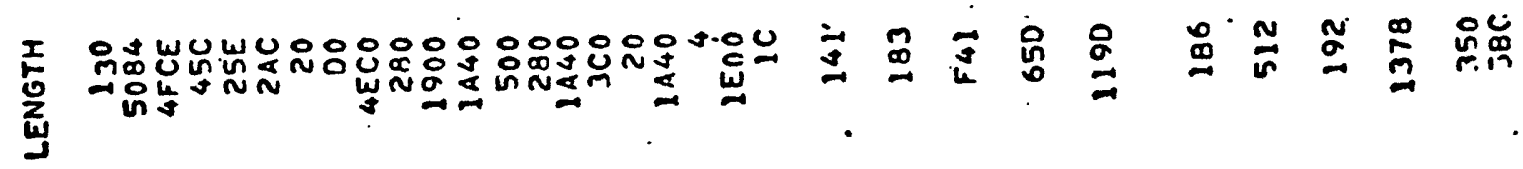

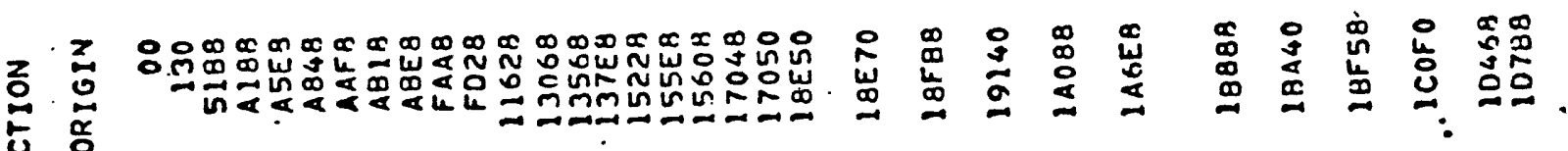

Ju

离

宸

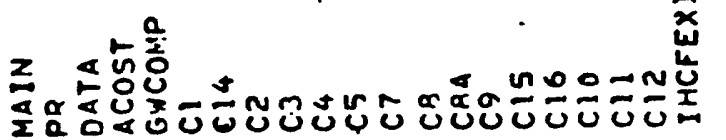

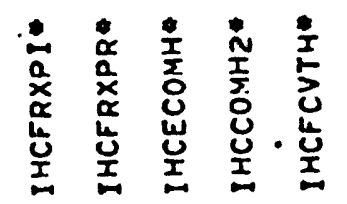

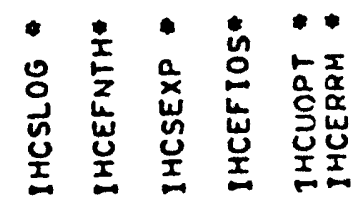
E-36 
妾

$\frac{\omega}{2}$

ż

$\frac{u}{2}$

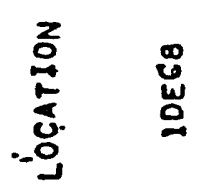

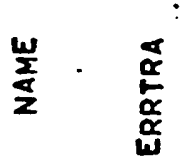

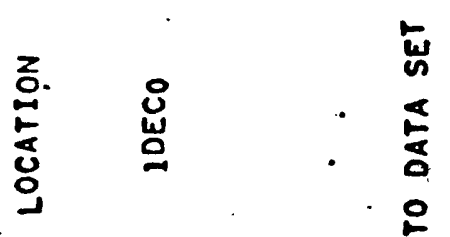

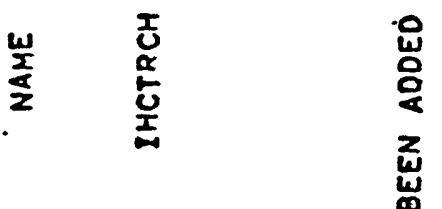

$\stackrel{n}{x}$

点。

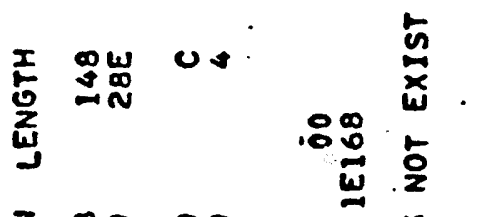

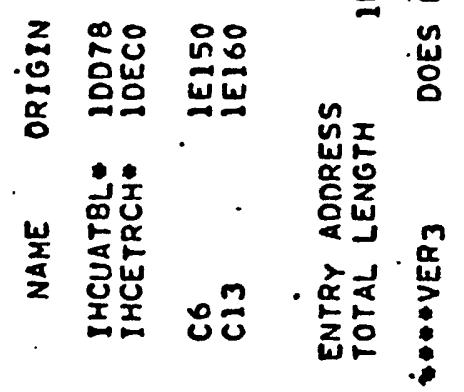

